\title{
Abstracts:
}

\section{International Society}

for Aerosols

in Medicine e.V.

20th ISAM Congress

Munich Holiday Inn-City Center, Germany

May 30-June 3, 2015

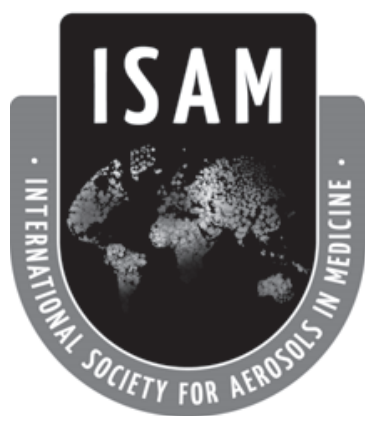




\section{Oral Abstracts}

\section{Regulatory and Standardization}

\section{O-01 NUTS AND BOLTS OF PLANNING AND CONDUCTING INHALATION TOXICOLOGY STUDIES FOR DRUG DEVELOPMENT}

\author{
Ron K Wolff
}

Fort Myers, Florida

New inhalation systems may involve, a novel drug, formulation, or device delivery system, or some combination of these individual elements. In addition, in some cases the drug may be approved for a different route of delivery such as oral or subcutaneous injection, but not for inhalation delivery. The drug may be a small molecule or a biologic. Therefore, there are a wide range of possible scenarios. Inhalation studies are frequently more technically complex than other types of toxicology studies and require their own specific considerations in order to support clinical trials adequately and optimize drug development. One frequent challenge is dose selection, particularly for high dose clinical applications when maximum feasible animal dosing may be required. Another issue is determining dose multiples for nonclinical studies in animals compared to human doses for clinical trials because determination of both nonclinical and clinical dose have their challenges. These considerations have a major impact on allowable doses in clinical trials. Estimating amount of compound needed to conduct inhalation studies will be discussed. There will also be discussion of inhalation exposure systems for large and small animals, study interpretation challenges including relating dose to effects, implications of using novel excipients, and strategies for effective collaboration with CROs.

\section{New Devices and Emerging Therapy \\ O-02 AEROSOLTHERAPY OF ANTI-VEGF IN PRIMARY PULMONARY ADENOCARCINOMA WITH K-RAS ACTIVATING-MUTATIONS}

\author{
Nathalie Heuzé-Vourc' ${ }^{1}$, Hervé Virginie ${ }^{1}$, Nathalie Rabbe ${ }^{2}$, \\ Laurent Guilleminault ${ }^{3}$, Flora Paul ${ }^{3}$, Lauren Schlick ${ }^{2}$, \\ Nicolas Azzopardi ${ }^{4}$ \\ ${ }^{1}$ Université François Rabelais, Cepr, Umr Inserm 1100, \\ ${ }^{2}$ Sorbonne Universités, Upmc Univ Paris 06, Paris, \\ ${ }^{3}$ Université François Rabelais, Cepr, Umr Inserm 1100, \\ Tours, France, \\ ${ }^{4}$ Université François Rabelais, Cnrs, Gicc Umr 7292, Chru, Tours
}

K-ras mutations promote angiogenesis in lung cancer and contribute to the drug resistance of cancer cells. It is not clear whether K-ras mutated adenocarcinomas are sensitive to anti-angiogenic therapy with monoclonal antibodies (mAbs) that target vascular endothelial growth factor (VEGF). Anti-angiogenic mAbs are usually delivered systemically, but only a small proportion reaches the lung after intravenous injection. We investigated the relevance of a non-invasive pulmonary route for the delivery of anti-VEGF $m A b$ in the mouse K-ras ${ }^{\mathrm{LA1}}$ model.

We found that pulmonary delivery of this mAb significantly reduced the number of tumor lesions and inhibited malignant progression. The antitumor effect involves the VEGFR2-dependent inhibition of blood vessel growth, which impairs tumor proliferation. Pharmacokinetic analysis of aerosolized anti-VEGF showed its low rate of passage into the bloodstream, suggesting that this delivery route is associated with reduced systemic side effects.

Our findings highlight the value of the aerosol route for the administration of anti-angiogenic mAbs in pulmonary adenocarcinoma with K-ras activating-mutations.

\section{O-03 CLINICALLY RELEVANT IN VITRO TESTING-BRIDGING THE GAP BETWEEN THE LAB AND THE PATIENT}

\author{
Jolyon P. Mitchell
}

Inhaler Consulting Services Inc. London

The current pharmacopeial methods for in vitro inhaler performance testing were developed primarily to support requirements for drug product registration and quality control. In addition, separate in vivo studies are undertaken in order to understand clinical impact. However, since in-vivo studies are not always economically or practically possible, there are a number of modifications to laboratory test methodologies that could be incorporated without difficulty to provide a better linkage of in vitro to clinical reality. Suggestions for such more clinically relevant in vitro testing include the following considerations:

1. Patient-representative breathing profiles;

2. Inclusion of relevant time delays before inhalation applicable to pMDI/VHC use;

3. Realization of unintended patient misuse scenarios;

4. Analytical tools based on patient-simulated face and upper airway models.

Although it is not necessarily foreseen that these suggestions would form part of future routine quality control testing of inhalers, they should provide a closer approximation to the clinical setting, and therefore be useful in the preparation for in vivo studies and in providing clinical use guidance.

\section{O-04 BREATHPRINTS}

Renato Zenobi

Eth Zürich

It has been suggested that exhaled breath contains relevant information on a person's health status. In this contribution, a novel methodology to analyze breath in real time will be presented. It 
is based on secondary electrospray ionization coupled to mass spectrometry (SESI-MS), which affords ppb...ppt limits of detection, and analysis of compounds with molecular weights up to $400 \mathrm{Da}$. Extensive statistical and chemometric evaluation of the large data sets is another important element for the success of these experiments.

This approach is able to generate "breathprints" from individuals that are representative of a variety of metabolic states. A number of interesting questions can now be addressed via on-line mass spectrometric analysis of exhaled breath: is there a core pattern for individual phenotypes visible in mass spectrometric "breathprints"? Can diurnal changes be monitored via exhaled breath? Can diseases be diagnosed via exhaled breath, and if yes, which ones? Can proper drug use (or drug abuse) be detected via analysis of the chemical composition of exhaled breath? These studies have obvious ramification for using exhaled breath as a non-invasive alternative to the analysis of blood or urine in medical diagnosis, doping control, forensics, and other areas.

\section{O-05 DEVELOPMENT OF AN ALGORITHM FOR QUALITATIVE MEASUREMENTS OF DEVICE SPECIFIC INHALATION MANEUVERS}

\author{
P. Haidl ${ }^{1}$, S. Heindl ${ }^{2}$, K. Siemon ${ }^{1}$, R. M. Cloes ${ }^{3}$ \\ ${ }^{1}$ Hospital Kloster Grafschaft, Germany, \\ ${ }^{2}$ Gauting, ${ }^{3}$ Mundipharma GmbH
}

Introduction: For a planned measurement system to test the quality of patient inhalation with inhalation devices, an inhalation flow algorithm was required to set the limits for the different flow check points.

Methods: A literature search was carried out to find the required flow parameters for inhalation devices. The data found were analyzed in the Medical Department Mundipharma, Germany. Unpublished data were discussed at an expert meeting and added.

Results: Flow acceleration with reservoir and blister DPIs should be $\geq 1 \mathrm{~L} / \mathrm{s}^{2}$. With capsule devices, $\geq 500 \mathrm{~mL}$ should be inhaled after reaching the minimum flow. The inhalation time should be $\geq 1$ s.

Conclusion: Based on published data regarding the flow requirements of individual inhalation systems, a simple test algorithm could be developed to measure the inhalation quality at different inhalation devices. Sponsor: Mundipharma GmbH

Table 1: Minimum acceptable and minimum flow values for an optimum result of different inhalation devices

\begin{tabular}{|c|c|c|c|c|c|c|c|c|c|c|c|c|c|c|}
\hline $\begin{array}{l}\text { Minimum flow for an } \\
\text { optimum result in } \mathrm{U} / \mathrm{min}\end{array}$ & 20 & 20 & 30 & 30 & 30 & 30 & 60 & 30 & 40 & 50 & 40 & 30 & 40 & 40 \\
\hline \multirow[t]{2}{*}{$\begin{array}{l}\text { Minimum acceptable } \\
\text { flow in } \mathrm{L} / \mathrm{min}\end{array}$} & 10 & 20 & 30 & 30 & 30 & 30 & 30 & 30 & 40 & 35 & 40 & 20 & 40 & n.a. \\
\hline & & 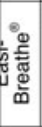 & $\begin{array}{l}\frac{2}{2} \\
\frac{d}{\pi} \\
\frac{2}{0} \\
\frac{3}{3}\end{array}$ & 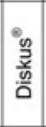 & $\begin{array}{l}\text { 음 } \\
\text { के } \\
\text { 훈 }\end{array}$ & 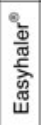 & 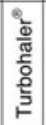 & $\begin{array}{l}\times \\
\text { है } \\
\text { है } \\
\text { के }\end{array}$ & 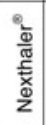 & 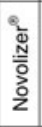 & 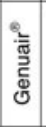 & 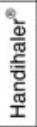 & 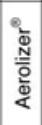 & 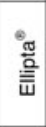 \\
\hline
\end{tabular}

\section{O-06 INHALED GMCSF THERAPY IN PULMONARY ALVEOLAR PROTEINOSIS (PAP)}

Ilaria Campo, Francesca Mariani, Elena Paracchini, Zamir Kadija, Carmine Tinelli, Maurizio Luisetti

Irccs San Matteo Hospital Foundation
Rationale: Pulmonary Alveolar Proteinosis (PAP) is a rare syndrome characterized by pulmonary surfactant accumulation within alveolar spaces. The autoimmune form, associated with the presence of GM-CSF auto-antibodies, accounts for the vast majority of PAP cases.

Although WLL is still considered the gold standard for treatment, the discovery of alveolar macrophage involvement and anti GM-CSF neutralizing antibodies led to the use of GM-CSF as a potential therapeutic approach for PAP.

Aims: In this context, we have planned to identify the best treatment schedule for PAP patients, looking at the evaluation of the superiority of the combination WLL/inhaled rGM-CSF vs WLL alone in PAP patients.

Methods: We designed an experimental, phase II, parallel randomized trial of two groups (NCT00901511). PAP patients matching the enrolment criteria have been randomized to undergo WLL or WLL/ followed by inhaled rGM-CSF, according to an acute (12 weeks) followed by maintenance (6 months) schedule. PAP patients have been evaluated by questionnaire, respiratory function testing, CT-assisted lung profusion score, severity score, quality of life form, clinical chemistry serum markers (LDH, CYFRA, CEA) and CD11b stimulation index.

Results: From July 2009 we enrolled 18 PAP patients, 11 males and 7 females. In the ongoing evaluation, the rGM-CSF seems to be a drug well tolerated and free of side effects. The physiology and CT scoring data collected up today are encouraging.

Conclusion: We are confident that, at the end of this study, we will be able to identify the optimal sequence of the treatments to gain the complete and durable resolution of lung infiltrates in PAP patients.

Funding: AIFA(FARM7MCPK4), eRARE(EuPAPNet).

\section{ISAM IPAC-RS Workshop}

\section{O-07 TECHNOLOGY TO ENABLE TELEHEALTH IN RESPIRATORY MEDICINE}

John Pritchard

Philips Respironics

Control in respiratory disease is often suboptimal, due in part to patients either failing to adhere to the dosing regimen, or failing to use their inhaler correctly. Whilst patient education is essential, monitoring offers additional benefits. Electronic monitors provide an accurate and objective indication of adherence whilst newer, prototype devices may also be of future value in assessing inhaler competence. The information provided by such devices is a helpful aid to understanding a patient's behaviour, and may be crucial to the development and assessment of interventions. This can apply equally to securing successful outcomes in clinical trials, as it does to clinical care. Whilst a periodic download of data can keep a check on long-term trends, intervention is not necessarily timely, particularly for the patients most at risk of an exacerbation and thus, most likely to benefit. Adding connectivity allows a patient either to capture data in coaching programmes on smartphones or computers, or to allow remote monitoring by relatives, caregivers, or healthcare professionals. Successful intervention remains a challenging task, dependent not only upon tailoring this information to the patient's and caregivers' needs, but also on inclusion of health symptoms to provide positive reinforcement for changing behavior. Since such services will not be cheap to provide, to gain reimbursement by payors requires the value of the technology to be shown clinically; "no outcome, no income." 


\section{O-08 QBD FOR INHALER DEVICES}

\author{
Wilbur de Kruijf $^{1}$, Matt Wilby ${ }^{2}$, Phil Swanbury ${ }^{3}$, \\ Andrew Dundon ${ }^{4}$ \\ ${ }^{1}$ Medspray Bv, ${ }^{2} 3 m$ Drug Delivery Systems, \\ ${ }^{3}$ Vectura, ${ }^{4}$ Glaxosmithkline
}

The International Committee on Harmonisation's Quality by Design $(\mathrm{QbD})$ principles are widely accepted for the development of drug products. Generally they are being applied to formulations, especially to the chemical manufacturing processes. The $\mathrm{QbD}$ approach, as described by ICH Q8-11 can also be applied to the development of complex drug delivery devices, such as inhalers. This workshop lecture describes how this can be done in practice. The framework for applying $\mathrm{QbD}$ to devices has been developed by the International Pharmaceutical Aerosol Consortium on Regulation and Science (IPAC-RS). QbD principles can be used to increase the robustness of the device design as it is scaled from clinical trial supply through to commercial supply. In this lecture practical examples will be used from SHL and Medspray's development of a novel liquid inhaler device for antibiotics.

\section{O-09 DEVICE RELATED CHANGES AND ISO INITIATIVE FOR INHALATION DEVICES}

Loy Britto

Glaxosmithkline; Manufacturing and Supply

The approval of pharmaceutical products by regulatory agencies at a fundamental level is based on meeting patient efficacy and safety requirements. Achievement of patient efficacy and safety requirements is governed by defined Critical Quality Attributes (CQAs) of a pharmaceutical product. In the case of inhaled products, CQAs are in turn dependent on input materials and formulation characteristics; manufacturing processes and its parameters; and characteristics of device components. This presentation is focused on the impact and control of device attributes and its associated changes on product CQAs.

Device attributes include material composition; material properties that can include physical, mechanical and electrical; and component dimensions. Changes in device attributes occur during each and every stage of its life cycle. In the case of inhaled products changes in device parameters can have a significant impact on product critical quality attributes such as delivered dose, particle size distribution and non-formulation related impurities such as leachables. These changes can impact patient efficacy and safety attributes of the drug product and need to be thoroughly evaluated. This evaluation should take into consideration principles and guidelines set forth in documents such as the ISO initiative for inhaled devices and ICH8, 9 and 10.

Several case studies will be presented to exemplify the complexity and challenges associated with management of device related changes.

\section{0-10 PATIENT ADHERENCE AND DEVICE DESIGN: CLINICAL PERSPECTIVE, WHAT INDUSTRY CAN DO BETTER}

Nicolas Roche

\section{Cochin Hospital Group and University Paris Descartes}

Adherence and correct inhaler technique are crucial to ensure treatment effectiveness in chronic airways diseases (asthma and COPD), and are inter-related. Yet, numerous studies found largely suboptimal adherence and a high frequency of incorrect inhaler use. Determinants of adherence and inhalation technique include not only age, socio-economic and educational characteristics, number of different types of devices used, specific education received, but also patients' individual abilities, perceptions (of efficacy, tolerance, comfort...), beliefs, preferences and satisfaction. Since these differ markedly from one patient to another and since the universally ideal device does not exist, individualization of treatment choice is key. Additionally, the importance of patient's participation in this choice has been demonstrated in a randomized controlled trial. Anticipating patients' preferences is a difficult task. Studies allowed to describe and hierarchize the characteristics of inhalers that are considered as the most important by patients, including: ease of use and simplicity of instructions, convenient size, robustness, no need for maintenance/ cleaning, minimal preparation manoeuvers, reproducibility of delivered dose, minimal inspiratory effort required, feedback regarding whether the dose was correctly taken, indication of the number of remaining doses, etc. Taking these requirements into account when designing new devices is of major importance to maximize the chance for the device to be well accepted and used. 


\section{Poster Abstracts}

\section{Pediatrics and CF \\ P-058 EFFECT OF ELECTROSTATIC CHARGE ON THE DEPOSITION OF INHALED AEROSOLS IN INFANT, CHILD, AND ADULT EXTRATHORACIC AIRWAYS}

\author{
Mehdi Azhdarzadeh, Jason Olfert, Reinhard Vehring, \\ Warren Finlay
}

University of Alberta

An in vitro study was performed to carefully study the effect of electrostatic charge on the deposition of monodisperse uniformly charged particles in extrathoracic airways. An atomizer was designed to generate monodisperse particles all with the same specified charge by using controlled Plateau-Rayleigh breakup with induction charging. Experiments were conducted in adult oral-extrathoracic, child oral-extrathoracic (children aged 6-14 years), and infant nasalextrathoracic (infants aged 3-18 months) airways.

The Alberta idealized mouth-throat, the Alberta idealized child mouth-throat, and the Alberta idealized infant nose-throat models were used to mimic the extrathoracic airways for the three aforementioned cases. Aerosol particles with aerodynamic diameters of $3-$ $6 \mu \mathrm{m}$ were generated, and studied at inhalation flow rates of $15-30 \mathrm{~L} /$ min for the adult, $10-20 \mathrm{~L} / \mathrm{min}$ for the child, and $7.5-15 \mathrm{~L} / \mathrm{min}$ for the infant cases, respectively. Charge per particle was controlled over the range of $0-25,000$ elementary charges for the adult and $0-10,000$ elementary charges for the child and infant tests.

The in vitro results showed deposition enhancement for the charged particles due to electrostatic effects. A nonlinear least squares minimization was used to develop empirical dimensionless equations to predict particle deposition in the extrathoracic airways in infants, children and adults, including electrostatic charge, flow rate, and aerodynamic diameter of the particles.

\section{P-072 PROMPT FIRING FOLLOWING SHAKING OF A PMDI DELIVERED VIA A VALVED HOLDING CHAMBER IS IMPORTANT IN ACHIEVING THE CORRECT DOSE OF FLOVENT}

\author{
Ariel Berlinski ${ }^{1}$, Dirk von Hollen ${ }^{2}$, John N Pritchard ${ }^{3}$, \\ Ross HM Hatley ${ }^{3}$ \\ ${ }^{1}$ Pulmonology Section, Dept. of Pediatrics, Uams, Com/Pediatric \\ Aerosol Research Laboratory, \\ ${ }^{2}$ Philips Respironics, ${ }^{3}$ Respironics Respiratory Drug \\ Delivery (UK) Ltd, A Business of Philips Electronics UK Limited
}

Inhaled corticosteroids are used to treat pediatric asthma. The shaking of a pMDI is required to ensure consistency of emitted dose. In a recent clinical trial (NCT01714063) we found that the delivered dose of Flovent HFA through a Valved Holding chamber in 5-8 year old asthmatic children was highly variable. In the study a monitoring device was used to record shaking and firing of the device. Initial analysis of the data indicated no correlation between the delay between shake and fire and the delivered dose of that actuation. However, a strong correlation was observed between shake and fire delay and the subsequent dose emitted from the MDI. A 10s, and 30s delay resulted in an emitted dose of the subsequent actuation of $136 \%$, and $222 \%$ of the nominal dose respectively. Our findings are consistent with settling of drug towards the metering chamber before it replenishes at the time of the fire. It would be expected that if high dose deliveries were given in the beginning of canister life, then shots towards the end of life would contain little if any drug. This phenomenon would lead to variable over- and under-dosing. Manufacturers of pMDIs containing drugs formulated as suspensions should specify the maximum delay time between shaking and firing that doesn't significantly affect the delivered dose. If the dose cannot be administered within this time, the shake should be repeated before attempting again to fire the pMDI.

\section{P-121 PHARMACOKINETICS AND SAFETY OF ONCE DAILY DOUBLE DOSE INHALED TOBRAMYCIN ADMINISTERED WITH CCONTROLLED-INHALATION AND JET-NEBULIZER IN CYSTIC FIBROSIS}

\author{
Aukje Bos ${ }^{1}$, A.J. van Velzen ${ }^{2}$, D.J. Touw ${ }^{3}$, H.A.W.M. Tiddens ${ }^{1}$, \\ H.G.M. Heijerman ${ }^{4}$, H.M. Janssens ${ }^{5}$ \\ ${ }^{1}$ Erasmus MC-Sophia Children's Hospital, Department \\ of Pediatric Pulmonology and Allergology; Erasmus MC, \\ Department of Pediatric Radiology, ${ }^{2}$ Central Hospital Pharmacy, \\ ${ }^{3}$ University of Groningen, University Medical Center \\ Groningen, Department of Clinical Pharmacy \\ and Pharmacology; University of Groningen, Guide, \\ Farmacokinetics, Toxicology and Targeting, \\ ${ }^{4}$ Haga Teaching Hospital, Department of Pulmonology, \\ ${ }^{5}$ Erasmus MC-Sophia Children's Hospital, Department \\ of Pediatric Pulmonology and Allergology
}

Background: Once daily double dose inhalation of tobramycin (T) may have advantages over twice daily regular dose in cystic fibrosis (CF), because of higher antibiotic concentrations and less treatment burden. Moreover, increasing small airways deposition with the controlled-inhalation AKITA nebulizer may improve bacterial killing, but may also cause higher serum levels with a higher toxicity risk.

Aim: To determine pharmacokinetics (PK) and safety of the double T dose with the AKITA compared with the conventional jet-nebulizer (PARI-LC Plus) in patients with CF. PK was used as surrogate for drug safety.

Methods: Randomized, crossover study. PK were assessed in 10 adult CF patients following a single inhalation of the double recommended $\mathrm{T}$ dose with the AKITA ( $300 \mathrm{mg}$ fill dose) and PARI-LC Plus (600 mg fill dose) nebulizer. Blood samples were drawn until 24 hours after inhalation. 
Results: No significant differences were found in maximum and trough serum levels, time to maximum level and area under the curve. Maximum and trough levels were well below their toxic limits for both nebulizers and all patients. All inhalations were well tolerated and no serious adverse events occurred. Nebulization time was $33 \%$ shorter with the AKITA.

Conclusion: Once daily inhalation of the double $\mathrm{T}$ dose with the AKITA resulted in safe serum levels, with comparable systemic exposure to once daily inhalation with PARI-LC Plus and higher peak levels compared to the standard twice daily dosing regimen.

\section{P-123 DAILY OBSERVATIONS OF NEBULIZER COMPETENCE IN CHILDREN WITH CYSTIC FIBROSIS: THE DONUT STUDY}

\author{
Aukje Bos ${ }^{1}$, H.A.W.M. Tiddens ${ }^{1}$, K. Tong Minh ${ }^{2}$, I. Heeres ${ }^{2}$, \\ J.L. Overweel-Uijterlinde ${ }^{2}$, N.E. Kok ${ }^{2}$, H.M. Janssens ${ }^{2}$ \\ ${ }^{I}$ Erasmus MC-Sophia Children's Hospital, Department \\ of Pediatric Pulmonology and Allergology; Erasmus MC, \\ Department of Pediatric Radiology, \\ ${ }^{2}$ Erasmus MC-Sophia Children's Hospital, \\ Department of Pediatric Pulmonology and Allergology
}

Background: Poor nebulizer competence reduces the efficacy of inhaled drugs in cystic fibrosis (CF). Therefore, $\mathrm{CF}$ caregivers focus on instructing correct inhalation technique. However, little is known on this nebulizer 'competence' of patients in the home environment.

Aims: To determine the percentage of CF patients with adequate nebulizer competence and to identify errors made by patients during nebulization in daily life.

Methods: Three hidden video registrations were made of children with CF (6-18 years) nebulizing at home. Videos were scored in random order by 2 observers on competence items using devicespecific checklists. A total score for nebulizer competence was calculated, with a higher weight for critical items. Number and type of errors between nebulizers were compared.

Results: Thirty patients ( $43 \%$ male) were included. Nebulizers: Akita $16.7 \%$, I-neb $60.0 \%$, Sidestream 23.3\%. Between observer agreement was good (ICC: 0.81). Median nebulizer competence score was $91.9 \%$ of max score. Overall, $23.3 \%$ of the patients had a perfect score $(100 \%)$ and $13.3 \%$ a fully incorrect score $(0 \%)$. Most mistakes were made in execution of the correct breathing manoeuvre.

Conclusion: Most CF patients had good nebulizer competence in daily life. Errors observed in some children likely result in reduced treatment efficacy. Systematic evaluation of nebulizer competence by the $\mathrm{CF}$ team is needed to maximise efficacy of inhaled drugs.

Funding: Unrestricted research grant Chiesi Farmaceutici S.p.A.

\section{P-134 REALISTIC FACE MODEL SURFACE IMPROVES RELEVANCE OF PEDIATRIC IN VITRO AEROSOL STUDIES}

\author{
Israel Amirav ${ }^{1}$, Asaf Halamish ${ }^{2}$, Miguel Gorenberg ${ }^{3}$, \\ Hamza Omar ${ }^{3}$, Michael Newhouse ${ }^{4}$ \\ ${ }^{1}$ Department of Pediatrics; University of Alberta, \\ ${ }^{2}$ Technosaf, ${ }^{3}$ Nuclear Medicine Department; Ziv Medical Center, \\ ${ }^{4}$ Firestone Institute for Respiratory Health; Mcmaster University
}

Background: Various hard face models are commonly used to evaluate the efficiency of aerosol face masks. Softer more realistic "face" surface materials, like skin, deform upon mask application and should provide more relevant in-vitro tests. Studies that simultaneously take into consideration many of the factors characteristic of the in vivo face are lacking. These include airways, various application forces, comparison of various devices, comparison with a hardsurface model and use of a more representative model face based on large numbers of actual faces.

Aim: To compare mask to "face" seal and aerosol delivery of two pediatric masks using a soft vs a hard, appropriately representative, pediatric face model under various applied forces.

Methods: Two identical face models and upper airways replicas were constructed, the only difference being the suppleness and compressibility of the surface layer of the "face." Integrity of the seal and aerosol delivery of two different masks [AeroChamber (AC) and SootherMask (SM)] were compared using a breath simulator, filter collection and realistic, applied forces.

Results: The soft "face" significantly increased the delivery efficiency and the sealing characteristics of both masks. Aerosol delivery with the soft "face" was significantly greater for the SM compared to the AC $(\mathrm{p}<0.01)$. No statistically significant difference between the two masks was observed with the hard "face."

Conclusions: The material and pliability of the model "face" surface has a significant influence on both the seal and delivery efficiency of face masks. This finding should be taken into account during in-vitro aerosol studies.

\section{P-147 TOTAL AEROSOL DEPOSITION IN REALISTIC AND IDEALIZED PEDIATRIC CENTRAI CONDUCTING AIRWAY GEOMETRIES}

\author{
Azadeh AT Borojeni, Michelle L. Noga, \\ Andrew R. Martin, Warren Finlay \\ University of Alberta, Edmonton, Canada
}

Background: This research explored the ability of existing empirical correlations to accurately predict aerosol deposition measured in the central conducting airway replicas (trachea to generation 3) of children. In addition, an idealized geometry was designed to mimic average total aerosol deposition in the airways of 4-8 year old children.

Methods: Experiments were conducted using steady inhalation air flow rates to measure the deposition of monodisperse particles with diameters of $3.5-5.5 \mu \mathrm{m}$ in 11 airway replicas and one idealized geometry. The total deposition of particles was measured using gravimetry. Experimental validation was performed by also measuring deposition in five adult replicas and comparing with existing published data.

Results: Deposition in the child airway replicas was higher than in the adult airway replicas for the same value of the impaction parameter, but was similar when instead compared at the same Stokes number. The empirical correlation of Chan \& Lippmann (Am Ind Hyg Assoc J, 41:399-459,1980), based on Stokes number, was found to predict total deposition reasonably well in all of our adult and child replicas. Aerosol deposition in the idealized geometry was consistent with average deposition measured in realistic airway replicas for children 4-8 years old.

Conclusions: Aerosol deposition in pediatric central conducting airways, at least for generations 0-3, may be predicted using existing Stokes number-based correlations developed for adult airway deposition. 


\section{P-176 TOTAL LUNG DEPOSITION IN CHILDREN WITH CYSTIC FIBROSIS: EFFECTS OF USING DIFFERENT NEBULISERS ON DEPOSITION}

\author{
Stephanie Trend ${ }^{1}$, William Ditcham ${ }^{1}$, Jasminka Murdzoska ${ }^{1}$, \\ Guicheng Zhang ${ }^{2}$, Christine Roller ${ }^{1}$, Rosina Ledermueller ${ }^{3}$, \\ Sunalene Devadason ${ }^{1}$ \\ ${ }^{1}$ University of Western Australia, ${ }^{2}$ Curtin University, \\ University of Western Australia, ${ }^{3}$ Pari $\mathrm{GmbH}$
}

Background: The aim of this study was to assess the effectiveness of two different nebulisers with slightly differing particle size on aerosol delivery to the lungs of children with cystic fibrosis.

Methods: Ten children (4-9 years old) were enrolled to compare the in vivo deposition of ${ }^{99 \mathrm{~m}} \mathrm{Tc}-\mathrm{DTPA}$ using PARI LC SPRINT Junior ("Junior"; volume mean diameter [VMD] $=2.9 \mu \mathrm{m}$ ) and PARI LC SPRINT Star ("Star"; VMD $=2.5 \mu \mathrm{m}$; PARI GmbH, Germany) nebulisers, on separate occasions, according to the order determined by randomisation. Supine transmission scans were obtained before nebulisation and anterior and posterior planar scintigraphic scans were taken afterwards. The geometric means of the count rates for regions of interest (lung and oro-gastric (OG)) were calculated. Effects of choice of nebuliser on lung deposition were analysed.

Results: The mean lung deposition using the Junior nebuliser was $13.76 \%$ compared to $13.26 \%$ for the Star. There were no significant differences in total lung deposition between the two nebulisers when the results from all children were analysed together. However, when grouping the children into those $<7$ and $>7$ years old, the Junior provided better lung deposition than the Star in older children (mean $16.12 \%$ vs. $13.11 \%, \mathrm{p}=0.03)$.

Conclusions: PARI LC SPRINT Junior was associated with greater lung deposition than the PARI LC SPRINT Star in children in the 7-9 year old age group; there were no significant differences between the devices in younger children.

\section{P-201 SALBUTAMOL VIA PRESSURISED METERED DDOSE INHALER (pMDI) IN VENTILATED CHILDREN - DOES IT GET TO WHERE WE WANT IT?}

William Ditcham ${ }^{1}$, Britta Regli von Ungern-Sternberg ${ }^{2}$, Anoop Ramgolam ${ }^{3}$, Stephanie Trend ${ }^{1}$, Mary Hegarty ${ }^{2}$, Mark Everard $^{1}$, Andre Schultz ${ }^{1}$, Sunalene Devadason ${ }^{1}$

\section{${ }^{1}$ University of Western Australia, ${ }^{2}$ Princess Margaret Hospital for Children, ${ }^{3}$ Telethon Kids Institute}

Background: Salbutamol is commonly used to treat perioperative bronchospasm. It is usually administered via pMDI and spacer in awake children; intra-operatively, the three main administration techniques for pMDI in ventilated children are 1) via inline adaptor, 2) in a $50 \mathrm{ml}$ syringe attached to the angle-piece of the ventilator and 3) via an actuator directly attached to endotracheal tube (ETT). This pilot study aimed to compare the efficiency of these techniques.

Methods: Techniques were assessed in-vitro under simulated spontaneous ventilation conditions. 3 and $7 \mathrm{~mm}$ ETTs, and two brands of salbutamol were tested. Drug recovered from each component was assayed, and particle size distribution determined using a Next Generation Impactor (NGI).

Results: All results as \% label claim ug/actuation, via the actuator, adaptor or syringe, respectively.

Ventolin: $7 \mathrm{~mm}$ ETT (NGI@ 30 L/min): Total 21.3, 10.7 and 8.4; fine particle fraction (FPF) 9.6, 5.2 and $1.73 \mathrm{~mm}$ ETT (NGI@ 15 L/ min): Total 40.9, 26.6 and 14.9; FPF 4.3, 0.2 and 0.6.

Spacer: Total 24.34; FPF; 17.66.
ProAir HFA: 7 mm ETT: Total 7.48, 2.72 and 1.3, FPF 4.71, 0.87 and $0.073 \mathrm{~mm}$ ETT: Total 30.8, 26.9, 13.4, FPF 9.2, 0.7 and 0 Spacer: Total 19.66, FPF 15.21.

Conclusions: Inter-technique differences were significant; with the syringe being the least efficient. In the event of a bronchospasm in intubated children, the impact of these differences in drug delivery must be considered, particularly in very young children when small sized ETTs are used.

\section{P-202 ANALYSIS OF LUNG DEPOSITION OF RADIOLABELED SALBUTAMOL COMPARED TO BREATHING PARAMETERS IN ASTHMATIC CHILDREN USING PRESSURISED METERED-DOSE INHALERS (pMDIs) WITH VALVED HOLDING CHAMBERS (VHCs), WITH AND WITHOUT A FACE MASK (FM)}

Stephanie Trend ${ }^{1}$, William Ditcham ${ }^{1}$, Guicheng Zhang ${ }^{2}$, Dirk von Hollen ${ }^{3}$, Kurt Nikander ${ }^{4}$, Sunalene Devadason ${ }^{1}$

${ }^{1}$ University of Western Australia, ${ }^{2}$ Curtin University, ${ }^{3}$ Respironics Inc, A Philips Healthcare Company, ${ }^{4}$ Indevco Ab

Background: We compared breathing pattern data collected using a pMDI with a VHC (OptiChamber Diamond) or VHC and FM (medium LiteTouch), with reference to total lung deposition in young children with stable asthma.

Methods: Data from ten children (3-5 years old) collected during radiolabeled salbutamol deposition study (PMID: 25054483) were assessed. Correlation between deposition (\%) and age, average inhaled volume (L), average inhalation time(s), wave period and rate of rise to peak inhalation flow was assessed. The effects of subjective compliance (satisfactory/unsatisfactory) on the outcomes of lung deposition (\%) were compared using unpaired t-tests.

Results: Using the VHC, lung deposition was correlated with the average inhalation time, wave period, and rise to peak inhalation flow $(\mathrm{p}<0.05)$. Using the VHC with FM, the average inhalation time was significantly correlated with lung deposition. In children using the VHC, lung deposition was significantly higher in those that were compliant $(n=8)$ compared to those that were not $(n=2)$ (mean $25.5 \%$ vs. $10.3 \%$, respectively, $\mathrm{p}<0.05$ ). No significant differences in lung deposition were observed between subjectively compliant $(n=6)$ and non-compliant $(n=4)$ children using the VHC and FM (mean $20.4 \%$ vs. $14.6 \%$ ).

Conclusions: Since subjectively assessed poor compliance was only associated with worse deposition outcomes in children using a VHC alone, young children with poor technique may benefit from using face masks in combination with spacers.

\section{P-219 EFFICIENT TOBRAMYCIN INHALATION: THE COMBINATION OF A HIGH CONCENTRATION DRUG WITH AN INTELLIGENT INHALATION SYSTEM REDUCES THE INITIAL DOSAGE, THE INHALATION TIME AND THE THERAPY COSTS}

\author{
Juliane Schick ${ }^{1}$, Wolfgang Deml ${ }^{1}$, Christine Hardung ${ }^{2}$, Jens \\ Paulukat $^{1}$, Sebastian Canisius ${ }^{1}$, Andreas Linke ${ }^{2}$
}

${ }^{1}$ Vectura GmbH, ${ }^{2}$ Infectopharm Arzneimittel und Consilium GmbH

Success in inhalation therapy depends on adherence and sufficient drug deposition. Moreover, therapy costs are of growing importance. In 2006, an in-vivo gamma scintigraphy study with a Tobramycin dose of only $160 \mathrm{mg}$ (Gernebcin $160 \mathrm{mg} / 4 \mathrm{ml})$ nebulised via the highly 
efficient AKITA JET Inhalation System (AJ) showed an equal lung deposition (LD) compared to $300 \mathrm{mg}$ TOBI (T300) nebulised via PARI LC Plus.

The current study aimed to examine whether the new, high concentration GERNEBCIN $160 \mathrm{mg} / 2 \mathrm{ml}$ (G160) and the new AJ would achieve equivalence to $\mathrm{T} 300$ in $<10 \mathrm{~min}$ which may improve adherence.

$\mathrm{G} 160+\mathrm{AJ}$ were compared to $\mathrm{T} 300+$ eFlow rapid (EF). Aerosols were characterised and drug contents quantified. A standard adult breathing pattern was set for EF. AJ parameters were $200 \mathrm{ml} / \mathrm{s}$ flow and tidal volume of 11. LD was calculated by the ICRP-Model.

In comparison, the $\mathrm{AJ}$ generated smaller particles but a wider range (VMD 3.57/3.93; GSD 1.95/1.5). The delivered dose (DD) was $110.3 \mathrm{mg}$ for T300 + EF. Despite the almost half initial dose, DD of $\mathrm{G} 160+\mathrm{AJ}$ was $73.0 \mathrm{mg}$. In contrast to AJ, the EF wasted $75.0 \mathrm{mg}$ into the environment. Finally, both systems delivered a comparable LD of $50.8 \mathrm{mg}(\mathrm{EF})$ and $53.6 \mathrm{mg}(\mathrm{AJ})$, respectively. Alveolar deposition was higher in case of $\mathrm{AJ}(34.2 \mathrm{mg})$ than $\mathrm{EF}(26.1 \mathrm{mg})$.

In conclusion, compared to $\mathrm{T} 300+\mathrm{EF}$ the $\mathrm{G} 160+\mathrm{AJ}$ gained an equivalent $\mathrm{LD}$ providing a tool to reduce therapy costs. Moreover, G160 reduced AJ inhalation time from $13.9 \mathrm{~min}$ (2006) to $9.7 \mathrm{~min}$ potentially retaining adherence.

\section{P-248 EFFECT OF CANNULA DESIGN AND GAS FLOW RATE ON TRACHEAL DOSE IN AN ORO NASAL AIRWAY MODEL OF A NEWBORN (RONAN)}

\author{
Andrew O'Sullivan ${ }^{1}$, Louise Sweeney ${ }^{1}$, Monika Wolny ${ }^{1}$, \\ Paul Fahy ${ }^{2}$, Ronan MacLoughlin ${ }^{1}$ \\ ${ }^{1}$ Aerogen Limited, Ida Business Park, Dangan, Galway, Ireland, \\ ${ }^{2}$ Galway Medical Technologies Centre (Gmedtech), \\ Department of Mechanical and Industrial Engineering, \\ Galway Mayo Institute of Technology, Galway, Ireland
}

Introduction: Aerosol delivery in the newborn population is not well described in the literature. The aim of this study was to document the effect of cannula design and gas flow rate on tracheal dose in an oro nasal airway model of a newborn during high flow nasal therapy.

Method: Neonate and Infant nasal cannula (OPT314 and OPT316, Fisher Paykel) were positioned on the RONAN model which was connected to a breathing simulator (Ingmar ASL 5000) via an absolute filter (RespirGard II 303). The breathing pattern was as follows; BPM 30 , Vt $50 \mathrm{~mL}$, I:E 1:3. Testing was completed using heated humidified air across 2, 4, 6 and 8 LPM. $2 \mathrm{ml}$ of $2 \mathrm{mg} / \mathrm{ml}$ of Albuterol was delivered using a vibrating mesh nebuliser (Aerogen Solo, Aerogen Ireland) $(n=3)$. At the end of each dose the drug was extracted and quantified using UV spectrophotometry.

Results: The recorded tracheal doses (drug delivered beyond the trachea) were as follows; OPT316 $(10.15 \pm 0.75 \%) v s$ OPT314 (6.26 $0.37 \%)$ at $2 \mathrm{LPM}, \mathrm{OPT} 316(6.44 \pm 0.30 \%) v s$ OPT $314(3.13 \pm 0.12 \%)$ at 4 LPM, OPT316 $(1.99 \pm 0.36 \%)$ vs OPT314 $(0.88 \pm 0.12 \%)$ at 6 LPM and OPT316 $(2.58 \pm 0.35 \%)$ vs OPT314 $(0.86 \pm 0.09 \%)$ at 8 LPM.

Conclusions: Varying the cannula size from neonatal to infant had an effect on the tracheal dose across the range of gas flow rates. At 2 LPM and 8 LPM the tracheal dose nearly doubled with the larger cannula. This is likely a direct result of the reduced impactional losses within the cannula and the tighter seal in the nose.

\section{P-276 IN VITRO PERFORMANCES OF A VALVED HOLDING CHAMBER WITH DIFFERENT GENERIC DRUGS}

Nabile Boukhettala, Thierry Porée

Laboratoire Protec'som
In young and elderly patients with asthma, it is recommended to use pressurised metered dose inhaler (pMDI) with a valved holding chamber. The objective of this study was to evaluate the performances of a valved holding chamber with different generic drugs.

In this study, the valved holding chamber (VHC) called Tipshaler (Protec'som, France) was evaluated with salbutamol (Asthalin ${ }^{\circledR}$, $100 \mu \mathrm{g} /$ dose, Cipla, India) and budesonide (Budecort ${ }^{\circledR}, 200 \mu \mathrm{g} / \mathrm{dose}$, Cipla, India). The method according to the European Pharmacopoeia used a constant flow rate $(30 \mathrm{~L} / \mathrm{min})$ was used. Particle size distribution was measured using a NGI cascade impactor (Copley Scientific, Nottingham, United Kingdom). The salbutamol and budesonide concentrations were assayed by spectrophotometry at $240 \mathrm{~nm}$ and $244 \mathrm{~nm}$ respectively.

In the trachea, the mass of salbutamol was higher with pMDI alone in comparison with VHC $(15.6 \pm 1.9$ vs $2.3 \pm 0.5, \mathrm{p}<0.05)$. In addition, deposition of fine particles of salbutamol was similar with pMDI alone compared to VHC $(26.0 \pm 4.6 \mu \mathrm{g}$ vs $31.8 \pm 2.9 \mu \mathrm{g}, \mathrm{p}<0.05)$. Concerning budesonide, the mass of drugs in the trachea was higher with pMDI alone compared to VHC $(48 \pm 1.6$ vs $8.3 \pm 1.0, \mathrm{p}<0.05)$. However, the fine particle dose was similar with the pMDI alone compared to VHC $(73.2 \pm 9.5 \mu \mathrm{g}$ vs $81.9 \pm 11.8 \mu \mathrm{g})$.

In conclusion, the use of valved holding chamber reduces the deposition of drugs in the trachea and enhances the deposition of these drugs.

\section{Regulatory and Standardization}

\section{P-012 POTENTIAL BENEFIT OF REPEATED AEROLIZER DPI INHALATION TECHNIQUE COUNSELING ON ASTHMATIC AND COPD PATIENTS}

\author{
Marwa Elgendy ${ }^{1}$, Mohamed Abdelrahim ${ }^{2}$, Randa Salah Eldin ${ }^{3}$ \\ ${ }^{1}$ Hospital Pharmacy Department, Teaching Hospital of Faculty \\ of Medicine, Faculty of Medicine, Beni Suef University, \\ ${ }^{2}$ Clinical Pharmacy Department; Faculty of Pharmacy, \\ Beni Suef University, ${ }^{3}$ Respiratory Department, Faculty \\ of Medicine, Beni Suef University
}

Patients' incorrect use of their Dry powder inhalers (DPIs) is a major reason for poor asthma and chronic obstructive pulmonary disease (COPD) control.

Hence, the aim of the present work was to study the role of DPI counselling on the patients inhalation technique and their lung function test scores.

310 asthma or COPD subjects (164 female) using aerolizer DPI were collected from Beni Suef University hospital outpatient clinics through a two year study period with mean (SD, range) age 48.7 (13.1, 19-77) years old. Their results were collected as whole one group and divided into 3 different age groups. Their DPI inhalation technique was checked and the number of mistakes was detected and corrected at the start of the study and every month for two months (three visits). Their peak expiratory flow (PEF) and forced expiratory volume in one second $\left(\mathrm{FEV}_{1}\right)$ as percentage of the forced vital capacity (FVC) were checked at every visit.

The mean number of mistakes observed was significantly decreased $(\mathrm{p}<0.001)$ as the number of visits increased. "To inhale fast" and "To maintain a fast inhalation rate until the lungs are full" were the most common repeated mistakes. There was a significant increase $(\mathrm{p}<0.001)$ in the pulmonary function test after the period of counselling in all age group.

DPI's counselling should be repeated at every opportunity to improve and maintain the recommended DPI inhalation technique and possibly improve patients' lung function test scores. 


\section{P-013 POSSIBLE EFFECTS OF REPEATED MDI INHALATION TECHNIQUE COUNSELING ON ASTHMATIC AND COPD PATIENTS}

\author{
Marwa Elgendy ${ }^{1}$, Mohamed Abdelrahim ${ }^{2}$, Randa Salah Eldin ${ }^{3}$ \\ ${ }^{1}$ Hospital Pharmacy Department, Teaching Hospital of Faculty \\ of Medicine, Faculty of Medicine, Beni Suef University, \\ ${ }^{2}$ Clinical Pharmacy Department, Faculty of Pharmacy, \\ Beni Suef University, ${ }^{3}$ Respiratory Department, Faculty \\ of Medicine, Beni Suef University
}

Patients' incorrect use of their metered dose inhalers (MDI) is a major reason for poor asthma and chronic obstructive pulmonary disease (COPD) control.

Hence, the aim of the present work was to study the role of MDI counselling on the patients inhalation technique and their lung function test scores.

491 asthma or COPD patients ( 281 female) were collected from Beni Suef University hospital outpatient clinics through a two year study period with mean (SD, range) age 42.1 (17.1, 10-78) years old. Their results were collected as whole one group and divided into 4 different age groups. Their MDI inhalation technique was checked and the number of mistakes was detected and corrected at the start of the study and every month for two months (three visits). Their peak expiratory flow (PEF) and forced expiratory volume in one second $\left(\mathrm{FEV}_{1}\right)$ as percentage of the forced vital capacity (FVC) were checked at every visit.

The mean number of mistakes observed was significantly decreased $(p<0.001)$ as the number of visits increased especially in children age group. "To maintain a slow inhalation rate until the lungs are full" was the most common repeated mistake. There was a significant increase $(\mathrm{p}<0.001)$ in the pulmonary function test after the period of counselling in all age group particularly in $>60$ years old patients.

MDI's counselling should be repeated at every opportunity to improve and maintain the recommended MDI inhalation technique and possibly improve patients' lung function test scores.

\section{P-095 DRY POWDER INHALER DEVELOPMENT: WHY ARE THERE SURPRISES WHEN CORRELATING IN VITRO AND IN VIVO?}

\author{
Herbert Wachtel ${ }^{1}$, Steve Horhota ${ }^{2}$ \\ ${ }^{1}$ Boehringer Ingelheim Pharma GmbH \& Co. Kg, Analytical \\ Development, ${ }^{2}$ Boehringer Ingelheim Pharmaceuticals Inc.
}

Recently, two case studies have been shared by major pharma companies where seemingly similar in vitro data of the respective inhalation products resulted in similar PD, but in different $\mathrm{pK}$ data. The active substances were tiotropium, salmeterol and fluticasone.

The in-vitro investigations were based on standard pharmacopeial methods determining delivered dose and providing an aerodynamic assessment of fine particles. The set of experiments covered i) different formulations in different inhalers tuned for the same impactor sized mass (ISM) and ii) identical formulations in two different inhalers tuned for the same fine particle mass. The corresponding invivo studies investigated $\mathrm{pK}$ and $\mathrm{PD}$.

Results: i) In spite of a similar ISM ( ISM $_{A}=11.4 \mu \mathrm{g}, \mathrm{ISM}_{\mathrm{B}}=10.6$ $\mu \mathrm{g})$ the $\mathrm{pK}$ data provided a ratio of AUC of 0.6 for salmeterol. ii) In spite of similar fine particle mass and identical formulations the $\mathrm{pK}$ data provided a ratio of AUC of 2 for one drug and a ratio of $\mathrm{C}_{\max }$ of almost 2 for the second drug in the combination formulation. PD data showed no statistically significant differences in both cases.
Conclusion: Even if pharmaceutical products for inhalation provide similar results in one or two aspects (be it in-vitro, pK or PD data) obvious differences may still exist which motivate that at least in vitro, $\mathrm{pK}$, and $\mathrm{PD}$ data of inhaled products including risk management should be considered in a holistic way.

\section{P-149 THE USE OF PATIENT-GENERATED BREATHING WAVEFORMS FOR THE CLINICALLY APPROPRIATE EVALUATION OF A REPRESENTATIVE NEBULIZING SYSTEM}

\author{
Jason Suggett ${ }^{1}$, Mark Nagel ${ }^{1}$, Cathy Doyle ${ }^{1}$, Vivian Wang ${ }^{1}$, \\ Jolyon Mitchell ${ }^{2}$ \\ ${ }^{1}$ Trudell Medical International, ${ }^{2}$ Jolyon Mitchell \\ Inhaler Consulting Services Inc.
}

Several international standards provide idealized breathing patterns to demonstrate nebulizer performance. However, such continuous sinusoidal patterns fail to capture the nuances affecting therapy, such as difficulty in inhaling, coughing, or pausing to catch the breath. It should therefore be useful to use in-vivo breathing profiles obtained in the appropriate clinical setting to evaluate in vitro nebulized drug delivery using technology available with current breathing simulators. The aim of this study was to develop a methodology that could be used to capture multiple in vivo breathing patterns taken from patients having defined disease conditions, and then simulate such breathing patterns in-vitro, measuring medication delivery from a breath actuated nebulizer (BAN). Breathing patterns were recorded over the entirety of the treatment using a RSS 100 Research Pneumotach Instrumentation system (Hans Rudolph). The patterns were then replicated using the ASL 5000 breathing simulator (Ingmar Medical). AeroEclipse* II BANs (Trudell Medical International) were operated under each of the recorded breathing patterns with a representative inhaled medication. Emitted aerosol was captured on filters at the mouthpiece, replaced at minute intervals. We were successfully able to replicate patient-generated breathing waveforms that could then be used to produce in-vitro delivery data from the nebulizer.

\section{P-225 INCORPORATING BATCH-TO-BATCH PHARMACOKINETIC VARIABILITY IN THE BIOEQUIVALENCE INTERPRETATION}

\author{
Kevin Carroll
}

Kjc Statistics Ltd, Sovereign House

Pharmacokinetic (PK) bioequivalence (BE) is defined as a $90 \%$ confidence interval $(\mathrm{CI})$ around Test $(\mathrm{T})$ to Reference $(\mathrm{R})$ mean ratio within $80-125 \%$ for max blood concentration and total blood exposure. Recent regulatory changes expand these CI limits when R demonstrates high dispositional/biological variability but the requirement for T/R mean PK ratios within $80-125 \%$ remains.

The adequacy of current statistical BE requirements is brought into question by data on the between-batch PK variability of branded fluticasone propionate/salmeterol dry powder products on the US and EU markets. These data demonstrate that between-batch variability can exceed $50 \%$ for both active ingredients, across all PK metrics. Clearly, this variability causes difficulty meeting BE expectations for a generic product through standard regulatory paradigms. Although one solution is to relax the $80-125 \%$ ratio requirement consistent with high variability implying a wide therapeutic window, regulatory 
practice is reluctant to diverge from the established $80-125 \%$ acceptance range.

Solutions that acknowledge that $\mathrm{R}$ diversity exceeds the $\mathrm{BE}$ acceptance range include use of random effects meta analysis across many clinical studies and application of reference-scaling rules across $\mathrm{R}$ batches. Meta analysis responds to between-batch PK differences by inclusion of multiple batches to provide a robust T/R comparison, precisely predicting overall patient experience to inform a scientifically driven regulatory decision.

\section{P-257 VALIDATION OF THE PH.EUR. METHOD FOR THE AEROSOL ASSESSMENT OF PREPARATIONS FOR NEBULISATION}

\author{
Martina Schmidmeir, Barbara Daumann, Daniela Bräutigam, \\ Hilke Ehlich, Claudius Kietzig, Knut Sommerer
}

\section{Inamed $\mathrm{GmbH}$}

Chapter 2.9.44 Ph.Eur. describes the characterisation of preparations for nebulisation. It is a general, not API specific method using a cooled NGI. Defined method validation parameter is the confirmation of non-occurrence of impactor stage-overloading.

The aim of this study was to validate the method for $0.9 \% \mathrm{NaCl}$ and a jet nebulizer applying the additional, lab-specific parameters reproducibility and robustness.

Method: Pre-cool a NGI in a refrigerator $\left(\sim 5^{\circ} \mathrm{C}\right)$ for $\geq 90 \mathrm{~min}$ Start nebulization at $15 \mathrm{l} / \mathrm{min}$ within $5 \mathrm{~min}$ after NGI removal from the refrigerator. Quantify $\mathrm{NaCl}$ mass per stage by conductivity. Evaluate the parameters stage-overloading, precision (6 tests on two different days +3 tests performed by a second technician) and robustness (varying the flow rate through the NGI $(13-17 \mathrm{~L} / \mathrm{min})$ and the nebulisation time $(2-5 \mathrm{~min}))$.

During validation no stage overloading occurred. The PSD was similar for all 9 precision-tests and delivered a reproducible MMAD of $4.5 \mu \mathrm{m} \pm 1.6 \%$ and a FPF of $54.2 \% \pm 1.5 \%$. Robustness tests showed a variation in MMAD and $\mathrm{FPF}<6.5 \%$ for flow rate and $<4.8 \%$ for nebulisation time.

In summary the method is accurate and robust within the tested parameters and drug/nebulizer combination. However, the method allows a temperature variability within the impactor, which could lead to higher PSD variability for evaporation sensitive drugs or/and low output nebulizers and therefore additional tests are planned for other drug/nebulizer combinations.

\section{P-270 FLOW PROFILE MEASUREMENT IMPROVEMENT THROUGH INDIVIDUAL CALIBRATION CURVES}

\author{
Simon Prentner, Claudius Kietzig, Knut Sommerer
}

\section{Inamed $\mathrm{GmbH}$}

Flow profile measurements are requested in the EMA guideline 4151. Several methods are available to trace the volume flow rate through the device. Our preferred method is to measure the differential pressure in the mouthpiece of an inhaler by inserting a pressure sensor probe into the mouthpiece and using a software which includes a calibration curve to determine the volume flow rate. This method has a high accuracy because no extra resistance is introduced during the measurement and reduces interferences of the measurement system with the patient when inhaling through an inhaler to a minimum.
In previous software versions this calibration curve was determined using a sinusoidal flow profile generated by a flow volume simulator and parallel measurement of the volume flow rate and pressure signal using a mass flow meter and the measurement system. This calibration curve was determined from 5 devices and a mean calibration curve was calculated. Because of fabrication tolerances of the inhalers of more than $5 \%$ the resulting calibration curve has the same inaccuracy. To compensate this divergence a software routine was developed which is able to generate automatically an individual calibration curve for each single inhaler using three calibration runs resulting in a mean calibration curve for each inhaler with a very low variability of $<1 \%$.

This new individual calibration procedure for all inhalers used in a clinical trial is faster and increases the accuracy of the flow profile measurements.

\section{New Devices \& Emerging Therapy}

\section{P-014 IN VITRO CHARACTERISATION OF AEROSOLISED DRUG DURING NON-INVASIVE VENTILATION (NIV)}

\author{
Ahmed Hassan ${ }^{1}$, Hoda Rabea ${ }^{2}$, Raghda Hussein ${ }^{2}$, \\ Mohamed Abdelrahim ${ }^{2}$, Randa Salah Eldin ${ }^{3}$, Amira S. A. Said ${ }^{2}$, \\ Maha M. Abdelrahman ${ }^{4}$ \\ ${ }^{1}$ Hospital Pharmacy Department, Beba General \\ Hospital, Beni Suef, Egypt \\ ${ }^{2}$ Clinical Pharmacy Department, Faculty of Pharmacy, \\ Beni Suef University \\ ${ }^{3}$ Respiratory Department, Faculty of Medicine, \\ Beni Suef University \\ ${ }^{4}$ Analytical Chemistry Department, Faculty of \\ Pharmacy, Beni Suef University
}

Many devices are used to deliver aerosol in NIV. 3 spacers and 3 vibrating mesh nebulisers were compared to Sidestream jet nebulizer (SIDE). Device was placed proximal to a breathing simulator in a standard NIV circuit with $500 \mathrm{ml}$ tidal volume, 15 breaths/min, $20: 5 \mathrm{~cm} \mathrm{H}_{2} \mathrm{O}$ inspiratory (I) : expiratory (E) pressures and $1: 3 \mathrm{I}: \mathrm{E}$ ratio. $2 \mathrm{ml}$ of sulbutamol solution containing $12100 \mu \mathrm{g}$ was nebulised using Aeroneb Pro (AERO), Aeroneb Solo (SOLO), NIVO and SIDE. 16 MDI doses containing $100 \mu \mathrm{g}$ sulbutamol each were delivered using AeroChamber MV (AC), AeroChamber Vent (VC) and AeroChamber Mini (MC).

Total emitted dose (TED) and its percentage were determined. Aerodynamic droplet characteristics were measured using cooled Andersen Cascade Impactor (1).

Differences and superiorities of all tested nebulisers and spacers over jet nebuliser were found. Hence device used to deliver aerosol in NIV should be chosen with care.

1. Abdelrahim ME. Aerodynamic characteristics of nebulized terbutaline sulphate using the Andersen Cascade Impactor compared to the Next Generation Impactor. Pharm Dev Technol. 2011;16(2):137-45.

Table 1: Mean (SD) dose emission characteristics from all devices
\begin{tabular}{|c|c|c|c|c|c|c|c|}
\hline & AERO & SOLO & NIVO & SIDE & AC & VC & MC \\
\hline \multirow{2}{*}{ TED $(\mu \mathrm{g})$} & 3186.3 & 3042.5 & 3274.9 & 2056.8 & 552.1 & 687.3 & 602.8 \\
& $(491.4)$ & $(621.0)$ & $(57.6)$ & $(922.0)$ & $(157.3)$ & $(224)$ & $(106)$ \\
\hline \multirow{2}{*}{ TED $(\%)$} & 26.3 & 25.1 & 27.1 & 17.0 & 34.5 & 43.0 & 37.7 \\
& $(4.1)$ & $(5.1)$ & $(5.1)$ & $(7.6)$ & $(9.8)$ & $(15.3)$ & $(6.6)$ \\
\hline \multirow{2}{*}{ FPD ( $\mu \mathrm{g})$} & 465.8 & 797.5 & 258.2 & 386.2 & 323.1 & 223.1 & 234.6 \\
& $(80.8)$ & $(373.8)$ & $(134.8)$ & $(202.0)$ & $(30.4)$ & $(19.8)$ & $(143.7)$ \\
\hline \multirow{2}{*}{ FPF (\%) } & 46.5 & 59.1 & 42.7 & 65.2 & 56.6 & 49.1 & 56.5 \\
& $(16.3)$ & $(13.3)$ & $(1.9)$ & $(3.6)$ & $(6.2)$ & $(3.3)$ & $(5.5)$ \\
\hline \multirow{2}{*}{ MMAD (um) } & $4.5(0.7)$ & $3.9(0.3)$ & $5.1(0.1)$ & $3.7(0.1)$ & $2.7(1.1)$ & 3.8 & $2.7(0.7)$ \\
\hline
\end{tabular}




\section{P-024 VHC PERFORMANCE EVALUATION AT CONSTANT FLOW}

\author{
Ricardo Oliveira ${ }^{1}$, José Carlos Teixeira ${ }^{2}$, \\ Senhorinha FCF Teixeira ${ }^{3}$, Helena Cabral-Marques ${ }^{4}$ \\ ${ }^{I}$ Ct2m R\&D Research Center, Department of Mechanical \\ Engineering, University of Minho \\ ${ }^{2}$ Ct $2 m$ R\&D Center, Department of Mechanical \\ Engineering, University of Minho \\ ${ }^{3}$ Algoritmi R\&D Center, Department of Production \\ and Systems, University of Minho \\ ${ }^{4}$ Imed.Ul R\&D Center, Faculty of Pharmacy,
} Universidade de Lisboa

Increasing incidence of asthma in the world pushes forward the development of inhalation devices, particularly Valved Holding Chambers (VHC), an add-on device for pressurized Metered-Dose Inhaler (pMDI). VHC allows the patient to breathe normally without the need for coordinated respiratory manoeuvres, nullifies the "coldfreon" effect caused by the high velocity spray and reduces the Mass Median Aerodynamic Diameter of the plume.

A study was carried out using a cascade impaction method (i.e. MSLI) at $34 \mathrm{~L} / \mathrm{min}$ for $8 \mathrm{VHC}$ devices: Aerochamber Plus ${ }^{\circledR}$, A2A Spacer ${ }^{\circledR}$, Compact Space Chamber Plus ${ }^{\circledR}$, Space Chamber Plus ${ }^{\circledR}$, Nebuchamber $^{\circledR}$, Vortex $^{\circledR}$, OptiChamber Diamond ${ }^{\circledR}$ and Volumatic ${ }^{\circledR}$. The Ventolin ${ }^{\circledR}$ (salbutamol sulphate $100 \mu \mathrm{g} / \mathrm{dose}$ ) was chosen model pMDI due to its widely prescription and acceptance. Drug mass per stage was quantified by UV-Vis Spectrometry.

The VHC results were analysed in terms of Emitted Dose (ED) and Fine Particle Mass (FPM). VHC performance was also evaluated according to performance indexes.

In terms of FPM the VHC devices rank as following: Volumatic $(24.9 \pm 2.9 \mu \mathrm{g})>$ Nebuchamber $(24.3 \pm 1.7 \mu \mathrm{g})>$ Vortex $(24.2 \pm 2.5 \mu \mathrm{g})>$ Aerochamber Plus $(24.2 \pm 3.8 \mu \mathrm{g})>$ Compact Space Chamber Plus $(22.2 \pm 1.8 \mu \mathrm{g})>\mathrm{A} 2 \mathrm{~A}$ Spacer $(19.2 \pm 1.9 \mu \mathrm{g})>$ Space Chamber Plus $(18.8 \pm 2.6 \mu \mathrm{g})>$ OptiChamber Diamond $(18.1 \pm 2.3 \mu \mathrm{g})$. Results show that the VHC reduces the throat deposition in $82.7 \%$ to $95.3 \%$, in comparison with the use of pMDI alone.

Differences were found between the ED and FPM, showing that emitting higher dose does not correlate with higher FPM.

\section{P-027 TRAIN PATIENTS TO PROLONG THEIR INHALATION MANOUVRE WHEN USING A METERED DOSE INHALER (MDI)}

\author{
Hassane El Larhrib ${ }^{1}$, Hazel Jones ${ }^{2}$, \\ Stephen Rawson ${ }^{2}$, Henry Chrystyn ${ }^{3}$ \\ ${ }^{1}$ Dept of Pharmacy; School of Applied Science; \\ University of Huddersfield \\ ${ }^{2}$ Dept of Pharmacy; School of Applied Sciences; \\ University of Huddersfield \\ ${ }^{3}$ Inhalation Consultant
}

Using a fast inhalation flow manoeuvre is the most common error when using a MDI. Dose actuation is not critical as long as the inhalation flow is slow and it happens during the inhalation phase (Newman et al. Eur J Respir Dis Suppl 1982; 119:57-65). We have studied the effect of prolonging the inhalation phase of asthmatics that use a MDI. At visit 1 asthmatics, using a MDI, were randomised into an untrained group (CONTROL), training using the Patient Information leaflet (PIL) and a group that received the PIL training plus detailed instructions for their inhalation manoeuvre to be prolonged to

\begin{tabular}{|l|l|l|l|}
\hline \multicolumn{5}{|c|}{ Mean(SD) inhalation characteristics } \\
\hline & Control $(n=12)$ & PIL $(n=13)$ & SSEC $(n=14)$ \\
\hline Age & $23.3(4.9)$ & $27.4(11.4)$ & $22.6(4.9)$ \\
\hline FEV1(\% predicted) & $83.3(17.1)$ & $85.8(20.4)$ & $90.1(17.6)$ \\
\hline PRE & & & \\
\hline PIF & $161.6(63.9)$ & $226.4(77.7)$ & $191.7(107.9)$ \\
\hline Vin & $2.47(1.03)$ & $3.43(1.43)$ & $2.54(1.10)$ \\
\hline Ti & $2.09(1.21)$ & $1.65(0.54)$ & $1.76(0.72)$ \\
\hline POST & & & \\
\hline PIF & $164.6(68.0)$ & $218.6(85.0)$ & $88.47(28.82)^{* *}$ \\
\hline Vin & $2.62(1.02)$ & $3.91(1.46)$ & $3.12(0.70)^{* *}$ \\
\hline Ti & $1.90(0.95)$ & $2.03(0.62)$ & $4.08(1.04)^{* * *}$ \\
\hline Visit 2 & & & \\
\hline PIF & $160.0(66.7)$ & $237.7(100.3)$ & $103.2(41.2)^{* *}$ \\
\hline Vin & $2.52(1.00)$ & $4.07(1.52)$ & $3.38(0.66)^{*}$ \\
\hline Ti & $1.79(0.97)$ & $1.97(0.59)$ & $3.49(1.30)^{* *}$ \\
\hline$*$ p $<0.05 ; * *<0.01 ; * * * 0.001$ compared to pre visit 1 & \\
\hline
\end{tabular}

5 seconds (5SEC). Inhalation characteristics (peak inhalation flow $\mathrm{PIF}$ in $\mathrm{L} / \mathrm{min}$; inhaled volume - Vin in L; and inhalation time - Ti in sec) were measured. All patients returned after 4 weeks (Visit 2) to repeat their inhalation characteristics. Table 1 shows that the only change in the inhalation characteristics occurred in the 5SEC group.

Patients using a MDI should be encouraged to use an inhalation phase that lasts upto 5 seconds. This provides an objective definition for the generic instruction of 'slow and deep inhalation' recommended in PILs.

\section{P-045 DOSE EMISSION FROM A COMBINATION TURBUHALER USING PATIENT INHALATION PROFILES}

\author{
Golshan Bagherisadeghi ${ }^{1}$, El Hassane Larhrib ${ }^{1}$, Henry Chrystyn ${ }^{2}$
${ }^{1}$ Dept of Pharmacy, School of Applied Science, University of Huddersfield
${ }^{2}$ Inhalation Consultant

The dose emitted from dry powder inhalers varies from patient to patient depending on their inhalation maneuver. The compendial method for the Andersen Cascade Impactor has been adapted to use inhalation profiles in place of the square wave generated by a vacuum pump. This ex-vivo method has been used to characterise the emitted dose from a $200 \mu \mathrm{g}$ budesonide (BUD) plus $6 \mu \mathrm{g}$ formoterol (FORM) Symbicort ${ }^{\circledR}$ Turbuhaler ${ }^{\circledR}$ using inhalation profiles from COPD patients. Table 1 shows the total emitted dose (TED), fine particle dose (FPD) and mass median aerodynamic diameter (MMAD) using inhalation profiles with a similar peak inhalation flow (PIF) and acceleration of the flow (ACC) but different inhaled volumes (IV). After each determination residual amounts were measured using a PIF of $90 \mathrm{~L} / \mathrm{min}$ and IV of $4 \mathrm{~L}$.

The results suggest that inhaled volume has an effect on the characteristics of the emitted dose. This Ex-vivo methodology provides an insight into the dose each patient would have received in real life.

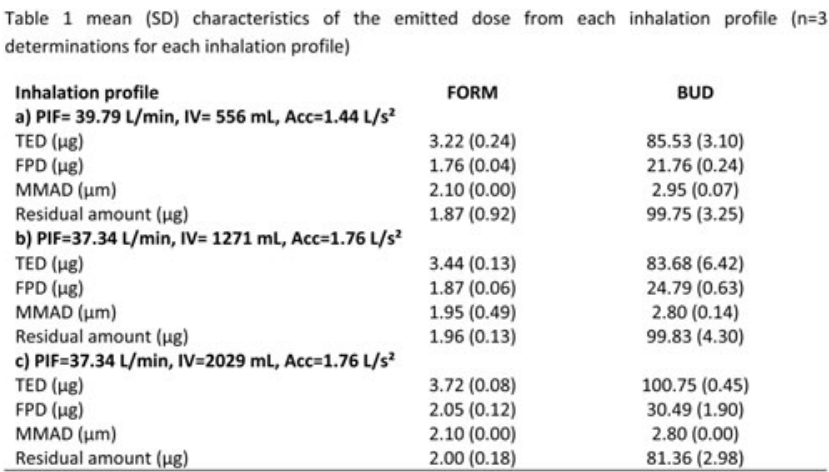




\section{P-050 TRAINING PATIENTS TO IMPROVE THEIR INHALATION MANOUVRE WHEN USING DIFFERENT DRY POWDER INHALERS (DPIS)}

\author{
Hassane El Larhrib ${ }^{1}$, Lindilu Gombakomba ${ }^{1}$, \\ Alpa Thakrar ${ }^{1}$, Henry Chrystyn ${ }^{2}$ \\ ${ }^{1}$ Dept of Pharmacy, School of Applied Science, \\ University of Huddersfield \\ ${ }^{2}$ Inhalation Consultant
}

Patients should be trained to use a fast inhalation manoeuvre from the start of their inhalation that should be maintained during real life use. This ensures the required de-aggregation of the formulation during each inhalation manoeuvre which is driven by a turbulent energy (measured as a pressure change) that is created by an interaction between the inhalation flow and the resistance of the DPI. The inhalation characteristics of asthmatics, regular DPI uses, have been measured pre and post training and four weeks later (Visit 2). The inhalation characteristics measured were peak inhalation flow (PIF in $\mathrm{L} / \mathrm{min}$ ), the maximum pressure change ( $\triangle \mathrm{P}$ in $\mathrm{kPa}$ ) and the acceleration rate ( $\mathrm{ACC}$ in $\mathrm{kPa} / \mathrm{sec})$. The DPIs used were the Diskus (DSK), Turbuhaler (TBH) and Easyhaler (EASY) - these have medium, medium/high and high resistance. 29 asthmatics, mean $\mathrm{FEV}_{1}$ 92.2\% predicted completed the study. A summary of their inhalation characteristics is presented in Table 1 .

Mean (SD) ACQ on Visit 1 and 2 was 1.41(0.85) and 1.27(0.78).

Training patients to use a fast inhalation, with emphasis on rapid acceleration, improves the inhalation manoeuvre when using a DPI and this is maintained during short-term real life use. DPIs with higher resistance provide better inhalation characteristics for de-aggregation.

\begin{tabular}{|l|l|l|l|l|}
\hline \multicolumn{5}{|c|}{ Table 1 mean (SD) inhalation characteristics } \\
\hline Inhaler & Event & PIF & \multicolumn{1}{|c|}{$\Delta$ P } & ACC \\
\hline DSK & & & & \\
\hline & PRE & $81.9(14.6)$ & $4.3(1.4)$ & $18.1(14.9)$ \\
\hline & POST & $101.0(15.7)$ & $6.5(2.0)$ & $26.7(14.1)$ \\
\hline & VISIT 2 & $96.8(12.2)$ & $5.9(1.4)$ & $24.1(12.1)$ \\
\hline TBH & & & & \\
\hline & PRE & $66.7(13.4)$ & $5.1(1.9)$ & $19.6(14.3)$ \\
\hline & POST & $82.0(11.6)$ & $7.5(2.1)$ & $31.5(12.9)$ \\
\hline & VISIT 2 & $81.4(10.4)$ & $7.4(1.9)$ & $31.7(18.4)$ \\
\hline EASY & & & & \\
\hline & PRE & $67.2(9.3)$ & $8.3(2.2)$ & $29.7(15.2)$ \\
\hline & POST & $77.5(8.4)$ & $10.9(2.3)$ & $44.0(20.8)$ \\
\hline & VISIT 2 & $77.6(8.9)$ & $11.0(2.5)$ & $47.3(22.6)$ \\
\hline
\end{tabular}

\section{P-056 EFFECTS OF HEAT AND MOISTURE EXCHANGERS AND EXHALED HUMIDITY ON AEROSOL DEPOSITION IN A SIMULATED VENTILATOR DEPENDENT ADULT LUNG MODEL}

Arzu Ari, Mohammed Alqahtani, Mohammed Almeshari, James Fink

\section{Georgia State University, Department of Respiratory Therapy}

Many in-vitro models report higher inhaled dose with dry versus heated humidity. The impact of heat moisture exchangers designed to allow aerosol delivery (HME-AD) have not been well described. The aim of this study is to determine the effect of HME-ADs with and without exhaled humidity on aerosol deposition in a simulated ventilator-dependent adult model.

An in-vitro model including an intubated teaching mannequin with bronchi directly attached to a collecting filter and rubber test lung to provide testing without active exhaled humidity. To stimulate exhaled humidity, the bronchi was connected to a humidifier $\left(37^{\circ} \mathrm{C}\right.$ and $100 \%$ relative humidity) via a collecting filter. Albuterol sulfate $(2.5 \mathrm{mg} /$ $3 \mathrm{~mL}$ ) was delivered with a nebulizer (Aerogen) attached to the $\mathrm{Y}$, with no HME in place (Control) and with 3 HME-AD devices such as Circuvent (Smiths), HumidFlo (Hudson) and Airlife (Carefusion) with and without exhaled humidity $(n=3)$. Drug was eluted from the filter and analyzed with spectrophotometry $(\mathrm{p}<0.05)$.

Drug delivery with Circuvent, Humidflo and Airlife was less than control ( $p=0.0001, p=0.012$ and $p=0.0001$, respectively) without exhaled humidity. No difference was found between HME-ADs $(\mathrm{p}=0.890)$ with exhaled humidity. Also, a greater variation between control and the 3 HME-ADs was observed without exhaled humidity. Drug delivery without exhaled humidity exceeded drug delivery obtained with exhaled humidity in all conditions tested in this study.

In this model simulating exhaled humidity, aerosol delivery distal to the bronchi was lower and more consistent with both Control and the HME-ADs. Further studies are needed to determine whether greater deposition in a dry model is an artifact of the model that does not simulate exhaled humidity

\section{P-066 IN VITRO EVALUATION OF THE AEROGEN MICROPUMP AEROSOL DELIVERY SYSTEM FOR DELIVERING ADHU5AG85A TB VACCINE TO HUMAN SUBJECTS}

\author{
Myrna Dolovich $^{1}$, Tracy Tazzeo ${ }^{2}$, Zhou Xing $^{3}$, MF Medina ${ }^{3}$, \\ Marek Smieja $^{3}$, Kathy Luinstra ${ }^{2}$, Fiona Smaiil ${ }^{3}$ \\ ${ }^{1}$ St Joseph's Healthcare, Mcmaster University \\ ${ }^{2}$ St Joseph's Healthcare \\ ${ }^{3}$ Mcmaster University
}

A human serotype 5 adenovirus-based TB vaccine (AdHu5Ag85A) developed at McMaster University and tested successfully in various animal models was evaluated to determine the possibility of delivering it as an aerosol to man.

Methods: The Aeroneb ${ }^{\circledR}$ Solo Micropump (Aerogen, Ireland) nebulizer was selected as the delivery device. The aerosol performance of the Aeroneb ${ }^{\circledR}$ Solo with the TB vaccine (V) using standard procedures was determined. Fill volume (FV), delivery time, emitted dose (ED) of vaccine aerosol available at the mouth collected on standard filters, droplet size characteristics using the NGI Cascade Impactor operated at $15 \mathrm{Lpm}$ were measured. The presence of $\mathrm{V}$ in the NGI and on filters was determined by PCR. Salbutamol sulphate (SS) served as the tracer for saline droplets containing vaccine (V) particles. The available dose of $\mathrm{V}$ at the mouth was predicted from ED measurements. Viability and potency of $\mathrm{V}$ was determined by plaque assay.

Results: A FV of $0.5 \mathrm{ml}$ was fully delivered the V in saline. The time to completely aerosolize $0.5 \mathrm{ml}$ was highly reproducible. Subjects inhaled $0.5 \mathrm{ml}$ of vaccine using tidal breathing in $\sim 2 \mathrm{~min}$. The ED of V available at the mouth was approximately $50 \%$ of what was loaded into the nebulizer. The fine particle fraction of the salbutamol aerosol with vaccine showed that $85 \%$ of the aerosol was contained in droplets $<5 \mu \mathrm{m}$ in diameter. Thus, the amount of aerosol available at the mouth and subsequently deposited in the lung was estimated at $42.5 \%$. The estimated rate of recoverable viable (infectious) AdHu5Ag85A vaccine from aerosol droplets generated by the Solo nebulizer was $17.4 \%$.

Conclusion: The particle size characteristics of the SS/V aerosol are well within the respirable range, ensuring high deposition below the larynx. 


\section{P-067 SYNTHESIS AND IN VITRO EVALUATION OF POLYETHYLENE GLYCOL-PACLITAXEL CONJUGATES FOR SUSTAINED DRUG RELEASE IN THE LUNG}

\author{
Tian Luo ${ }^{1}$, Johannes Magnusson ${ }^{2}$, Veronique Preat ${ }^{3}$ \\ Raphael Frederick ${ }^{3}$, Cameron Alexander ${ }^{2}$, \\ Cynthia Bosquillon ${ }^{2}$, Rita Vanbever ${ }^{3}$ \\ ${ }^{1}$ Louvain Drug Research Institute, Addb \\ ${ }^{2}$ School of Pharmacy, University of Nottingham \\ ${ }^{3}$ Louvain Drug Research Institute, Université \\ Catholique de Louvain
}

Pulmonary delivery of chemotherapeutic agents is considered an attractive route of administration, with the advantages of high drug concentrations locally and low side effects systemically. However, achieving a sustained release of drugs in the lung is challenging due to the fast clearance mechanisms in the lung. In this study, we synthesized two different polyethylene glycol-paclitaxel (PEG-PTX) ester conjugates with molecular weights of $6 \mathrm{kDa}$ and $20 \mathrm{kDa}$ with the aim to achieve sustained release of paclitaxel in the lung. These conjugates were characterized physicochemically and showed good stability in PBS pH 6.9 and in brochoalveolar larvage, but hydrolyzed quickly in mouse serum. The conjugates showed cytotoxicity to B16-F10 melanoma cells, CT26 cells and Calu- 3 cells but less than Taxol, which is the commercial paclitaxel formulated with Cremophor EL. The conjugates will be further investigated in vivo on B16-F10 lung metastasis mouse model to test the sustained drug release as well as the anti-tumor efficacy.

Acknowledgment: This thesis project is funded by the European Commission, Education, Audiovisual and Culture Executive Agency (EACEA), Erasmus Mundus programme, NanoFar doctorate.

\section{P-069 NOVEL INHALED LIPOSOMAL CIPROFLOXACIN FORMULATIONS FOR PERSONALIZED THERAPY}

\author{
David Cipolla ${ }^{1}$, Huiying $\mathrm{Wu}^{1}$, Hak-Kim $\mathrm{Chan}^{2}$, Igor Gonda ${ }^{1}$ \\ ${ }^{1}$ Aradigm Inc. \\ ${ }^{2}$ Faculty of Pharmacy, Sydney University
}

Introduction: Inhaled liposomal ciprofloxacin (Pulmaquin) is in development to treat lung infections. ${ }^{1,2}$ A simple method was developed to attenuate the release rate of ciprofloxacin without changing its lipid composition.

Methods: A liposomal ciprofloxacin formulation was modified by freeze-thaw to form nanocrystals inside the liposomes to create a slower releasing formulation. These liposome formulations were characterized by cryo-TEM, dynamic light scattering, in vitro release (IVR) assay, ${ }^{3}$ aerosol particle size distribution and the effect of mesh nebulization (PARI eFlow) on functionality.

Results and Discussion: The addition of sucrose or trehalose to the external buffer of the liposomal ciprofloxacin formulation stabilized the liposomes to freeze-thaw. After freeze-thaw, ciprofloxacin in the liposome vesicles formed nanocrystals which resulted in slower release profiles as measured by IVR. The shape and length of the nanocrystals and the release profiles of ciprofloxacin from the formulation could be adjusted by varying the amount of polysorbate 20. These formulations were robust to mesh nebulization, with retention of nanocrystals within the vesicles, and formed aerosols with a VMD of 3.8-3.9 $\mu \mathrm{m}$ and a GSD of 1.7 .

Conclusions: These studies describe a simple and novel method to modify the encapsulation state and release properties of an inhaled drug in a liposome formulation. The new method has the potential to personalize therapy for patients by modulating the encapsulation and release properties of a liposomal drug product to suit an individual patient's needs.

1. Serisier DJ et al. Thorax 68(9) 812-817 (2013).

2. Cipolla D et al. Ther Delivery 4(8) 1047-1072 (2013).

3. Cipolla D et al. J Pharm Sci 103(1) 314-327 (2014).

\section{P-090 PARTICLE ENGINEERING TO DELIVER MONTELUKAST PLUS HEPARIN TOGETHER TO TREAT ASTHMA}

\author{
Brijeshkumar Patel, Nilesh Gupta, Fakhrul Ahsan
}

Texas Tech University Health Sciences Center

This study seeks to develop a steroid-free inhalable combination therapy to alleviate the broad spectrum of inflammatory reactions in asthma. Montelukast, a cysteinyl-leukotriene type 1 receptor antagonist, possesses a series of secondary anti-inflammatory property at a relatively higher concentration. Low molecular weight heparin (LMWH) also exhibits anti-inflammatory effect by interfering leukocyte adhesion and migration. Thus, we hypothesize that inhalable particles containing montelukast and LMWH is a viable combination therapy for asthma. To test this hypothesis, we prepared and characterized dual drug containing microparticles, and optimized formulations were evaluated for efficacy in asthmatic rats. The infiltration of inflammatory cells in BAL fluid was quantified; the influence of the formulations on bronchoconstriction was evaluated in plethysmograph after methacholine challenge. Large porous particles (size: $10.3 \pm 0.7 \mu \mathrm{m}$ ) showed $66.8 \pm 0.4 \%$ entrapment for montelukast and $91.7 \pm 0.8 \%$ adsorption efficiency for LMWH. Dual-drug particles produced $\geq 4 \%$ reduction in the number of infiltrating cells compared with untreated asthmatic animals; dual-drug treated rats showed significantly reduced airway wall-thickness $(17.96 \pm 4.11 \mu \mathrm{m})$ compare with that observed in untreated asthmatic animals $(p<0.001)$. Untreated asthmatic animals showed a $>50 \%$ reduction in mid-tidalend-expiratory-flow $\left(\mathrm{EF}_{50}\right)$, optimized formulation reduced the $\mathrm{EF}_{50}$ to $\sim 20 \%$, indicating a significant improvement in lung functions. Thus, this study demonstrates the feasibility of a novel steroid-free dual-drug approach to enhance drug concentrations in the lungs and amplify anti-inflammatory effect in asthmatic condition.

\section{P-102 COMPARISON OF THREE MODALITIES OF CORTICOSTEROIDS ADMINISTRATION IN CHRONIC RHINOSINUSITIS}

\author{
Gregory Reychler, Colbrant Coralie, Huart Caroline, \\ Leguellec Sandrine, Laurent Vecellio, Giuseppe Liistro, \\ Rombaux Philippe
}

Cliniques Universitaires Saint-Luc

Background: Olfactory dysfunction is deemed to be a significant contributor to poor quality of life in chronic rhinosinusitis (CRS).

Objective: To compare the effectiveness of three modalities of corticosteroids administration in patients with CRS.

Methods: 30 patients with CRS were randomized in three groups depending on the route of corticosteroids administration. Corticosteroids were administrated during 16 days by oral $\left(\right.$ Medrol $^{\circledR}, 32 \mathrm{mg} / 8 \mathrm{~d}$ - $16 \mathrm{mg} / 4 \mathrm{~d}-8 \mathrm{mg} / 4 \mathrm{~d}$ ), nasal spray (Rhinocort ${ }^{\circledR}, 2 \times 2 \times 64 \mu \mathrm{g} /$ nostril) or nebulized (Pulmicort ${ }^{\circledR}, 2 \times 1 \mathrm{mg} / 4 \mathrm{~mL}$ ) (Sonic nebulizer, AOHBOX NL11SN, DTF Medical) route. Olfactory function was assessed 
using orthonasal (Sniffing stick test) (TDI) and retronasal psychophysical olfactory (odors identification) (RETRO) tests at inclusion and after the treatment.

Results: TDI and RETRO were similar between three groups at baseline. TDI improved by 5.5, 5.8 and -1.1 for sonic nebulization, oral and nasal spray groups respectively. This improvement was similar between oral and nebulized administration but significantly higher than nasal spray administration $(\mathrm{p}=0.010)$ and only clinically relevant for oral and nebulized administration. RETRO improved by 1.1, 4.2 and 0.7 for sonic nebulization, oral and nasal spray groups respectively $(\mathrm{p}=0.231)$

Conclusion: Effectiveness of nebulized and oral administration is demonstrated on orthonasal olfactory. The benefit is better than with nasal spray.

\section{P-103 INFLUENCE OF TRACHEOSTOMY ON LUNG DEPOSITION IN SPONTANEOUSLY BREATHING PATIENTS}

Pitance Laurent, Gregory Reychler, Laurent Vecellio, Leal Teresinha, Reychler Hervé, Giuseppe Liistro

Cliniques Universitaires Saint-Luc

Rationale: Nebulized drugs are frequently administrated through tracheostomy in clinical routine. So far, the amount of drug deposited to the lung in these patients remains unknown.

Objectives: To compare lung deposition of amikacin in 2 conditions: in spontaneously breathing through a tracheostomy and through the mouth.

Methods: Lung delivery was measured by amikacin urinary drug concentration in nine patients who were transitory tracheostomized for the need of a head and neck oncologic surgery. Patients performed two nebulization sessions: with and without tracheostomy using an adapted jet nebulizer (Sidestream ${ }^{\circledR}$ ).

Measurements and main results: Lung deposition was similar with the two conditions of nebulization $(6.5 \pm 2.5$ vs. $6.3 \pm 2.0 \%$ of the nominal mass of amikacin respectively for $\mathrm{MB}$ and $\mathrm{TB} ; \mathrm{p}=0.87$ ). Duration of nebulization was also comparable (19.7 \pm 1.6 vs. $20.1 \pm 1.8 \mathrm{~min}$ respectively for mouth and tracheostomy breathing; $\mathrm{p}=0.92$ ). The half-life and elimination rate constant were not different between the two settings.

Conclusions: The nebulized therapy can be administered in spontaneously breathing tracheostomized patients with a similar amount of drug deposited in the lung compared with untracheostomized spontaneously breathing patients.

\section{P-108 CATIONIC LIPOSOMES AS CARRIERS FOR LOCAL IMMUNOTHERAPY OF LUNG CANCER}

Cristina Loira Pastoriza, Caroline Herin, Rita Vanbever

Université Catholique de Louvain

Lung cancer is the leading cause of cancer-related death worldwide with more than 1.2 million of new cases per year. Local immunotherapy may be an effective approach for the treatment of lung cancer. Liposome-based vaccines have the advantage that they can be prepared with lipids endogenous to the lungs. The goal of our work was to develop liposomes containing both tumor antigens (Melan A and Gp 100) and adjuvants (CpG or Poly IC) able to target lung dendritic cells and to produce a specific immune response against cancer cells. For this purpose, different lipid compositions have been studied, in- cluding cationic lipids (DOTAP and DC-Cholesterol) which are reported to present immunostimulatory capacities.

We have obtained two liposome formulations which remain stable for at least three weeks. These formulations can successfully co-encapsulate both peptides and adjuvants. For instance, peptide loading efficiency is comprised between 50 to $80 \%$ depending on liposome composition and peptide sequence and more than $80 \%$ of adjuvant is also encapsulated. Sizes are comprised between 150 and $180 \mathrm{~nm}$ which is suitable for lung dendritic cells targeting. Moreover, a sustained release from liposomes has been observed: 20 to $40 \%$ of peptide is released during the first $30 \mathrm{~h}$.

In a next step, liposomes fate will be studied after intratracheal delivery in mice. Different techniques as confocal microscopy and HPLC-MS will be used in order to study peptide disposition within the lungs.

\section{P-111 THE INFLUENCE OF ENVIRONMENTAL FACTORS ON PRESSURIZED METERED DOSE INHALER PERFORMANCE}

\author{
James Ivey, Chelsea Morin, Farzin Shemirani, \\ Jonathan Suderman, Jordan Titosky, Susan Hoe, \\ Warren Finlay, Reinhard Vehring
}

University of Alberta, Department of Mechanical Engineering

Recent experimental work evaluating the influence of environmental factors on pressurized metered dose inhaler (pMDI) performance is presented. The effects of ambient temperature, ambient humidity, device temperature, and altitude on the in vitro lung dose of five commercial and two research pMDIs was explored. The Alberta Idealized Throat was utilized to assess the in vitro lung dose. An environmental chamber allowed experiments with variable temperature and humidity, while a mobile testing station was developed to enable the high altitude tests. It was found that increasing altitude and thus reducing ambient pressure had a negligible effect in the tested range. However, reducing ambient or device temperature or increasing ambient humidity reduced the in vitro lung dose. The magnitude of the temperature and humidity effects was found to depend on formulation and device variables, indicating that further experimental and theoretical work is required to better understand the interactions. The results of this work illustrate the challenges inherent in utilizing pMDIs outside of ideal laboratory conditions, and highlight opportunities for developing more environmentally robust pMDI therapies.

\section{P-112 MONITORING OF ADHERENCE WITH AN EFLOW NEBULIZER IN CLINICAL TRIALS FOR INHALATION THERAPIES}

Carola Fuchs, Matthias Finke, Gerhard Boerner, Stephanie Prante, Philipp Kroneberg, Stefan Seemann, Martin Knoch

\section{Pari Pharma GmbH}

A telemonitoring feature was implemented in an eFlow nebulizer system (PARI Pharma, Germany) for monitoring adherence to inhalation therapies. The system fulfils requirements for clinical trials and potentially subsequent transfer to commercial products. The eFlow device is equipped with a Bluetooth chip and automatically transfers data on each nebulization via a hub and a cloud to a server for evaluation by the physician. 
Previous versions of the monitoring device were already used in several clinical trials in chronic obstructive pulmonary disease (COPD), cystic fibrosis (CF) and lung transplant patients. Duration of the studies ranged between 4 weeks and 2 years. In all studies high adherence levels were reached. Two clinical studies over 4 weeks in CF and 8 weeks in COPD patients resulted in adherence rates of $99 \%$ and $98 \%$, respectively. Even in long-term studies covering 6-month periods in CF patients and 2-year periods in lung transplant patients, an average adherence rate of $76 \%$ was determined in each study.

The consideration of adherence in the interpretation of clinical trial results is highly valuable and enhances the assessment and statements regarding efficacy of inhalation therapies. The remote and automatic evaluation of adherence with the new generation monitoring device is more reliable and convenient than the use of data from patient diaries and potentially allows immediate intervention. The system is designed to allow a fast upscale for commercialization.

\section{P-119 BREATH TO BREATH UNIFORMITY OF AEROSOL QUALITY FROM A BREATH- ACTIVATED NEBULIZER}

\author{
Jacob Parker, Lucy Hardaker, Ross Hatley \\ Respironics Respiratory Drug Delivery (UK) Ltd, \\ Chichester Business Park
}

The Micro nebulizer (Respironics Respiratory Drug Delivery [UK] Ltd [RRDD]) is designed to nebulize low fill volumes with high efficiency. One Micro nebulizer was tested with a $300 \mu \mathrm{L}$ fill volume of salbutamol sulphate solution $(2 \mathrm{mg} / \mathrm{mL}$; IVAX Pharmaceuticals UK) using 7, 5, and 3-second simulated breaths (inhalation only) in order to determine if the aerosol quality was maintained across all breaths taken within a nebulization. Aerosol quality was measured as mass median diameter (MMD) and fine particle fraction (FPF; $\%<5 \mu \mathrm{m}$ ) using a Malvern Spraytec (Malvern Instruments Ltd); a TSI mass flow meter (TSI Instruments Ltd) was used to set a $10 \mathrm{~L} / \mathrm{min}$ extraction flow and a Whisperflow flow meter (RRDD) was used to set a $9 \mathrm{~L} / \mathrm{min}$ shroud air. The Micro nebulizer was attached to the Malvern Spraytec flow cell via a Micro to Spraytec custom connector and an inhalation delay test rig used to set the simulated breaths. Nebulization was run to completion and repeated 3 times each for the 7,5, and 3-second simulated breaths. The low standard deviations (SD; Table 1) suggest that the Micro nebulizer aerosol quality was maintained across each breath. The mean MMD and FPF were also consistent across the 3 different lengths of simulated breaths tested (Table 1).

Table 1: Mean MMD and FPF results for the 3 simulated breath lengths
\begin{tabular}{|l|c|c|c|c|}
\hline \multirow{2}{*}{ Breath length (s) } & $\begin{array}{c}\text { Mean number of } \\
\text { breaths for } \\
\text { completion of } \\
\text { nebulization }\end{array}$ & & MMD $(\mu \mathrm{m})$ & FPF (\%) \\
\hline 7 & 4 & Mean & 4.78 & 52.72 \\
\cline { 3 - 5 } & \multirow{2}{*}{6} & SD & 0.06 & 0.89 \\
\hline \multirow{2}{*}{5} & \multirow{2}{*}{10} & Mean & 4.84 & 51.90 \\
\hline \multirow{2nyyy}{*}{3} & & SD & 0.13 & 1.52 \\
\cline { 3 - 5 } & & SD & 4.82 & 52.15 \\
\hline
\end{tabular}

\section{P-130 CURCUMIN AND SILVER NANOPARTICLE HYDROGELS FOR ENDOTRACHEAL TUBE- ASSOCIATED INFECTIONS: CHARACTERIZATION AND ANTI-BIOFILM ACTIVITIES}

Judy Loo ${ }^{1}$, Wing-Hin Lee ${ }^{1}$, Paul M. Young ${ }^{1}$, Daniela Traini ${ }^{1}$, Rosalia Cavaliere $^{2}$, Cynthia B Whitchurch ${ }^{2}$, Ramin Rohanizadeh ${ }^{3}$

${ }^{1}$ Respiratory Technology, Woolcock Institute of Medical Research and the Discipline of Pharmacology, Sydney Medical School

${ }^{2}$ The Ithree Institute, University of Technology Sydney

${ }^{3}$ Advanced Drug Delivery Group, Faculty of Pharmacy, University of Sydney

Silver nanoparticles (AgNP) are effective as anti-biofilm agent for treating bacterial infections associated with the use of mechanical ventilations, such as endotracheal intubation. Curcumin, a phenolic plant extract, has displayed natural anti-biofilm properties through the inhibition of bacterial quorum sensing systems. In this study, poly(vinyl alcohol)/poly(N-vinyl pyrrolidone) (PVA-PVP) hydrogels, containing AgNPs and CurNPs, were prepared via physical cross-linking techniques (freeze-thaw) to form hydrogels with mechanical properties comparable to commercial endotracheal tubes. The morphologies of nanoparticles in PVA-PVP hydrogels were examined using transmission electron microscopy (TEM) and no significant aggregation was observed during the freeze and thawing procedures. The average diameter of nanoparticles was $30 \mathrm{~nm}$. Fourier transform infrared analysis demonstrated that both AgNPs and CurNPs interacted with the hydroxyl groups of PVA-PVP, probably due to the formation of intramolecular hydrogen bonds. The hydrogels containing combination of AgNPs and CurNPs displayed excellent bactericidal activities and simultaneously inhibited the attachment of Pseudomonas aeruginosa PAO1 and Staphlococcus aureus ATCC 25923. Our results also showed that hydrogels containing AgNPs or CurNPs were only effective against $P$. aeruginosa or $S$. aureus, respectively. These hydrogels containing combination of AgNPs and CurNPs shows promising potential and studies to coat the hydrogels on commercial tubes are ongoing.

\section{P-132 CURCUMIN IS EFFECTIVE TO CONTROL INFLAMMATION AND OXIDATIVE STRESS IN ALVEOLAR MACROPHAGE CELLS: COMPARISON AGAINST CORTICOSTEROIDS}

Wing Hin Lee, Ching-Yee Loo, Daniela Traini, Paul M. Young

Respiratory Technology, Woolcock Institute of Medical Research and the Discipline of Pharmacology, Sydney Medical School

Systemic inflammation and oxidative stress is known to be central in the pathogenesis of chronic obstructive pulmonary disease (COPD). Both oral and inhaled corticosteroids are used for the treatment COPD, but clinical success remains controversial. Therapeutic molecules with both anti-oxidant and anti-inflammatory activities could be explored as alternative to target key COPD mediators. Curcumin is a natural polyphenol compound with excellent activities against inflammation-related diseases, such as neurodegenerative diseases and lung injury. In this study, the suitability of curcumin to attenuate inflammation in lipopolysaccharides induced alveolar macrophages, in comparison to the established corticosteroids (fluticasone propionate, budesonide and beclometasone dipropionate) is presented. Curcumin exerted higher anti-inflammatory activity irrespective of doses and duration of treatment. The expressions of Interleukin- $1 \beta$, IL- 6 and tumor necrosis factor $\alpha$ were reduced by approximately $50 \%$ after treatment with $20 \mu \mathrm{M}$ curcumin. Meanwhile, budesonide only 
reduced $\sim 20 \%$ of pro-inflammatory markers expression. Curcumin also exhibited strong anti-oxidant activity, as demonstrated in DPPH and nitric oxide scavenging assays. In comparison, the corticosteroids only exhibited minor anti-oxidant activities at higher concentrations ( $>1 \mathrm{mM})$. Consequently, curcumin could be a potential compound for lung inflammation treatments in conjunction with corticosteroids and further studies on these compounds are ongoing.

\section{P-136 DISPOSABLE SPACERS FOR PRESSURISED METERED DOSE INHALERS (pMDIs)-BACK TO THE FUTURE?}

\author{
Mark Sanders, Ronald Bruin \\ Clement Clarke International Ltd.
}

Misuse of pMDIs led to the development of chamber and spacer devices, the use of which is now recommended internationally in Guidelines. Other considerations - economics, emergencies, disposal affect access and adherence, hence use of improvised devices has paralleled pMDI development. We describe a new, disposable spacer (DispozABLE Spacer ${ }^{\mathrm{TM}}$ ) that has both a secure pMDI fit and mouthpiece. We have compared salbutamol sulphate delivery (Ventolin ${ }^{\circledR}$ HFA GSK, $90 \mu$ g ex-mouthpiece) alone $(\mathrm{n}=5)$ and with the new spacer $(n=3)$. An ACI was used according to manufacturers' instructions. Data were also collected following a 1-second delay between actuation and Impactor function to mimic sub-optimal use (eg. open-mouth, misaligned device, an emergency). The mean fine particle dose ( $\mu \mathrm{g} \pm \mathrm{SD}$, particle size $<5 \mu \mathrm{m})$ from optimal use of the pMDI alone (55.1 \pm 4.55$)$ and from pMDI plus new spacer $(56.6 \pm 5.65)$ were very similar, and comparable to conventional valved spacers. When used sub-optimally, the pMDI plus new spacer performed much better $(37.7 \pm 7.65)$ than the pMDI (10.2 \pm 2.17$)$, delivering three times the dose. Although use of a conventional spacer is preferable to a homemade device (except where no alternative exists), a developed and tested, low-cost, disposable device may be a preferable, accessible substitute in the home or emergency inhaler toolkit.

\section{P-137 IMPROVING THE VALVED HOLDING CHAMBER (VHC)-PRESSURISED METERED DOSE INHALER (pMDI) COMBINATION}

\author{
Mark Sanders ${ }^{1}$, Ronald Bruin ${ }^{1}$, Cuong Tran $^{2}$ \\ ${ }^{1}$ Clement Clarke International Ltd. \\ ${ }^{2}$ I2c Pharmaceutical Services, Cardiff Medicentre
}

Many VHCs have an integral whistle (IW) to aid use. Previously we have shown that the inspiratory flow rate (IFR) at which the IW sounds the alert varies with pMDI resistance, and that the FloTone $2^{\mathrm{TM}}$ whistle used with the VHC A2A Spacer ${ }^{\circledR}$, external and downstream the VHC valve, is independent of this effect. Using Ventolin ${ }^{\circledR}$ HFA (GSK), we have now (study A) compared pMDI alone, pMDI + A2A, and pMDI + A2A + Flo-Tone2 (DUSA; $\mathrm{n}=5)$ and (study B) assessed pMDI+ A2A + Flo-Tone2 at 20, 25, 40, 54, and $70 \mathrm{~L} / \mathrm{min}$ IFRs (NGI; $\mathrm{n}=3$ ), determining (A) the effect of Flo-Tone2 on drug delivery and (B) characterizing the Flo-Tone2 whistle-sound IFR, with Induction Port-to-stage 2 (large), stage 3-to-5 (useful), and stage 6-to-MOC (small) particle size data adjusted for aerodynamic cut-off diameter and graphed against IFR. There were no differences (A) within metered dose, actuator or A2A drug mass recovery (FloTone2 minimal: $3.64 \mu \mathrm{g}$ ). The dynamic picture of drug recovery with increasing IFR (B) enabled the identification of two whistle IFRs.
DUSA and NGI data were comparable, particularly for the recovery of useful particles. The next steps in our research are to determine if a two-signal system can operate reliably across pMDIs of varying resistance when combined with a VHC and, if possible, to extend data collection beyond $70 \mathrm{~L} / \mathrm{min}$.

\section{P-144 ASSESSING THE BREATHING CAPABILITY OF PATIENTS THROUGH INHALERS}

\author{
Gerhard Pohlmann, Jens Hohlfeld, Jelena Pankalla
}

Fraunhofer Item, Medical Inhalation Technology

Drug delivery to the lungs is often facilitated by portable devices such as dry powder and metered dose inhalers. These have in common a certain resistance to flow. Resistances are different, depending on purpose. As a result, a minimum flow exists that has to be exceeded to achieve a sufficient drug release. The resistances have to be matched to the breathing capability of the patients. In a doctor's office, normally no information about resistances and a patient's breathing capability is available. Having a single parameter to estimate the breathing capability would help to choose the most appropriate device.

Method: Flow-pressure data of breathing maneuvers through defined flow resistors from literature and own measurements with different volunteers have been analyzed so as to identify a common factor to describe the breathing capability of the volunteers independent of the flow resistor used.

Results: Analysis of breathing curves shows that the excess energy (excess work of breathing) used per inhalation maneuver could be a possible candidate for a unique parameter describing the breathing capability of a patient. Using, e.g., the data from De Boer (International Journal of Pharmaceutics 130 (1996):231-244) and calculating the excess breathing energy for these curves results in the values below.

Discussion: With a defined flow resistor the excess work of breathing can be easily determined. Using state-of-the-art microelectronics, a system for such measurements can be reduced to a handheld device. Knowing also the minimum excess work of breathing for successfully operating the inhaler one can easily assess its suitability.

\begin{tabular}{|l|r|r|}
\hline & \multicolumn{2}{|c|}{ Excess energy (J) } \\
\hline $\begin{array}{c}\text { Resistance } \\
\text { mbar^ } \mathbf{0 . 5} /(\mathbf{I} / \mathrm{min})\end{array}$ & $\mathbf{0 . 0 4}$ & $\mathbf{0 . 1 3}$ \\
\hline Healthy & 16.1 & 20.7 \\
Asthmatics & 12.4 & 12.2 \\
COPD & 6.8 & 8.1 \\
\hline
\end{tabular}

\section{P-145 EFFECTS OF EMULSION COMPOSITION ON PULMONARY TOBRAMYCIN DELIVERY DURING ANTIBACTERIAL PERFLUOROCARBON VENTILATION

\author{
Ryan Orizondo ${ }^{1}$, Mario Fabiilli ${ }^{1}$, Marissa Morales $^{2}$, Keith Cook $^{2}$ \\ ${ }^{1}$ University of Michigan \\ ${ }^{2}$ Carnegie Mellon University
}

The effectiveness of inhaled aerosolized antibiotics in the setting of lung disease is limited by proximal airway impaction and poor ventilation of infected airways. Antibacterial perfluorocarbon ventilation (APV) has potential to remedy this by delivering the antibiotics via 
perfluorocarbon emulsions. The purpose of this study was to investigate the effects of emulsion composition on the pharmacokinetics (PK) of antibiotic delivery via APV as well as the uniform dispersion of antibiotic within the emulsion. Serum and pulmonary tobramycin concentrations in rats were evaluated following antibiotic delivery via aerosol or APV utilizing emulsions of varying aqueous volume percentage $\left(\mathrm{V}_{\mathrm{aq}}\right)$, aqueous tobramycin concentration $\left(\mathrm{C}_{\text {tobra/aq }}\right)$, and fluorosurfactant concentration $\left(\mathrm{C}_{\mathrm{fs}}\right)$. To help understand $\mathrm{PK}$ results, emulsion stability was evaluated by measuring tobramycin concentrations at varying heights within an emulsion column for varying $\mathrm{C}_{\mathrm{fs}}$. Results showed that APV resulted in 5 to 22 times greater pulmonary tobramycin concentrations at four hours post-delivery relative to aerosolized delivery. Pulmonary concentrations increased with increasing $\mathrm{V}_{\mathrm{aq}}$ and, to a lesser extent, $\mathrm{C}_{\mathrm{fs}}$. In vitro assessment showed spatial and temporal uniformity of tobramycin dispersion within the emulsion for both values of $\mathrm{C}_{\mathrm{fs}}$ examined. Thus the optimal emulsion composition should increase $\mathrm{V}_{\mathrm{aq}}$ to the greatest degree possible and may significantly decrease $\mathrm{C}_{\mathrm{fs}}$ relative to previous studies if necessary.

\section{P-157 CASE REPORT: PROLONGED THERAPY OF PULMONARY FIBROSIS WITH INHALED INTERFERON-GAMMA}

\author{
Timothy Fusiak ${ }^{1}$, Gerald Smaldone ${ }^{1}$, Rany Condos $^{2}$ \\ ${ }^{1}$ State University of New York - Stony Brook \\ ${ }^{2}$ New York University School of Medicine
}

Most forms of pulmonary fibrosis (idiopathic or secondary to systemic disease) are fatal in a few years. We have tested inhaled interferon, a potent inhibitor of TGF- $\beta$, in small human trials with encouraging results (J Aerosol Med Pulm Drug Deliv. 25(2): 79-87). Here we describe a patient receiving inhaled IFN $-\gamma$ for 7 years.

Patient PK, (66 year old male) with biopsy proven Usual Interstitial Pneumonia (UIP) was initially diagnosed with IPF and entered in our published trial ( $100 \mu \mathrm{g}$ inhaled 3 times per week for a planned 80 weeks). Raynaud's phenomenon was reported at initial presentation, which improved dramatically with sildenafil. Following the study he was able to obtain the drug and continued therapy for a total of 7 years. Lung dose was determined by gamma camera imaging $(67-91.8 \mu \mathrm{g})$. He felt better on therapy, returning to work. His only complaint was transient cough during inhalation. Pulmonary function tests (PFTs), particularly the diffusion capacity (DLCO) dropped before treatment ( $75 \%$ to $58 \%$ at baseline, increasing to $81 \%$ after 2 years and $69 \%$ currently). Clinical monitoring showed preserved exercise tolerance and stable CT scans. He was ultimately diagnosed with scleroderma-like connective tissue disease after he developed sclerodactyly and a positive antinuclear antibody (2012) and started on hydroxychloroquine.

Inhaled IFN $-\gamma$ was well tolerated for 7 years and may stabilize pulmonary fibrosis related to poorly defined systemic connective tissue disease.

\section{P-159 MEASUREMENT OF PARTICLE SIZE PENETRATING INTO THE MAXILLARY SINUSES OF A NASAL CAST MODEL}

Deborah Le Pennec ${ }^{1}$, Sandrine Le Guellec ${ }^{2}$, Laurent Vecellio ${ }^{2}$

\author{
${ }^{1}$ Université François Rabelais, Cepr, Umr Inserm 1100 \\ ${ }^{2}$ Université François Rabelais, Cepr, Umr Inserm 1100, \\ Aerodrug, Dtf-Medical, Faculté de Médecine
}

Aerosol delivery into maxillary sinuses is challenging to treat chronic rhinosinusitis. Particle size is one of the key factor for predicting the aerosol deposition into the nasal cavity. The aim of this study was to measure the particle size penetrating into the maxillary sinuses for determining the optimal particle size.

A nasal cast model was made from an adult sinus CT scan. A cascade impactor aspirating at a flow rate of $1.2 \mathrm{~L} / \mathrm{min}$ was connected to the external surface of maxillary sinus. An air flow rate of $1.2 \mathrm{~L} / \mathrm{min}$ was administrated to the external surface of the same sinus to avoid the influence of air aspiration by cascade impaction measurement on aerosol penetration into maxillary sinus.

Aerosol was delivered by nebulization with a nasal plug trough the nostrils. Two kinds of nebulizers generating two different particles size were tested $(\mathrm{VMD}=5 \mu \mathrm{m}$ and $10 \mu \mathrm{m})$. Aerosol was delivered with or without the addition of a $100 \mathrm{~Hz}$-sound (acoustic airflow). Two kinds of ventilation were tested: the first simulated a nasal inhalation and mouth expiration ( 15 breaths $/ \mathrm{min} \mathrm{I} / \mathrm{E}=40 / 60$ $\mathrm{TV}=500 \mathrm{~mL}$ ) and the second, the mouth inhalation and expiration (no nasal inhalation except the air flow rate from the nebulizer). A sodium fluoride solution was loaded in the nebulizer and the aerosol was delivered during $10 \mathrm{~min}$.

The aerosol penetrating into the maxillary sinuses had a MMAD of $2 \mu \mathrm{m} \pm 0.2 \mu \mathrm{m}$ for all conditions of nebulization. The addition of sound improved the aerosol mass collected by the cascade impactor.

As conclusion, the particle size penetrating into the maxillary sinuses of the nasal cast model had a $2 \mu \mathrm{m}$ of MMAD. This particle size was not influenced by the ventilation, the addition of the $100 \mathrm{~Hz}$ sound, or the initial particle size produced by the tested nebulizers.

\section{P-160 INHALED NEWS DRUGS AND BIODRUGS: PERFORMANCE OF A NEW VIBRATING MESH NEBULIZER}

\author{
Denis Marchand ${ }^{1}$, Maria Cabrera ${ }^{2}$, Mathieu Pinel ${ }^{3}$, \\ Laurent Vecellio ${ }^{4}$ \\ ${ }^{1}$ Aerodrug \\ ${ }^{2}$ Université François Rabelais, Cepr, Umr Inserm 1100 \\ ${ }^{3}$ Dtf-Medical \\ ${ }^{4}$ Aerodrug, Dtf-Medical
}

Biodrugs are used in a wide range of applications and are currently the fastest growing drug category. They are approved as new drugs, for their use in several conditions like cancer, inflammatory and autoimmune diseases. The majority are administered by the intravenous route, one of the possible reasons for the limited efficacy of this therapeutics. Therefore biodrugs delivery directly to the lung via inhalation may hold several advantages of local-acting. The aim of this study was to measure the in vitro performances of a new DTF mesh nebulizer prototype designed for new drugs.

The DTF mesh nebuliser (DTF-VM) and two commercial devices, Omron Microair and Aeroneb GO, were used to nebulize Pulmozyme. The inhalable fraction (IF) was determined by a filtering method using either a respiratory pump or person during ex-vivo assay. The particle size distribution of mesh nebulizers was measured using laser diffraction. The respirable fraction (RF) was calculated as the percentage of aerosol particles smaller than $5.0 \mu \mathrm{m}$ predicting the particle penetration in the lungs.

The IF was $86 \% \pm 2 \%, 28 \% \pm 9 \%, 32 \% \pm 1 \%$ and the RF was $90 \% \pm 4 \%, 42 \% \pm 3.0 \%, 63 \% \pm 7 \%$ and respectively for the DTF-VM, Microair and Aeroneb GO. The IF for DTF-VM in ex vivo conditions was $71 \% \pm 7 \%$. 
Based on in vitro and ex vivo results, the DTF-VM nebulizer could be used as an aerosol generator to achieve high lung deposition for new drugs and making it suitable for expensive biodrugs in development.

\section{P-173 CHARACTERIZATION OF A COMMERCIAL NASAL POWDER DRUG DELIVERY DEVICE}

\author{
Michele Pozzoli ${ }^{1}$, Fabio Sonvico ${ }^{2}$, Bing Zhu ${ }^{3}$, Philippe Rogueda ${ }^{4}$, \\ Daniela Traini ${ }^{5}$, Paul Young ${ }^{5}$ \\ ${ }^{1}$ Graduate School of Health, University of Technology, Sydney \\ ${ }^{2}$ Department of Pharmacy, University of Parma, Italy; Graduate \\ School of Health - Pharmacy, University of Technology Sydney \\ ${ }^{3}$ Respiratory Technology, Woolcock Institute of Medical Research \\ ${ }^{4}$ Aedestra Ltd \\ ${ }^{5}$ Respiratory Technology, Woolcock Institute of Medical Research \\ and Discipline of Pharmacology, Sydney Medical School, \\ Sydney University
}

Recently, interest in the development of dry powder nasal formulation has increased due to the ability to formulate insoluble compounds and increased physical-chemical stability compared to liquid based sprays. Only two nasal dry powder inhalers are present on the market: Rhinocort Turbohaler commercialized by AstraZeneca Canada and Rhinicort Pulverizer by Teijin Japan. Both are used for the rhinitis treatment but with different active Ingredients, budesonide for the Canadian market and beclomethasone dipropionate (BDP) for the Japanese one. The Pulverizer is the only device capsule based. It is composed of two parts: a squeezable plastic ball that generates the airflow, and a stem in which a capsule is placed. The device is actuated by squeezing the rubber ball. Our interest in this work was the characterization of the nasal powder formulation. Laser diffraction measured the powder particle size distribution, the relative location of the formulation components was determined with a Raman spectroscopy microscope and DVS was used to investigate the powder behavior to different relative humidity levels. From Raman microscopy imaging, it is evident the powder results in a blend where the hydroxypropyl-cellulose represents the majority component and the BDP particles are clustered in areas around the diluent. These explain the ability of the powder to adsorb $20 \% \mathrm{w} / \mathrm{w}$ when exposed to $90 \%$ humidity. The Dv50 was $98.0 \pm 1.3 \mu \mathrm{m}$ and more than $99 \%$ of the powder had size larger than $10 \mu \mathrm{m}$.

\section{P-179 IMPACT OF SIZE AND SURFACE MORPHOLOGY OF MANNITOL CARRIER PARTICLES ON THE FPF OF DPI FORMULATIONS}

\author{
Mathias Mönckedieck ${ }^{1}$, Jens Kamplade ${ }^{2}$, Phanuel Fakner ${ }^{2}$, \\ Regina Scherlie $\beta^{1}$, Peter Walzel ${ }^{2}$, Hartwig Steckel ${ }^{3}$ \\ ${ }^{1}$ Kiel University, Department of Pharmaceutics \\ and Biopharmaceutics \\ ${ }^{2}$ Tu Dortmund \\ ${ }^{3}$ Eastpharma Ltd
}

The combination of coarse carrier $(>50 \mu \mathrm{m})$ with small APIs $(<5 \mu \mathrm{m})$ is a well-known approach to overcome dosing problems of a small cohesive active in a dry powder inhaler. Good flowability of these blends is crucial for comparting the doses accurately. Shear forces trigger the detachment of the drug during inhalation.
In this study mannitol carrier of different size and surface morphology were prepared by spray drying at different conditions according to a design of experiments (DoE). Particle size, surface morphology and BET surface area were determined. A selection of mannitol batches was blended with salbutamol sulfate as model active to perform impaction analyses with a Novolizer ${ }^{\circledR}$. Fine particle fractions (FPFs) were then related to BET surface areas as a measure of size and morphology. FPF appeared to be lower for higher surface areas. Evaluation of the DoE revealed morphology to have the main effect on FPFs, while the effect of size was not significant. This was further confirmed by scanning electron microscopy pictures, which exhibit deep indentions filled with drug particles. At present, interactions between mannitol carrier and further actives are under investigation.

\section{P-185 A NOVEL UNIVERSAL ALLERGEN CHALLENGE TECHNIQUE FOR EFFICACY TESTING OF IMMUNOTHERAPY}

Katharina Schwarz ${ }^{1}$, Katrin Lueer ${ }^{1}$, Heike Biller ${ }^{1}$, Horst Windt ${ }^{1}$, Philipp Badorrek ${ }^{1}$, Dietrich Häfner ${ }^{2}$, Armin $\mathrm{Koch}^{3}$, Norbert Krug ${ }^{4}$, Wolfgang Koch ${ }^{1}$, Jens Hohlfeld ${ }^{4}$

${ }^{1}$ Fraunhofer Institute for Toxicology and Experimental Medicine ${ }^{2}$ Allergopharma $\mathrm{GmbH} \& \mathrm{Co} . \mathrm{Kg}$

${ }^{3}$ Hannover Medical School

${ }^{4}$ Fraunhofer Institute for Toxicology and Experimental Medicine, Biomedical Research in Endstage and Obstructive Lung Disease, Hannover (Breath), Member of the German Center for Lung Research

Standardized airborne allergen challenge is a valuable tool for drug testing. Regarding increasing importance of specific immunotherapy, atmospheres for various types of allergens have to be provided.

Therefore a universal allergen challenge method, simulating natural exposure, was developed.

The challenge aerosol is generated by spray-drying of an aqueous isotonic solution of lactose (e.g., $10 \mathrm{wt}-\%$ ) and the desired allergen extract in the turbulently mixed Fraunhofer Environmental Challenge Chamber (ECC). The dry lactose particles serve as universal carrier of adjustable size for targeted deposition in various regions of the respiratory tract.

Spray generation is realized via a syringe pump and an ultrasonic capillary wave atomizer, generating droplets of $30 \mu$ m quickly evaporating. The particle size is determined by initial droplet size and lactose/sodium chloride content, while influence of the small allergen content is negligible. Creating sizes preferentially depositing in the nose $(>10 \mu \mathrm{m})$ or in the lungs $(5-10 \mu \mathrm{m})$, challenge atmospheres for a large variety of indications can be realized. The concentration of the airborne allergen is adjusted by the feed rate of the syringe pump. In a pilot study with house dust mite allergen, efficacy and safety of this challenge method were proven.

In conclusion, providing the basis for future clinical studies with a large variety of allergens, this novel universal allergen challenge method might improve immunotherapy drug development.

\section{P-188 IN VITRO EVALUATION OF A NEW SPACER WITH RESPIMAT ${ }^{\circledR}$ IN MECHANICAL VENTILATION}

\author{
Nabile Boukhettala ${ }^{1}$, Thierry Porée ${ }^{1}$, Patrice Diot ${ }^{2}$, \\ Laurent Vecellio ${ }^{2}$ \\ ${ }^{1}$ Laboratoire Protec'som \\ ${ }^{2}$ Centre D'etude des Pathologies Respiratoires Inserm U1100
}


The purpose of this study was to evaluate the mass and the particle size of tiotropium delivered by Respimat ${ }^{\circledR}$ using a spacer named Combihaler in a model of adult mechanical ventilation.

According to the European Pharmacopoeia, particle size delivered by Respimat ${ }^{\circledR}$ was measured using a cascade impactor NGI (Next Generation Impactor, MSP, USA) at $30 \mathrm{~L} / \mathrm{min}$. To evaluate the drug delivery by Combihaler spacer in mechanical ventilation, the experimental set up assembly includes a respirator (Volume controlled, $\mathrm{Vc}=450 \mathrm{~mL}, \mathrm{f}=15 / \mathrm{min}, \mathrm{PEEP}=6, \mathrm{P} \max =19$, Ti $/ \mathrm{Ttot}=40 / 60)$ and a model of adult lung Dual TTL 5600i (Michigan Instruments). A $7.5 \mathrm{~mm}$ endotracheal tube and a right-angle elbow adapter were used. An absolute filter (Gelman, Ann Arbor, Michigan, USA) was placed between the extremity of the endotracheal tube and the lung model to filter the aerosol delivery to the lung model. The influence of the time of delivery has been studied: actuation at the beginning of the inspiratory phase and actuation at the beginning of the expiratory phase. Inhalable tiotropium deposited on filter was measured by spectrophotometry.

Based on the cascade impactor measurement, the MMAD is $1.4 \mu \mathrm{m} \pm 0.02$ with the Combihaler and $1.6 \mu \mathrm{m} \pm 0.03$ without the Combihaler. The fine particle mass is $1.42 \pm 0.20 \mu \mathrm{g}$ with the Combihaler and $1.41 \mu \mathrm{g} \pm 0.18 \mu \mathrm{g}$ without the combihaler.

Based on the mechanical ventilation experiments, the inhalable mass of tiotropium is $1.08 \pm 0.03 \mu \mathrm{g}$ during the inspiratory phase and $0.92 \pm 0.05 \mu \mathrm{g}$ during the expiratory phase.

In conclusion, the Combihaler spacer allows the aerosol administration by the Respimat device in mechanical ventilation conditions. A small difference was obtained between the actuation during the inspiratory phase and the expiratory phase.

\section{P-189 OBJECTIVE MEASUREMENT OF PEAK INSPIRATORY FLOW RATE (PIFR) IN THE DISKUS, TURBUHALER AND EVOHALER USING NON-CONTACT ACOUSTIC METHODS}

\author{
Martin Holmes ${ }^{1}$, Terence Taylor ${ }^{1}$, Richard Costello ${ }^{2}$, \\ Richard Reilly ${ }^{1}$ \\ ${ }^{1}$ Trinity Centre for Bioengineering, Trinity Biomedical Sciences \\ Institute, Trinity College Dublin \\ ${ }^{2}$ Department of Medicine Respiratory Research Division, The Royal \\ College of Surgeons in Ireland
}

Airway drug deposition is dependent on inhaler users peak inspiratory flow rate (PIFR), however, inhaler users do not always inhale with sufficient PIFR to extract the drug. There is therefore a need for an objective method that can monitor inspiratory inhaler technique, specifically PIFR, on a use-to-use basis. The aim of this study was to develop an acoustic method to quantify inhaler PIFR in three inhalers; Diskus $^{\mathrm{TM}}$, Turbuhaler ${ }^{\mathrm{TM}}$ and Evohaler ${ }^{\mathrm{TM}}$.

Three airtight containers, connected to a spirometer, were assembled to hold the Diskus ${ }^{\mathrm{TM}}$, Turbuhaler ${ }^{\mathrm{TM}}$ and Evohaler ${ }^{\mathrm{TM}}$ inhalers and obtain PIFR measurements. A non-contact microphone was positioned $5 \mathrm{~cm}$ from each inhaler mouthpiece to record acoustics associated with inhaler inhalations. Eleven healthy adult males inhaled through each inhaler at specific PIFRs. Six time and frequency based acoustic features were derived from the audio signals and compared to spirometer based PIFR using generalised least squares linear regression models. The acoustic features used were mean power, root mean square and mean absolute deviation of the amplitude, and the frequencies below which $25 \%$ (F25), 50\% (F50), 75\% (F75) of the spectral power lie.

Results indicate that all six acoustic features were significantly correlated with PIFR $(\mathrm{p}<0.05)$. Mean acoustic power had the greatest correlation with PIFR; Diskus ${ }^{\mathrm{TM}} \mathrm{R}^{2}=0.95$, Turbuhaler ${ }^{\mathrm{TM}} \mathrm{R}^{2}=0.92$,
Evohaler ${ }^{\mathrm{TM}} \mathrm{R}^{2}=0.85$. Results indicate that acoustics may be employed as an objective method to estimate PIFR.

\section{P-194 ACOUSTIC FEATURES OF INHALER INHALATION SOUNDS ARE REPEATABLE ACROSS A RANGE OF PEAK INSPIRATORY FLOW RATES: AN OPPORTUNITY TO MONITOR RESPIRATORY HEALTH LONGITUDINALLY}

\author{
Terence Taylor ${ }^{1}$, Martin Holmes ${ }^{1}$, Richard Costello ${ }^{2}$, \\ Richard Reilly ${ }^{1}$
}

\section{${ }^{1}$ Trinity Centre for Bioengineering, Trinity Biomedical Sciences Institute, Trinity College Dublin \\ ${ }^{2}$ The Department of Medicine Respiratory Research Division, The Royal College of Surgeons in Ireland}

There is a lack of objective methods to monitor respiratory health longitudinally. Acoustic features of healthy breath sounds obtained from the chest wall and trachea have been reported to be repeatable. However, little is known regarding inhaler breath sounds. The aim of this study was to determine if acoustic analysis of inhaler inspiratory sounds may be employed to present physiological information regarding respiratory health.

Three inhalers (Diskus ${ }^{\mathrm{TM}}$, Turbuhaler ${ }^{\mathrm{TM}}$ and Evohaler ${ }^{\mathrm{TM}}$ ) were positioned in separate airtight containers, each connected to a spirometer to record peak inspiratory flow rate (PIFR) measurements. A high quality microphone was positioned $5 \mathrm{~cm}$ from the inhaler mouthpiece to record inhaler inhalation acoustic signals. Eleven healthy adult males inhaled through the inhalers at specific PIFRs. The frequency spectrum of each inhalation sound was estimated and Pearson's linear correlation coefficient was employed to determine the repeatability of the spectral envelope of inhalation sounds across specific PIFRs.

The spectral envelope of inhaler inhalation acoustic signals was significantly correlated across all PIFRs $(\mathrm{p}<0.05)$. There existed a number of common peak formant frequencies in acoustic signals from each inhaler. This study provides evidence to suggest that inhaler inspiratory sounds contain physiological information and may be employed to monitor respiratory health.

\section{P-198 IN-VITRO STUDY OF AEROSOLISED COLISTIN DELIVERED TO THE NASAL TRACT VIA A PULSATING AEROSOL DELIVERY DEVICE (VIBRENT ${ }^{\circledR}$ )}

Uwe Schuschnig, Seidler Andrea, Seeman Stefan, Knoch Martin

\section{Pari Pharma GmbH}

Rationale: Successful aerosol delivery to the sinus cavities of healthy volunteers and chronic sinusitis patients has been demonstrated in previous deposition studies using a Vibrent (PARI) prototype. For subsequent studies the prototypes were re-designed to comply with the latest $\mathrm{CE}$ requirements. This in-vitro study was conducted to estimate colistin amounts delivered to the nose and the sinuses.

Methods: A nasal cast model equipped with two cavities (sinuses), each in frontal, maxillary and sphenoid position was used. 1 MIU ColiFin ( $80 \mathrm{mg}$ colistimethate sodium), reconstituted with $1 \mathrm{ml}$ saline, was filled into the nebulizer and alternatingly administered for 40 seconds into one nostril of the model while the contralateral nostril was equipped with a filter until end of aerosol production. Then the nasal cast model was dismantled and drug extracted by solvent from the sinus cavities, the nasal cavity, as well as from the nebuliser and the filter. Colistin content of these solutions was assayed by HPLC. Aerosol droplet size was assessed by laser diffraction. 
Results: Aerosolised colistin has a smaller droplet size than saline (MMD 3.5 vs. $4.1 \mu \mathrm{m}, \mathrm{p}<0.01$ ). After a nebulisation time of $4.5 \mathrm{~min}$, $10 \%$ of the Colistin dose loaded into the nebulizer was found in all six sinus cavities. Deposition in the single sinus cavities ranged from $0.3 \%$ to $3.3 \%$ depending on sinus volume $(5-20 \mathrm{ml})$ and ostium diameter $(1-6 \mathrm{~mm}) .19 \%$ of the initial drug charge remained in the nebulizer while $37 \%$ were found in the nasal cavity and $33 \%$ were found on the filter.

Conclusions: 1MIU ColiFin can be dissolved in $1 \mathrm{ml}$ saline and delivered to the upper respiratory tract with the PARI Vibrent in less than 5 minutes.

\section{P-203 APPLICATION OF BUDESONIDE USING CONTROLLED INHALATION COMPARED TO CONVENTIONAL NEBULISER TECHNOLOGY IS MORE EFFICIENT TO REDUCE SYSTEMIC STEROIDS IN SEVERE ASTHMA}

\author{
Sebastian Canisius ${ }^{1}$, Gerhard Scheuch ${ }^{1}$, \\ Karlheinz Nocker ${ }^{1}$, Thomas Hofmann ${ }^{2}$ \\ ${ }^{1}$ Vectura GmbH \\ ${ }^{2}$ Aumapharma LLC
}

In a Phase $2 \mathrm{~b}$ randomized, parallel-group, placebo-controlled trial, the oral corticosteroid (OCS)-sparing efficacy, safety and tolerability of nebulized budesonide (Bud) administered with a computercontrolled, compressor-driven inhalation system (AKITA) was investigated, given as add-on therapy to GINA (Global Initiative for Asthma) Step 5 treatment regimen.

Patients $(\mathrm{n}=199)$ with OCS-dependent asthma were randomized (2:1:1:1) to 18 -weeks, twice daily, blinded treatment with AICS (AKITA inhaled corticosteroid)-Bud $1 \mathrm{mg}$, AICS-Bud $0.5 \mathrm{mg}$, AICSplacebo, or open-label Bud $1 \mathrm{mg}$ via conventional nebulizer (CN-Bud).

From 199 randomized patients, more patients treated with AICSBud $1 \mathrm{mg}(80.0 \%)$ than with AICS-placebo $(62.5 \%)$ were able to reduce daily OCS dose by at least $50 \%$ and remain clinically stable until week $18(\mathrm{p}=0.04)$. The forced expiratory volume in 1 second $\left(\mathrm{FEV}_{1}\right)$ improved compared to week 18 for AICS-Bud $1 \mathrm{mg}$ $(+239 \pm 460 \mathrm{~mL} ; \mathrm{p}<0.001)$ and AICS-Bud $0.5 \mathrm{mg}(+126 \pm 345 \mathrm{~mL}$; $\mathrm{p}=0.01)$ but not for placebo $(93 \pm 419 \mathrm{~mL} ; \mathrm{p}=0.36)$ or $\mathrm{CN}-\mathrm{Bud}$ $(137 \pm 459 \mathrm{~mL} ; \mathrm{p}=0.18)$. Patients treated with AICS-Bud $1 \mathrm{mg}$ experienced less frequent asthma exacerbations (7.5\%) compared with placebo $(17.5 \%)$ or $\mathrm{CN}-\mathrm{Bud}(22.5 \%)$. All treatments were well tolerated.

Bud applied with AKITA allowed significant meaningful OCS reduction in OCS dependent asthma patients while improving pulmonary function and maintaining exacerbation control.

\section{P-208 PRODUCTION OF RESPIRABLE NANOSTRUCTURED POWDER PARTICLES}

\author{
Katarzyna Jabłczyńska, Tomasz Sosnowski
}

\section{Warsaw University of Technology, Faculty of Chemical} and Process Engineering

Background: Biodegradable polymer nanoparticles are good candidates for carriers in targeted and controlled drug delivery. However, due to poor aerosolization, nanopowders themselves cannot form the effective formulations for inhalations accomplished with DPIs Therefore, it is desirable to prepare micrometer-sized nanostructured powders which could be easily dispersed to achieve high lung deposition on inhalation.

Methods: Polymeric nanoparticles $(150 \pm 30 \mathrm{~nm})$ of polyaldehyde dextran and dialdehyde carboxymethylcellulose were synthesized by water-based methods. Aqueous nanosuspensions were used as precursors in production of powders by spray-drying. Dry particles were characterized by SEM and their size distribution after aerosolization in the DPI was determined by laser diffraction. In addition, trials on the restoration of the functional nanostructures by powder rehydration were undertaken.

Results: Obtained powders had grain size of $0.5-5 \mu \mathrm{m}$ and they differed in surface morphology depending on drying conditions. Aerosol particle median size was $1-2 \mu \mathrm{m}$ and the FPF was always above $80 \%$. Re-hydrated powders reconstituted the nanostructures with the original particle size.

Conclusions: Nanosuspensions of the selected biodegrable polymers can be spray-dried to obtain respirable powders characterized by a very good aerosolization properties, so they may be regarded as potential carriers of nanodrugs in pulmonary drug delivery.

Acknowledgment: Work supported by NCN grant 2014/13/B/ST8/ 00808 .

\section{P-211 COMPARISON OF AEROSOL PERFORMANCE OF DIFFERENT COMPRESSOR JET NEBULISER COMBINATIONS}

Erman Lu, Uwe Schuschnig, Emir Jelovac

Pari GmbH

Introduction: Design differences among jet nebulisers and compressors determine aerosol performance, such as Total Output Rate (TOR), Mass Median Diameter (MMD) and Respirable Fraction ( $\bar{R} F)$. Three commercially availbable combinations were investigated to obtain information on their performance compared to the PARI combination.

Methods: Droplet size distributions were measured by laser diffraction (Mie model) upon nebulization of $5 \mathrm{ml}$ isotonic saline at an inspiratory flow rate of $20 \mathrm{l} / \mathrm{min}$ for 5 minutes. The inspiratory air was conditioned to $50 \% \mathrm{RH}$ and $23^{\circ} \mathrm{C}$. TOR was calculated by dividing the weight loss of the nebulizer after the measurement by the nebulization time. Respirable Output Rate (RR) was calculated from TOR x RF (\% droplets $<5 \mu \mathrm{m})$. Data were analysed with Statgraphics Centurion software.

Results:

Conclusion: While there are no huge differences with respect to aerosol droplet size, the PARI BOY SX LC SPRINT yielded the highest output rate and delivers aerosol up to two fold faster than other devices.

The PARI device, being the gold standard in jet nebulization, is still unsurpassed.

\begin{tabular}{|l|l|l|l|}
\hline Device & MMD $\pm S D[\mu \mathrm{m}]$ & TOR \pm SD $[\mathrm{mg} / \mathrm{min}]$ & $R R \pm S D[\mathrm{mg}<5 \mu \mathrm{m} / \mathrm{min}]$ \\
\hline PARI BOY SX LC SPRINT & $3.62 \pm 0.16$ & $590 \pm 39$ & $348 \pm 12.6$ \\
\hline OMRON NE-C28P V.V.T. Kit & $3.97 \pm 0.12$ & $271 \pm 16.1$ & $183 \pm 13.5$ \\
\hline $\begin{array}{l}\text { Philips InnoSpire Elegance } \\
\text { SideStream }\end{array}$ & $3.62 \pm 0.09$ & $281 \pm 5.4$ & $209 \pm 0.3$ \\
\hline Trudell Ombra AeroEclipse & $3.63 \pm 0.02$ & $390 \pm 3.6$ & $283 \pm 2.7$ \\
\hline
\end{tabular}




\section{P-213 IMPROVING THE STATIC BURDEN OF PLASTIC VALVED HOLDING CHAMBERS (VHCs) - FROM RESEARCH TO MANUFACTURING}

\author{
Mark Sanders ${ }^{1}$, Ronald Bruin ${ }^{1}$, Cuong Tran $^{2}$, Simon Warren ${ }^{2}$ \\ ${ }^{I}$ Clement Clarke International Ltd. \\ ${ }^{2}$ I2c Pharmaceutical Services, Cardiff Medicentre
}

Valved holding chambers (VHCs) are one of the few patient respiratory devices that are in both daily and emergency use. Ideally VHCs should function optimally 'straight-from-the-bag' but consensus advice is to wash and air-dry new plastic VHCs before first use to minimise any effect of static on drug delivery. We have assessed the impact of static on a unused plastic-bodied VHC, A2A Spacer $^{\circledR}$, by comparing, under standard test conditions, NGI ${ }^{\mathrm{TM}}$ deposition of salbutamol (Ventolin ${ }^{\circledR}$ Evohaler ${ }^{\circledR}$ pMDI, GSK) following three methods of VHC preparation $(n=5$ replicates of each): 1 . Instructions for Use cleaned (IfU, baseline), 2. ex-supplier bag and unwashed, and 3. wiped with an anti-static (AS) cloth and ASbagged, during manufacture. Salbutamol respirable dose (RD) was calculated from the sum of NGI stages 3-5 $(30 \mathrm{~L} / \mathrm{min}$ effective cutoff diameter range: $1.36-3.99 \mu \mathrm{m})$. RD\%, fine particle (FP) fraction $(\%<5 \mu \mathrm{m})$ and FP dose $(\mu \mathrm{g}<5 \mu \mathrm{m})$ data, respectively, were: baseline 39.9 $\pm 4.8,46.2 \pm 4.8$ and $56.7 \pm 5.6$; ex-bag $15.4 \pm 4.0,20.1 \pm 3.8$

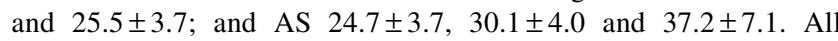
paired differences were significant $(\mathrm{P}<0.05)$. Ex-bag and AS-prepared VHCs delivered $45 \%$ and $66 \%$ of the baseline VHC RD\%. A2A prepared according to IfU provided the best data, with the use of AS measures contributing to an improved performance compared with ex-bag (emergency) use. As a result of this research, the inclusion of an AS bag is now routine during the manufacture of the A2A Spacer.

\section{P-216 HIGH SHEAR MIXING: THE RELATIONSHIP BETWEEN BLENDING ORDER AND TERNARY DRY POWDER INHALATION PERFORMANCE}

\author{
Mats Hertel $^{1}$, Steckel Hartwig ${ }^{2}$ \\ ${ }^{1}$ Kiel University, Institute of Pharmacy; Department \\ of Pharmaceutics and Biopharmaceutics \\ ${ }^{2}$ Eastpharma Ltd, Turkey
}

The addition of fines in ternary powder mixtures for inhalation is well-known to increase the fine particle fraction (FPF). Numerous theories like the active sites hypothesis, agglomeration hypothesis, buffer hypothesis and fluidisation hypothesis have been discussed. In this study the impact of these mechanisms on commercially available lactose grades was tested. A high shear mixer (Picomix ${ }^{\circledR}$ ) was used in this work for blending, which allows a scale up and is available in the industry. The influences of rotation speed, blending time and blending order were investigated. InhaLac $70^{\circledR}$ as a carrier, InhaLac $400^{\circledR}$ as fines, were used and Budesonide was added as a model drug. Performance of the different blends was tested with a commercial inhaler device $\left(\right.$ Novolizer $^{\circledR}$ ) by using the Next Generation Impactor. Results exhibit that the FPF was strongly dependent on the rotation speed, blending time and blending order. SEM pictures and blending order results substantiated that fines and API deposit in the dents of the carrier preferentially and remain there after dispersion. API was detached from the carrier surface more easily, when indentations were filled with fines initially, which increased the FPF.

\section{P-221 PERFORMANCE OF AMIKACIN INHALE: IMPACT OF SUPPLEMENTAL OXYGEN AND DEVICE ORIENTATION}

\author{
Nani Kadrichu ${ }^{1}$, Truong Dang ${ }^{1}$, Kevin Corkery ${ }^{1}$, Peter Challoner ${ }^{2}$ \\ ${ }^{1}$ Novartis Pharmaceuticals \\ ${ }^{2}$ Nektar Therapeutics
}

Introduction: Amikacin Inhale is an integrated drug-device combination in development (Bayer HealthCare and Nektar Therapeutics) to improve clinical outcome in intubated and mechanically ventilated patients with Gram-negative pneumonia. It is available in two configurations: on-vent for intubated patients and handheld $(\mathrm{HH})$ for extubated patients to complete therapy. This study evaluated the performance of the $\mathrm{HH}$ configuration with supplemental $\mathrm{O}_{2}$ supplied at different flow rates and in different orientations.

Methods: In the $\mathrm{HH}$ configuration, supplemental $\mathrm{O}_{2}$ may be supplied via the $\mathrm{O}_{2}$ port and mixed with aerosolized amikacin and ambient air in the holding chamber. The $\mathrm{O}_{2}$ concentration and DD at the mouthpiece exit were characterized in vitro at various $\mathrm{O}_{2}$ flow rates $(2-10 \mathrm{~L} / \mathrm{min})$ and measured every minute. In vitro amikacin DD was measured at the exit of the mouthpiece and analyzed using HPLC. DD was measured at nebulizer orientations of $0^{\circ}$ and $45^{\circ}(n=3$ per orientation) using a simulated breathing profile with no supplemental $\mathrm{O}_{2}$.

Results: Mean $\mathrm{O}_{2}$ concentration ranged $36-70 \%$ over $2-10 \mathrm{~L} / \mathrm{min}$ and was $\geq 40 \%$ at $\geq 3 \mathrm{~L} / \mathrm{min}$. DD did not change substantially with increasing $\mathrm{O}_{2}$ flow rate $\left(72-82 \%\right.$ of nominal dose). At $0^{\circ}$ and $45^{\circ}$ orientations, amikacin DD was $74-80 \%$ and $73-76 \%$ of nominal dose (400 mg), respectively.

Conclusions: Amikacin Inhale was shown in vitro to be suitable for extubated patients who require supplemental $\mathrm{O}_{2}$. DD was independent of supplemental $\mathrm{O}_{2}$ and device orientation.

\section{P-222 AMIKACIN IN VITRO DELIVERY WITH TRACHEOSTOMY SET UP}

\author{
Nani Kadrichu ${ }^{1}$, Truong Dang ${ }^{1}$, Kevin Corkery ${ }^{1}$, Peter Challoner ${ }^{2}$ \\ ${ }^{1}$ Novartis Pharmaceuticals \\ ${ }^{2}$ Nektar Therapeutics
}

Introduction: Amikacin Inhale is an integrated drug-device combination in development (Bayer HealthCare and Nektar Therapeutics) to improve clinical outcome in intubated and mechanically ventilated patients with Gram-negative pneumonia. It has two configurations: on-vent for intubated patients and handheld for extubated patients to complete aerosolized antibiotic therapy. This study evaluated the delivered dose (DD) of Amikacin Inhale with a tracheostomy (TT) set up and tested DD optimization using smooth bore tubing without an elbow.

Methods: Three TT internal diameters (ID), $6.4-8.9 \mathrm{~mm}$, and two tubing IDs $(15$ and $22 \mathrm{~mm}$ ) were evaluated. Three nebulizers were used for each test scenario. Optimization using smooth bore tubing without an elbow was performed. A filter at the exit of the TT to collected aerosolized drug. Drug distribution within the test setup compartments was analyzed using HPLC.

Results: The on-vent DD increased with increasing TT ID, while TT ID did not appear to influence the HH DD. The DD was approximately twice as high with $22 \mathrm{~mm}$ tubing ID as with $15 \mathrm{~mm}$ tubing ID, regardless of TT ID. Removal of the elbow in the TT set up played a significant role in HH DD optimization (45\% vs $65 \%$ ). Smooth bore tubing did not significantly affect the HH DD. 
Conclusions: We have shown that the on-vent DD is influenced by TT ID. However, TT ID did not affect HH DD. HH DD depends on the tubing ID and can be improved with the removal of the elbow connection typically used in the TT setup.

\section{P-228 IN VITRO STUDY OF NEBULIZATION DURING HIGH FLOW NASAL CANNULA OXYGEN THERAPY IN ADULTS}

\author{
François Réminiac ${ }^{1}$, Laurent Vecellio ${ }^{2}$, Deborah Le Pennec ${ }^{3}$, \\ Maria Cabrera ${ }^{3}$, Antoine Petitcollin ${ }^{4}$, Renaud Respaud ${ }^{5}$, \\ Nathalie Vourc' $h^{3}$, Patrice Diot ${ }^{6}$, Stephan Ehrmann ${ }^{7}$ \\ ${ }^{I}$ Chru de Tours, Département D'anesthésie Réanimation, \\ Université François Rabelais, Cepr, Umr Inserm 1100 \\ ${ }^{2}$ Aerodrug, Inserm, Université François Rabelais, Cepr, \\ Umr Inserm 1100 \\ ${ }^{3}$ Université François Rabelais, Cepr, Umr Inserm 1100 \\ ${ }^{4}$ Chru de Tours, Pharmacologie - Toxicologie \\ ${ }^{5}$ Chru de Tours, Pharmacie \\ ${ }^{6} 1$ centre D'etude des Pathologies Respiratoires Inserm U1100 \\ ${ }^{7}$ Chru de Tours, Réanimation Polyvalente, Université \\ François Rabelais, Cepr, Umr Inserm 1100
}

Nebulization through nasal high flow devices (HFT) may be relevant for patients suffering from respiratory failure and requiring aerosolized bronchodilatators. This study aimed to identify the optimal settings for the implementation of the nebulization combined with HFT in adults.

The aerosol emitted at the extremity of the cannula was assessed using mesh and jet nebulizers placed at various positions in the HFT circuit. The lung dose was measured using an anatomical model and a filtering method in different breathing conditions.

Placement of the nebulizers close to the humidification chamber provided a delivered mass of about $30 \%$ of the nebulizer charge, which was better than a position close to the cannula. A mesh nebulizer placed before the humidification chamber was the most efficient configuration, providing a lung dose of 3 to $10 \%$ of the nebulizer charge, negatively correlated with HFT flow rates (30 to $60 \mathrm{~L} / \mathrm{min}$ ). The lung dose was significantly higher when simulating "respiratory failure" with higher patients inspiratory flows, as compared to calm breathing with lower inspiratory flows.

The measured lung dose is likely to produce a therapeutic effect in the clinical setting and those findings bring the basis for further clinical evaluation of aerosoltherapy during HFT in adults.

\section{P-236 TOLL-LIKE RECEPTOR 2 STIMULATION ENHANCES BARRIER FUNCTION IN NORMAL AND ASTHMATIC BRONCHIAL EPITHELIAL CELLS}

\author{
Sakthikumar Ragupathy ${ }^{1}$, Sandra $\mathrm{Citi}^{2}$, Gerrit Borchard ${ }^{1}$ \\ ${ }^{I}$ School of Pharmaceutical Sciences, University of Geneva, University \\ of Lausanne \\ ${ }^{2}$ Department of Molecular Biology, Institute of Genetics and \\ Genomics, University of Geneva
}

The airway epithelium acts as a crucial physical and immunological barrier against several inhaled antigens and allergens. Tight junctions between these cells form a highly regulated and impermeable physical barrier. Disruption of airway epithelial tight junctions has been reported in asthmatic bronchial biopsies. Suggesting higher susceptibility of airway immune cells to inhaled particles and pathogens and hence asthmatic aggravation. We have previously shown that Toll-like receptor 2 (TLR 2) stimulation enhances the tight junction associated epithelial barrier function of human bronchial epithelial cell monolayers by increasing the expression of claudin-1 and ZO-1 tight junction proteins via atypical protein kinase C Zeta in Calu-3 cells. In the current study we investigated the effect of TLR2 stimulation in Mucilair ${ }^{\text {TM }}$ primary human bronchial cells and airway epithelial cells obtained from asthmatic, COPD and heavy cigarette smoker patients. TLR2 stimulation by peptidoglycan led to significant increase in transepithelial electrical resistance (TEER) and a decrease in paracellular flux of FITC $3 \mathrm{kDa}$ in primary human bronchial epithelial cells and cells from asthmatic individuals. Immunofluorescence analysis indicated an increase in the expression levels of tight junction proteins claudin- 1 and ZO-1in normal and asthmatic epithelial cells. These effects were not noticed in cells from COPD and heavy cigarette smokers. Thus TLR2 stimulation could be a promising therapeutic strategy for asthma.

\section{P-238 POWER REQUIREMENT OF PRESSURIZED METERED-DOSE AND DRY POWDER INHALERS (pMDIs AND DPIs)}

\author{
Peter Haidl ${ }^{1}$, Gerhard Pohlmann ${ }^{2}$, Rolf-Michael Cloes ${ }^{3}$ \\ ${ }^{I}$ Fachkrankenhaus Kloster Grafschaft \\ ${ }^{2}$ Fraunhofer Institute for Toxicology and Experimental \\ Medicine, Hannover \\ ${ }^{3}$ Mundipharma $\mathrm{GmbH}$
}

Introduction: For each inhalation device, a minimum flow rate must be exceeded in order to achieve acceptable drug release and lung deposition. These minimum required flows must be achieved by devicespecific resistances, which necessitate a specific inhalation power.

Methods: A literature search was carried out to find the minimum required flows for different MDI and DPI devices. The flow resistances were measured at Fraunhofer ITEM, Hannover, to calculate the necessary breathing power required to achieve the minimum flow rates for each device. The required power $(\mathrm{W})$ can be deduced using the following relations: $\mathrm{R}=\frac{\sqrt{4 P}}{\dot{V}}(\mathrm{R}=$ resistance of the device) [1]; volume work is defined as: $\mathrm{L}=\Delta \mathrm{P} \cdot \dot{V}$ [2]; inserting [1] in [2] and resolution according to $L$ results in: $\mathbf{L}=\mathbf{R}^{2} \cdot \dot{\mathbf{V}}^{3}$.

Results: Breathing power at minimum required flows.

Discussion: As the inspiratory power of patients can vary, these data may be useful in the future for selecting an appropriate inhalation device.

\begin{tabular}{|l|c|c|c|c|c|c|c|c|c|c|c|}
\hline Device & MDI & $\begin{array}{c}\text { Easi- } \\
\text { Breathe }\end{array}$ & $\begin{array}{c}\text { Auto- } \\
\text { haler }\end{array}$ & Diskus & $\begin{array}{c}\text { Aero- } \\
\text { lizer }\end{array}$ & $\begin{array}{c}\text { Handy- } \\
\text { haler }\end{array}$ & $\begin{array}{c}\text { Turbo- } \\
\text { haler }\end{array}$ & $\begin{array}{c}\text { Breez- } \\
\text { haler }\end{array}$ & $\begin{array}{c}\text { Easy- } \\
\text { haler }\end{array}$ & $\begin{array}{c}\text { Genu- } \\
\text { air }\end{array}$ & $\begin{array}{c}\text { NEXT- } \\
\text { haler }\end{array}$ \\
\hline $\begin{array}{l}\text { Flow } \\
\text { (L/min) }\end{array}$ & 15 & 20 & 30 & 30 & 40 & 20 & 30 & 50 & 30 & 45 & 40 \\
\hline $\begin{array}{l}\text { Power } \\
\text { (W) }\end{array}$ & 0,00 & 0,02 & 0,04 & 0,29 & 0,38 & 0,39 & 0,54 & 0,75 & 1,15 & 1,52 & 1,54 \\
\hline
\end{tabular}

\section{P-239 THE SELECTIVE PAN-JANUS KINASE (JAK) INHIBITOR VR588 DEMONSTRATES POTENT ANTI- INFLAMMATORY ACTIVITY IN A MURINE CHRONIC HOUSE DUST MITE (HDM) MODEL OF ASTHMA}

\author{
Cornelis H Wiegman ${ }^{1}$, Ian M Adcock ${ }^{1}$, Alan Rothaul ${ }^{2}$, \\ Mark Main ${ }^{2}$, Frazer Morgan ${ }^{2}$ \\ ${ }^{1}$ Imperial College London \\ ${ }^{2}$ Vectura Group Plc
}

Rationale: Janus kinases have a key role in cytokine signalling in asthma. VR588 is a potent, balanced and selective pan-JAK inhibitor. This study investigates the pharmacokinetics (PK) of inhaled VR588 and its in-vivo efficacy in an asthma model. 
Methods: Murine lung and plasma VR588 PK were measured for 24 hours following intranasal (i.n) delivery ( 1.5 to $50 \mathrm{mg} / \mathrm{kg}$; $\mathrm{n}=6$ per group). HDM extract $(25 \mu \mathrm{g})$ was given i.n 5 days/week for 3 weeks with i.n VR588 doses (1.5 to $7.5 \mathrm{mg} / \mathrm{kg}$ ) given 1 hour prior; another group received i.n VR588 $7.5 \mathrm{mg} / \mathrm{kg}$ during only the last week of HDM exposure $(\mathrm{n}=8)$. Oral tofacitinib $(\mathrm{T})(15 \mathrm{mg} / \mathrm{kg})$ and i.n fluticasone propionate (FP) $(1.5 \mathrm{mg} / \mathrm{kg}$ ) were controls. Airway hyperresponsiveness (AHR) was assessed 24 hours after the last HDM; bronchoalveolar lavage fluid (BAL) was assessed for differential cell count, STAT activation and cytokines.

Results: VR588 i.n rapidly ( 5 mins) achieved dose related lung levels which stayed at relevant levels for 24 hours; plasma levels were 1000-fold less. VR588 resulted in significant AHR reduction, at least equal to FP. All VR588 doses significantly reduced BAL total cell count with some doses inhibiting cell differentials. VR588 attenuated cytokine release (IL-4, IL-5, IL-17) compared with saline control and activation of STAT 3 at $24 \mathrm{hrs}$ comparable to FP and T.

Conclusions: VR588 i.n has a PK profile suited to inhaled delivery. Attenuation of HDM inflammation suggests that inhaled VR588 may represent a novel treatment for asthma.

\section{P-241 THE COMPLEX ASSESSMENT OF ENDPOINTS IN CLINICAL TRIAL}

Irene Heimbeck, Dominik Kappeler, Christer Beckmann, Diana Veverka

Inamed $\mathrm{GmbH}$

Clinical endpoints are the key analyses of disease characteristics observed in a clinical trial that reflect the effect of a therapeutic intervention. However, complex diseases with manifold pathological characteristics often need the assessment of various surrogate markers to analyze change in the disease outcome. Here we demonstrate possible alternatives to investigate the change of symptoms in patients with allergic asthma for randomized controlled trials. For recruitment, the exact target population can be chosen by characterizing the patients in their individual allergen profile by pulmonary provocation with an inhalative allergen. The pulmonary outcome under therapy then can be assessed by alteration in lung function $\left(\mathrm{FEV}_{1}\right)$ during different phases of allergen response. Further investigations reflecting the local treatment response are the change in airway responsiveness measured by Methacholine challenge test or $\mathrm{FE}_{\mathrm{NO}}$ levels which reveals pulmonary inflammation status. For systemic treatment reaction, a change in the Th2-driven immune response can be assessed, for example by measuring cytokine level in blood plasma using chemokine assay. Sputum induction by inhalation of hypertonic saline is a simple and noninvasive procedure to gain sputum cells, in order to explore a shift in the amount of eosinophil granulocytes before and after treatment.

\section{P-243 IN VITRO EVALUATION OF A NEW POTENT, SELECTIVE PAN-JANUS KINASE (JAK) INHIBITOR VR588}

\author{
Cornelis H Wiegman ${ }^{1}$, Ian M Adcock ${ }^{1}$, Alan Rothaul ${ }^{2}$, \\ Mark Main ${ }^{2}$, Frazer Morgan ${ }^{2}$ \\ ${ }^{1}$ Imperial College London \\ ${ }^{2}$ Vectura Group Plc
}

Rationale: VR588 is promising pan-JAK inhibitor suited to inhalation delivery. These studies were designed to characterise the invitro kinase inhibition profile of VR588 and to determine its selectivity versus non-JAK kinases.

Methods: Kinase activity was assessed in a non-cell (Z'Lyte ${ }^{\mathrm{TM}}$ Florescence assay) and in cell based assays using stimulation of hu- man whole blood (IL-2 stimulated INF $\gamma$ production and JAK1/JAK3 and $\mathrm{pSTATa} / \mathrm{b}$ activation and IL-6 stimulated pSTAT3 to assess JAK1, JAK2 and Tyk2 activity). Selectivity of VR588 (1 mM) against a panel of 93 human kinases was also assessed.

Results: VR588 potently inhibited JAK 1, 2, 3 and Tyk2 kinases (IC50 4.2, 0.7, $2.1 \& 6 \mathrm{nM}$ respectively) in the non-cell based assay and showed poor inhibitory activity against non -JAK kinases FLT3, PDGFB, JNK2 and Syk (IC50 247, 2350,4000, $8900 \mathrm{nM}$ respectively). JAK inhibition was confirmed in the cell based assays with inhibition of IL-2 stimulated INF $\gamma$, IL-2 stimulated pSTATa/b \& IL-6 stimulated pSTAT3 demonstrating IC50 values of 209, $29 \& 62 \mathrm{nM}$ respectively. Selectivity versus human kinases revealed no relevant off- target effects.

Conclusions: VR588 represents a potent, selective and balanced pan-JAK inhibitor, suggesting VR588 may have utility as a treatment for asthma and COPD.

\section{P-246 ACTIVITY OF THE NOVEL AND SELECTIVE PAN- JANUS KINASE (JAK) INHIBITOR VR588 IN A MURINE POLYINOSINIC:POLYCYTIDILIC ACID (POLY(I:C)) MODEL OF VIRAL LUNG INFLAMMATION}

\author{
Cornelis H Wiegman ${ }^{1}$, Ian M Adcock ${ }^{1}$, Alan Rothaul ${ }^{2}$, Mark Main ${ }^{2}$, \\ Frazer Morgan ${ }^{2}$ \\ ${ }^{1}$ Imperial College London \\ ${ }^{2}$ Vectura Group Plc
}

Rationale: VR588 is a potent, selective pan-JAK inhibitor. Viral infection is regarded as an important trigger of airway inflammation. This study investigates VR588 by the inhaled and oral routes in a murine model of viral lung inflammation

Methods: Male BALB/c mice were administered Poly(I:C) $1 \mathrm{mg} / \mathrm{ml}$ intranasally (i.n) 1 hour after VR588 administration and again 16 hours later. VR588 was given (i.n 1.5, 7.5, $15 \mathrm{mg} / \mathrm{kg}$ and p.o $15 \mathrm{mg} / \mathrm{kg}$; $\mathrm{n}=6$ per group). Lung tissue and bronchoalveolar lavage fluid (BALF) was harvested 40 hours after the initial Poly(I:C) challenge. Inflammatory cell count from BALF (FACS analysis), JAK-STAT activation (pSTAT1, 3 \& 5) (ELISA) and BAL inflammatory cytokines (Luminex immunoassay) were measured. Fluticasone propionate (FP) (i.n $1.5 \mathrm{mg} /$ $\mathrm{kg}$ ) and tofacitinib (T) (p.o $15 \mathrm{mg} / \mathrm{kg}$ ) were positive controls.

Results: Poly(I:C) increased total BAL cell count which was reduced in a dose-related manner by i.n VR588; oral VR588 was ineffective. Poly (I:C)-elevated BAL cytokines (eotaxin, MIP- $1 \alpha \& \beta$, IP-10, KC, TNF- $\alpha$ and MCP-1) were all reduced by i.n VR588. pSTAT1 and pSTAT5 (but not pSTAT3) were increased by Poly(I:C) and subsequently attenuated by VR588. Intranasal VR588 activity was typically greater than that seen for oral and at least as great as that with FP or T.

Conclusions: VR588 attenuation of Poly(I:C) induced inflammatory cell accumulation, cytokines and STAT phosphorylation supports its possible use in the treatment of viral induced airway inflammation.

\section{P-253 HIGH-EFFICIENCY ALBUTEROL DELIVERY IN SPONTANEOUSLY BREATHING PATIENTS: COMPARISON OF A VIBRATING MESH NEBULIZER AND NOVEL ADAPTER COMBINATION WITH A JET NEBULIZER}

\author{
Louise Sweeney, Andrew O’Sullivan, Monika Wolny, Ronan \\ MacLoughlin
}

Aerogen Limited, Ida Business Park, Dangan, Galway, Ireland

Introduction: The aim of this study was to compare the Inhaled efficiency of a vibrating mesh nebulizer (VMN) in combination with a 
novel adapter (Aerogen Ultra) to that of a standard jet nebulizer (JN) (AirLife $^{\circledR}$ Misty Fast ${ }^{\mathrm{TM}}$ ) under simulated healthy and COPD adult breathing conditions.

Method: Devices were connected to a breathing simulator (Ingmar ASL 5000) via an absolute filter (RespirGard II 303). Settings were as follows: Healthy (BPM 15, TV 500 ML, I: E 1:1), COPD (BPM 30, TV 265 ML, I: E 1:3). 2LPM $( \pm 5 \%)$ gas flow was added to the adapter. $2 \mathrm{ml}$ of $2 \mathrm{mg} / \mathrm{ml}$ Albuterol was loaded into each nebulizer. The drug was extracted from the filter using buffer and quantified using UV spec.

Results: In healthy patients, efficiency (\% Inhaled Dose) of the VMN $(56.92 \pm 1.91 \%)$ and a dose rate of $582.55 \mathrm{mg} / \mathrm{min}$ was greater than the JN $(25.03 \pm 1.6 \%)$ with a dose rate of $198.25 \mathrm{mg} / \mathrm{min}$. In the COPD group, the VMN $(51.41 \pm 0.86 \%)$ with a dose rate of $532.65 \mathrm{mg} / \mathrm{min}$ was also greater than the $\mathrm{JN}(11.24 \pm 0.49 \%)$ with a dose rate of $104.99 \mathrm{mg} / \mathrm{min}$.

Conclusions: Across both patient types and for both Inhaled Dose and Dose Rate, the VMN in combination with the novel adapter was superior to the JN. In a COPD patient, the VMN combined with the Aerogen Ultra will deliver more than 4 times the dose of Albuterol $v s$ the JN.

\section{P-259 ENGINEERED PARTICLES BY WAY OF SPRAY DRYING FOR INHALATION DELIVERY OF PHARMACEUTICALS}

\author{
Michael Tauber, Michael Lipp
}

Acorda Therapeutics

The ARCUS ${ }^{\mathrm{TM}}$ platform demonstrates engineered particles manufactured by way of spray drying that are easily dispersible, low density, porous with an aerodynamic diameter of $\sim 3 \mu \mathrm{m}$. The aerodynamic diameters of the particles is similar to that of conventional aerosol particles yet their lower density and larger geometric diameter $(\sim 10 \mu \mathrm{m})$ requires $>100 \mathrm{X}$ less powder to disperse (ideal in patients with compromised lung function).

The particles can be made physically stable in either an amorphous or crystalline matrix depending on what is best suited for the stability of the drug. Within an amorphous matrix, excipient selection is dictated by the ability of the particles to maintain a stable glass transition temperature with no evidence of crystallization and or form conversion. Within a crystalline matrix, excipients are chosen that maintain a stable crystalline structure that limits molecular mobility of the drug. In both amorphous and crystalline matrices excipients are selected for their role in enabling formation of the particle shell; enhancing porosity, dispersibility and aerosolization; and maintaining chemical stability.

The particles are capable of providing rapid onset that can take effect within minutes of inhalation, comparable to oral of sub cutaneous delivery. It is packaged in an easy to use and patient friendly product configuration consisting of a passive dry powder inhaler.

\section{P-260 UPTAKE OF LOS-FUNCTIONALIZED POLYMERIC PARTICLES FOR TARGETED DELIVERY TO THE LUNG EPITHELIUM}

\author{
Mai $\mathrm{Tu}^{1}$, Michael Apicella ${ }^{2}$, Jennifer Fiegel ${ }^{3}$ \\ ${ }^{1}$ University of Iowa, Department of Pharmaceutical \\ Sciences and Experimental Therapeutics \\ ${ }^{2}$ University of Iowa, Department of Microbiology, \\ College of Medicine \\ ${ }^{3}$ University of Iowa, Department of Chemical and Biochemical \\ Engineering, Department of Pharmaceutical Sciences and
} Experimental Therapeutics
A variety of phylogenetically distinct respiratory bacterial pathogens, such as Haemophilus influenzae, invade host cells in the upper airways by binding to the platelet-activating factor (PAF) receptor via lipooligosaccharide (LOS) on the bacterial surface. The goal of this project was to develop functionalized particles that mimic the binding and uptake behavior of non-typeable $H$. influenzae to the lung epithelium via isolated LOS. Polystyrene particles $(0.2$ and $1 \mu \mathrm{m})$ were coated with gelatin or $0.005-50 \mu \mathrm{g} / \mathrm{mL}$ LOS from $H$. influenzae 3198. The uptake of coated particles in two bronchial epithelial cell lines (16HBE14o- and Calu-3) was investigated at a different particle concentration over 24 hours. Particle uptake pathways were identified by pre-treatment with platelet activating factor (PAF), or with inhibitors of various endocytic pathways. The fate of functionalized particles was dependent on particle size, concentration, type of ligand coating, incubation time, and cell type. Particle-cell association was partially inhibited at $4{ }^{\circ} \mathrm{C}$, showing the importance of both active and passive uptake mechanisms. Particles were extensively taken up by energy-dependent endocytosis and macropinocytosis. Most importantly, activation of the PAF receptor with PAF resulted in enhanced uptake of the LOS-modified particles, whereas uptake was inhibited by preincubation with LOS, indicating the importance of the LOS ligand in targeting uptake via the PAF receptor.

\section{P-262 COMBINATION TREATMENTS FOR BETTER ERADICATION OF PSEUDOMONAS AERUGINOSA BIOFILMS}

\author{
Sachin Gharse ${ }^{1}$, Jennifer Fiegel $^{2}$ \\ ${ }^{1}$ University of Iowa, Department of Pharmaceutical Sciences \\ and Experimental Therapeutics \\ ${ }^{2}$ University of Iowa, Department of Chemical and Biochemical \\ Engineering, Department of Pharmaceutical Sciences and
} Experimental Therapeutics

Our goal for this project is to develop an inhalation formulation consisting of an antibiotic and a biofilm dispersion compound for eradication of Pseudomonas aeruginosa biofilms. Our previous studies performed on biofilms of the laboratory PAO1 strain of P. aeruginosa demonstrated that combinations of antibiotics and nutrient dispersion compounds provided enhanced eradication of both young and mature biofilms compared to antibiotic treatment alone. The current study aimed to determine whether these combinations were successful against biofilms of clinical isolates of $P$. aeruginosa. The minimum biofilm eradication concentration $\left(\mathrm{MBEC}^{\mathrm{TM}}\right)$ assay was used to determine the effects of antibiotics alone and combinations of antibiotics and nutrient dispersion compounds on eradication of three clinical isolates.

Results from the MBEC assays demonstrate that certain combinations of antibiotic and nutrient dispersion compounds were more effective in eradicating biofilms of the clinical isolates compared to antibiotics alone. For these combinations, biofilm eradication was observed at lower antibiotic concentrations than treatment with antibiotics alone. However, which combinations were effective were dependent on the exact isolate studied and were different than those predicted from the PAO1 strain, suggesting the need to test individual isolates for susceptibility prior to treatment. Our future studies will be aimed at identifying the most potent combinations for eradicating $P$. aeruginosa biofilms generated from clinical isolates and in validating the efficacy of these selected combinations in vivo. 


\section{P-265 NASAL NEBULISATION OF TOBRAMYCIN: PRECLINICAL AND CLINICAL STUDY ON POST- OPERATIVE SUPPURATIONS IN NASAL POLYPOSIS PATIENT}

\author{
Escabasse Virginie ${ }^{1}$, Vecellio Laurent ${ }^{2}$, \\ Leguellec Sandrine $^{2}$, Bonfils Pierre ${ }^{3}$ \\ ${ }^{1}$ Centre Hospitalier Intercommunal de Créteil \\ ${ }^{2}$ Aerodrug, Dtf Medical, Cepr Umr Inserm 1100, Université \\ François Rabelais \\ ${ }^{3}$ Département Orl, Hôpital Européen Georges Pompidou, \\ Faculté de Médecine Paris Descartes
}

The choice of nasal treatment for patients is conducted by EPOS guidelines. Treatments concern saline irrigation, spray of corticosteroid, oral antibiotherapy. Nasal nebulisation or topical antibiotherapy are not recommended due to the lack of clinical evidence. This study presents the preclinical and clinical results of the evaluation of tobramycin administered by nasal nebulisation in nasal polyposis (NP) patients.

Patients with NP often present recurring suppurations even after ethmoidal surgery.

The 4 preclinical steps of study were: (1) Bacteriological study of ethmoid specimens from NP patients obtained after ethmoidal surgery, (2) Selection of the antibiotic molecule, (3) Development of a new nasal nebulizer (Easynose) for the drug and patients, (4) In vitro and in vivo drug deposition measurements with Easynose.

The type of bacteria involved in these post-operative exacerbations was predominantly identified as S. aureus. Tobramycin $(150 \mathrm{mg}$, Erempharma) was selected for nasal nebulisation treatment. Aerosol delivered with Easynose allows 99\% of deposition in nasal cavities including ethmoid and sinuses.

Tobramycin was nebulized in 72 post-operative NP patients who presented nasal suppurations. After 7-days of treatment, significative bacteria eradication was reported, vs. serum physiology treatment (respectively $46.9 \%$ and $17.4 \%$ of eradication; $\mathrm{p}=0.02$ ).

As conclusion, tobramycin administered by nasal nebulisation is efficient for nasal bacteria eradication.

\section{P-271 DEVELOPMENT OF A DRUG AND DEVICE FOR THE PULMONARY DELIVERY OF AN ANTI-RICIN ANTIBODY}

Renaud Respaud $^{1}$, Denis Marchand ${ }^{2}$, Parent Christelle ${ }^{3}$, Guillemain Joel $^{4}$, Pelat Thibault ${ }^{5}$, Douziech-Eyrolles Laurence ${ }^{6}$, Levacher Eric ${ }^{7}$, Laurent Vecellio ${ }^{8}$, Nathalie Vourc' ${ }^{9}$, Thullier Philippe 5

${ }^{1}$ Chru de Tours, Pharmacie

${ }^{2}$ Aerodrug

${ }^{3} \mathrm{Umr} U 1100$

${ }^{4}$ Sesame

${ }^{5}$ Irba

${ }^{6}$ University of Tours

${ }^{7}$ Imt

${ }^{8}$ Centre D'etude des Pathologies Respiratoires Inserm U1100, Dtf-Aerodrug

${ }^{9}$ Université François Rabelais, Cepr, Umr Inserm 1100

Ricin is a toxin classified as a bioweapon, particularly toxic through inhalation. 43RCA is a human "like" IgG neutralizing ricin in vitro and limiting toxicity in vivo, by targeting with a high affinity the catalytic A chain of ricin. This project aimed at developing a drug formulation and a device to allow the direct delivery of aerosolized 43RCA into the deep lung through the airways. Firstly, we defined the best formulation allowing the lyophilization of the antibody for an easy storage, and its extemporaneously reconstitution and its nebulization with a mesh nebulizer. We monitored the amount of aggregates by Diffusion Light Scattering, Size-Exclusion Chromatography and fluorescence microscopy after Nile Red staining, analyzed changes in secondary structure by Infra-Red spectroscopy, and determined the antibody activity by verifying its affinity in surface plasmon resonance. Secondly, we used a customized vibrating mesh nebulizer associated with a new inhalation chamber to administer efficiently the drug into the deep lung. As assessed by cascade impaction, the respirable fraction was greater than $85 \%$ and the MMAD was $2.1 \mu \mathrm{m} \pm 0.4 \mu \mathrm{m}$ for the drug and device. Finally, in a non-human primate's model treated with aerosolized 43RCA, we assessed the antibody lung deposition and its transfer into the bloodstream. A mean lung deposition rate of over $10 \%$ was determined associated with a slowly and poorly transfer of the drug into the systemic circulation. For the first time, a drug formulation and device adapted for the efficient delivery through inhalation of a therapeutic antibody into the alveolar region has been developed.

\section{P-272 DRY POWDERS INHALERS FROM BUDESONIDE LOADED LIPID-CORE NANOCAPSULES FOR ASTHMA TREATMENT: DEVELOPMENT AND TOXICITY EVALUATION}

\author{
Manoel Ortiz ${ }^{1}$, Marco Aurelio Martins ${ }^{2}$, Adriana Pohlmann ${ }^{3}$, \\ Andressa Bernardi ${ }^{2}$, Silvia Guterres ${ }^{3}$, Carsten Ehrhardt ${ }^{4}$ \\ ${ }^{1}$ Universidade Federal Do Rio Grande Do Sul, Trinity \\ College Dublin \\ ${ }^{2}$ Instituto Oswaldo Cruz (Fiocruz) \\ ${ }^{3}$ Universidade Federal Do Rio Grande Do Sul \\ ${ }^{4}$ Trinity College Dublin, School of Pharmacy \\ and Pharmaceutical Sciences
}

Asthma is characterized as an inflammatory disease developed by multifactorial aspects. Budesonide is a glucocorticoid and is the most frequently used therapy in the treatment. However, this drug has low oral bioavailability and long term use may lead to adverse effects. In this context, nanotechnology is an important tool for the problems of bioavailability and adverse effects of conventional therapy. The aim of this work was to develop a nanostructured system as dry powder inhaler (DPI) containing budesonide loaded, obtained by spray-drying, targeting the treatment of acute asthma and toxicity evaluation using a human lung adenocarcinoma cell line (NCl-H441). This proposal was based on obtaining a nanostructured powder system with reduced and controlled size, aiming an alternative to treatment of asthma. The particle size, morphology and in vitro deposition of the DPI formulation were suitable for pulmonary administration. The in vivo experiments showed a decreasing in lung elastance and resistance when budesonide was used nanoencapsulated compared to the free drug in two utilized doses $(0.5$ and $1.0 \mathrm{mg} / \mathrm{kg})$. Also, a reduction of inflammation by decreasing of the total of leukocytes in the bronchial lavage fluid was showed. The quantification of eotaxin - 1 and proinflammatory cytokines, were reduced when compared to commercial budesonide treatment. The toxicity evaluation using the lung epithelium $\mathrm{NCl}-\mathrm{H} 441$ cell line showed increased cell survival at the highest doses when budesonide was used encapsulated compared to the free drug. All these results show the potential of the new budesonide loaded lipid-core nanocapsules, for the treatment of asthma. 


\section{P-278 IN VIVO SIRNA DELIVERY TO ACTIVATED T CELLS AS NOVEL ANTI-INFLAMMATORY ASTHMA THERAPY}

\author{
Yuran Xie $^{1}$, David J.P. Bassett ${ }^{1}$, Olivia Merkel $^{2}$ \\ ${ }^{1}$ Wayne State University \\ ${ }^{2}$ Wayne State University, Karmanos Cancer Institute
}

Local, targeted, cell-specific RNA interference (RNAi)-based therapies could improve patients' ability to control asthma. However, $\mathrm{T}$ cells which play a central role are hard to transfect cells and not accessible for RNAi-based therapies. We reported that activated $\mathrm{T}$ cells (ATCs) overexpress the transferrin receptor (TfR), an internalizing transmembrane receptor that is broadly exploited for targeted drug delivery.

Here we aim to therapeutically downregulate the Th2 transcription factor GATA-3 which drives IL-4, IL-5, and IL-13 secretion to silence their downstream inflammatory cascades.

$\mathrm{T}$ cells are isolated from full blood and activated with anti-CD3. TfR-targeted nanocarriers are designed by coupling $\mathrm{Tf}$ and low molecular weight polyethylenimine (PEI). Uptake of fluorescent siRNA in ATCs is evaluated by flow cytometry. Gene knockdown is quantified by qRT-PCR. Balb/c mice are sensitized and challenged with ovalbumin (OVA). Mice are treated intratracheally with fluorescent siRNA in targeted or non-targeted nanocarriers. Their lung function is measured via methacholine challenge. Uptake of the siRNA in specific lung cell types is measured by flow cytometry.

The coupling of Tf to PEI was optimized and the nanocarriers were about $50 \mathrm{~nm}$ in size. ATCs selectively took up targeted nanocarriers, and $70 \%$ gene knockdown was achieved in primary ATCs. OVAchallenged mice showed specific uptake of siRNA in T cells of the lung. The lung function was not negatively affected by the treatment.

Transferrin-coupled polymers can efficiently deliver siRNA to activated $\mathrm{T}$ cells and could therefore be efficient siRNA carriers in asthma. Currently, therapeutic gene knockdown is tested, and novel biodegradable targeted carriers are evaluated.

\section{P-280 IMPACT OF BREATHING PATTERN ON DEPOSITON AND TOLERABILITY OF A NOVEL LIQUID INHALER}

Valdecir Castor Galindo ${ }^{1}$, Jacqueline de Melo Barcelar ${ }^{1}$, Luciana Alcoforado ${ }^{1}$, Simone Cristina S. Brandão ${ }^{2}$, James B. Fink ${ }^{3}$, Armèle Dornelas de Andrade ${ }^{1}$

${ }^{I}$ Department of Physical Therapy, Universidade Federal de Pernambuco

${ }^{2}$ Departments of Physical Therapy and Nuclear Medicine, Universidade Federal de Pernambuco

${ }^{3}$ Georgia State University, Respiratory Therapy Program

Background: The aim of this study was to compare radio-aerosol deposition and tolerability in normal subjects with 2 breathing patterns, using 2-D planar scintigraphy.

Methods: 6 normal adults, inhaled $1 \mathrm{mCi}$ of $99 \mathrm{mTc}$ - DTPA with normal saline to $0.2 \mathrm{~mL}$ volume, using a novel vibrating mesh inhaler at $7-14 \mathrm{lpm}$ to maximal lung volume (pattern 1) and 5 second inspiration (pattern 2), both with $5 \mathrm{sec}$ breath hold.. Scintigraphy (2D) was used to determine mass balance between compartments.

Results: Inspiration of $0.2 \mathrm{~mL}$ required $2.7 \pm 0.8$ breaths ranged from $10-19 \mathrm{~s}$ with pattern 1 , vs $5.3 \pm 1.5$ breaths with pattern 2 . Subjects (5/6) stated preference for pattern 1. Table shows deposition in compartments as $\%$ of mass balance.

\begin{tabular}{|c|r|r|}
\hline Compartment & Pattern 1 & \multicolumn{1}{c|}{ Pattern 2 } \\
\hline Lung Dose & $71.45 \pm 6.48 \%$ & $62.18 \pm 10.24 \%$ \\
\hline Exhaled Dose & $1.62 \pm 1.06 \%$ & $1.48 \pm 0.31 \%$ \\
\hline Head & $8.92 \pm 5.60 \%$ & $11.38 . \pm 9.68 \%$ \\
\hline Stomach & $2.26 \pm 1.14 \%$ & $2.83 \pm 1.12 \%$ \\
\hline Mouthpiece & $15.47 \pm 4.22 \%$ & $21.86 \pm 7.64 \%$ \\
\hline Device & $0.29 \pm 0.18 \%$ & $0.22 \pm 0.11 \%$ \\
\hline
\end{tabular}

Conclusions: Trend towards higher lung dose and lower mouthpiece deposition in fewer breaths $(\mathrm{p}<0.05)$ with pattern 1 vs 2 . Both patterns were well tolerated with no cough, but subjects preferred pattern 1.

\section{P-282 DEPOSITION OF RADIO-AEROSOL VIA ADULT HIGH FLOW NASAL CANNULA}

James B. Fink ${ }^{1}$, Luciana Alcoforado ${ }^{2}$, Jacqueline Barcelar ${ }^{2}$, Valdecir Galindo ${ }^{2}$, Simone Brandão ${ }^{3}$, Armele Dornelas ${ }^{2}$

${ }^{I}$ Georgia State University, Respiratory Therapy Program

${ }^{2}$ Universidade Federal de Pernambuco, Department of Physiotherapy

${ }^{3}$ Universidate Federal de Pernambuco, Department of Nuclear Medicine

Background: Aerosol delivery with High Flow Nasal Cannula (HFNC) has been described with in vitro models. We wanted to determine feasibility of quantifying radio-aerosol deposition using Mesh Nebulizer (MN) with HFNC in a healthy subject, using 2-D planar scintigraphy with two levels of radiation.

Methods: A normal subject inhaled 99mTc-DTPA with an activity of 0.5 and $1.0 \mathrm{mCi}$ with normal saline to a total dose of $1 \mathrm{~mL}$ in a $\mathrm{MN}$ (Aeroneb Solo; Aerogen Galway, Ireland) placed at the inlet of a heated humidifier with nasal delivery system (Optiflow; F\&P) at $10 \mathrm{lpm}$. Scintigraphy was used to determine radiation deposition in lungs and distribution across compartments.

Results: Total counts were 1045903 and 505189 with 1.0 and $0.5 \mathrm{mCi}$, respectively. Percent of dose deposited across compartments with radiation of 1.0 and $0.5 \mathrm{mCi}$ shown in table.

Conclusions: Lung dose and distribution were consistent with both levels of radiation tested. This feasibility to be followed with in vivo testing at 10,30 and $50 \mathrm{lpm}$ in a larger population.

\begin{tabular}{lrr}
\hline Dose in mCi & 1.0 & 0.5 \\
\% Distribution & & \\
Lung & 15.4 & 15.6 \\
Upper airway & 7.9 & 8.9 \\
Stomach & 0.2 & 0.3 \\
Device & 26.5 & 32.3 \\
Nebulizer & 1.5 & 1.9 \\
Expiratory filter & 33.2 & 22.9 \\
\hline
\end{tabular}




\section{P-283 WHY IS LUNG CANCER NOT TREATED BY INHALATION DRUG DELIVERY?}

Jacob D. McDonald, Philip Kuehl, Matthew Reed, Steve Belinsky

\section{Lovelace Respiratory Research Institute}

Lung cancer currently accounts for $\sim 27 \%$ of all cancer related deaths in the US with 221,000 new cases each year. Inhalation drug delivery enables an increase drug concentration in the lung, which is often the target location for lung cancer treatment. However, to date there are no products approved for the treatment of lung cancer via inhalation delivery. The rationale for not treating lung cancer via inhalation has often included potential for bystander exposure to anticancer agents and inability to treat systemic disease. Therefore a meta analysis of previous data has been conducted to ameliorate these critiques. Analysis of exhaled breath samples during deposition imaging studies have shown that within a particle size range of 0.9 to $3.5 \mu$ m MMAD the exhaled fraction if less than $1 \%$, which can be captured via a simple exhaled breath filter. The critique on the inability to treat systemic disease is based on decreased exposure to the systemic plasma. Inhalation delivery of dry powder camptothecin, dry powder 5-azacytidine and nebulized 5-azacytidine have shown that pulmonary deposited doses of between 3 and 10x lower than systemic doses resulted in similar or increased lung exposure. Additionally each of these formulations displayed significant systemic exposure, which would enable treatment metastatic disease.

\section{P-286 THE DIGITAL PATIENT: THE FUTURE OF MOBILE HEALTH FOR RESPIRATORY PATIENTS}

\author{
Konstantinos Votis ${ }^{1}$, Dimitrios Kikidis ${ }^{1}$, \\ Dimitrios Tzovaras ${ }^{1}$, Omar S Usmani ${ }^{2}$ \\ ${ }^{1}$ Information Technologies Institute, 6th Km \\ Charilaou-Thermi Road, Thessaloniki \\ ${ }^{2}$ Nhli, Imperial College London and Royal \\ Brompton Hospital
}

on the identified gaps, a methodology approach will be presented for the optimisation of respiratory treatment, in particular asthma management, in the digital era.

\section{Environmental/Occupational Health/Toxicology}

\section{P-075 P-GLYCOPROTEIN AND MULTIDRUG RESISTANCE-RELATED PROTEIN 1 ARE FUNCTIONALLY EXPRESSED IN THE HUMAN DISTAL LUNG EPITHELIAL CELL LINE NCI-H441}

Viktoria E. Muchitsch, Carsten Ehrhardt

Trinity College Dublin, School of Pharmacy and Pharmaceutical Sciences

The cell line NCI-H441 has recently been introduced as an in vitro model for studying drug disposition at the distal lung air-blood barrier. Here, we determined levels of expression and function of $\mathrm{P}$ glycoprotein (P-gp) and multidrug resistance-related protein 1 (MRP1) in HCI-H441 cells by immunoblot and confocal laser scanning microscopy (CLSM). Efflux experiments with rhodamin 123 (Rh123, P-gp substrate) and 5,6-carboxyfluorescein-diacetate (CF, MRP1 substrate) were carried out to assess transporter function in vitro. Furthermore, the inhibitory effects of LY-335979 (specific P-gp inhibitor) and MK-571 (specific MRP1 inhibitor) were investigated. Immunoblot provided evidence that NCI-H441 cell monolayers expressed both efflux pumps on protein level. CLSM data confirmed these observations and revealed localisation of the transporters along apical membranes and in perimembranous vesicles. Rh123 and CF were both released from NCI-H441 monolayers in a time-dependent manner. This efflux was inhibited by the relevant modulators. P-gp and MRP1 expression and activity in NCIH441 cell monolayers were found to be consistent with data previously reported from human peripheral lung epithelial cells in primary culture. The use of NCI-H441 cells to investigate efflux pump effects at the air-blood barrier can therefore be recommended.

The wave of digital health is continuously growing and promises to transform the experience of patients. Respiratory medicine is in the centre of these developments, as it has the potential of being benefited by all the components of the digital patient experience. Firstly, mobile health technologies will allow the quantitative measurement of clinical, behavioural and environmental factors in the real life environment, allowing the accurate monitoring of the progression and treatment of respiratory diseases. Furthermore, the creation of strong communication links between patients, their families and the healthcare personnel promises to minimise the dangers connected to exacerbations and also elevate the related social barriers. Finally, the digital patient profile is expected to allow the efficient and safe self-management of respiratory diseases by patients, using the help of smart automated systems and under the supervision of healthcare professionals. The current presentation describes an EU Horizon2020 project; myAirCoach ${ }^{1}$ and its innovative vision for asthma treatment. It will focus on the above three pillars of the digital patient experience, present a technical review of the available solutions and devices, and relate this in particular to the foundation of respiratory management: inhaled drug delivery. Based

\footnotetext{
${ }^{1}$ This project has received funding from the European Union's Horizon 2020 Framework Programme for Research and Innovation under grant agreement no 643607.
}

\section{P-150 AUTOLOGOUS COCULTURE OF HUMAN ALVEOLAR EPITHELIAL CELLS AND MACROPHAGES FOR STUDYING THE EFFECT OF ANTI-INFLAMMATORY AEROSOL MEDICINES}

\author{
Marius Hittinger ${ }^{1}$, Nico Mell ${ }^{2}$, Brigitta Loretz ${ }^{1}$, Hanno Huwer ${ }^{3}$, \\ Nicole Schneider-Daum ${ }^{1}$, Claus-Michael Lehr $^{4}$ \\ ${ }^{1}$ Helmholtz-Institute for Pharmaceutical Research Saarland \\ ${ }^{2}$ Pharmaceutical Technology \\ ${ }^{3}$ Heart Center Voelklingen \\ ${ }^{4}$ Helmholtz-Institute for Pharmaceutical Research Saarland; \\ Pharmaceutical Technology, Pharmbiotec GmbH
}

While alveolar epithelial type I (ATI) cells cover the largest surface area of the air-blood-barrier, alveolar macrophages have important clearance and regulatory functions, especially in the context of particle deposition and inflammatory processes. The aim of the study was to model the interplay of these two cell types and their interaction with aerosol particles in vitro. Human ATII cells and macrophages were isolated from patients undergoing lung resection. The ATII cells were first differentiated to ATI-like cells on a Transwell membrane and characterized by immunohistochemistry. Seeding density was optimized with focus on barrier properties as determined by transepithelial electrical resistance (TEER). Upon formation of a tight epithelial monolayers 
(TEER $>500 \Omega * \mathrm{~cm}^{2}$ ), macrophages from the same donor were added on top of the epithelial cells. Inflammatory response upon stimulation by LPS was quantified by monitoring the secretion of IL-6, TNF $\alpha$ and IL-8.

As a proof of concept, spray-dried IL-10 loaded BSA particles were applied via the Pharmaceutical Aerosol Deposition Device on Cell Cultures onto the inflamed air/liquid coculture. In comparison to treatment with drug-free particles, a significant decrease of inflammatory markers was observed after 24 hours.

In combination with an appropriate deposition device, such coculture model appears as a valuable tool for evaluating the safety and efficacy of anti-inflammatory aerosol medicines under controlled conditions in vitro.

\section{P-153 BERYLLIUM CONCENTRATIONS AT EUROPEAN WORKPLACES: COMPARISON OF "TOTAL" AND INHALABLE PARTICULATE MEASUREMENTS}

\author{
Wolfgang Koch ${ }^{1}$, Heiko Kock ${ }^{1}$, Terence Civic ${ }^{2}$ \\ ${ }^{I}$ Fraunhofer Item, Division of Aerosol Research \\ and Analytical Chemistry \\ ${ }^{2}$ Materion Brush Inc.
}

A field study was carried out in order to derive a factor for the conversion of historic worker exposure data on airborne beryllium (Be) obtained by sampling with the closed faced filter cassette (CFC) "total" particulate method into exposure concentration values to be expected when sampling using the inhalable sampling convention (Gesamtstaubprobenahme, GSP). Workplaces selected to represent the different copper beryllium work processing operations typical for Germany and the EU were monitored revealing a broad spectrum of Be size distributions. 39 personal samples were taken using a CFC and a GSP worn side by side. In addition, 20 static area measurements were carried out with GSP, CFC and Respicon samplers in parallel, the latter one providing information on the extra-thoracic fraction of the workplace aerosol. The study showed that there is a linear relationship between the concentrations measured with the CFC and GSP sampler. The geometric mean value of the ratios of time weighted average concentrations determined from GSP and CFC samples of all personal samples was 2.88 . The individual values covered a range between 1 and 17 related to differences in size Be distributions. This was supported by the area measurements showing that the conversion factor increases with increasing values of the extra-thoracic fraction covering a range between 0 and $79 \%$. The size segregated static samples show that the CFC samples primarily the thoracic fraction.

\section{P-181 DETECTION OF PULMONARY GvHD IN ALLOGENIC STEM CELL TRANSPLANTED PATIENTS WITH AN ELECTRONIC NOSE}

Wilhelm Christian ${ }^{1}$, Jan-Christian Groß ${ }^{2}$, Vogelmeier Claus Franz ${ }^{2}$, Wollmer Ellen ${ }^{1}$, Jörg Ingo Baumbach ${ }^{3}$, Christoph Nell ${ }^{2}$, Akira Hattesohl ${ }^{2}$, Burchert Andreas ${ }^{1}$, Neubauer Andreas ${ }^{1}$, Rembert Koczulla ${ }^{2}$

${ }^{I}$ Department of Haematology and Oncology

${ }^{2}$ Internal Medicine - Pneumology and Critical Care Medicine,

German Center for Lung Research, Philipps-Universität Marburg

${ }^{3}$ Biomedizinzentrum, B\&s Analytik $\mathrm{GmbH}$

Introduction: Pulmonary GvHD is an important and life threatening complication of hematopoetic stem cell transplantation. Histological confirmation is required for definitive diagnosis but is frequently difficult to obtain. Diagnosis is based on clinical symptoms, pulmonary function (PFT), CT scans and especially ruling out of infections. Further diagnostic with bedside based tools might ease early detection and follow up measurements. Here we show results of a non-invasive pulmonary diagnostic tool using an electronic nose (eNOSE, Cyranose 320 ) and the Ion mobility spectromter (IMS, Bioscout TM) for detecting pulmonary GvHD.

Methods: 12 patients with the clinical diagnosis of pulmonary GvHD (pGvHD) were analysed and compared to a group of 16 allogeneic transplanted patients lacking signs of pulmonary impairment (non-pGvHD). Analysis of volatile organic components was done by eNOSE and IMS.

Results: Analyses and comparisons of patients with pGvHD and non-pGvHD have shown by eNOSE an accuracy of $96.3 \%$ (cross validation value of $50.57 \%$ ). Sensitivity was $100 \%$, specificity $91 \%$. The most likely substances measured by IMS are Hexanal and Terpinolen.

Conclusion: This is first data of a small sample collection of patients with and without pulmonary GvHD. Analyses by electronic nose and IMS seem to be in this proof of concept study a useful non invasive tool to underlay the diagnosis of pGvHD and should be further tested and confirmed.

\section{P-190 INCORPORATING MUCUS IN A CELL CULTURE MODEL OF THE CONDUCTING AIRWAYS}

\author{
Xabier Murgia, Cristiane de Souza Carvalho-Wodarz, \\ Claus-Michael Lehr
}

\section{Helmholtz Institute for Pharmaceutical Research Saarland (Hips), Helmholtz Center for Infection Research $(\mathrm{Hzi})$}

The interactions between inhaled particulates and therapeutics with mucus and lung epithelium are important issues in pulmonary research, which are mostly addressed by in vitro models. However available mucus-producing cells need long time in culture to build a mucus layer; nevertheless mucus yield is quite limited. Therefore in this work we incorporate a mucus layer on top of Calu-3 in order to develop a suitable in vitro model resembling both the epithelial and mucus barriers.

Lyophilized pig pulmonary mucus was added for 4 hours to Calu-3 cells grown for 12 days under liquid-liquid conditions (Exogenous Mucus Model, EMM). Mucus-secreting Calu-3 cells grown for 25 days under air-liquid conditions were used as a Native Mucus Model (NMM). In the EMM, cell viability was not compromised as determined by MTT and fluorescein diacetate (FDA) assays. The cellular barrier integrity was also preserved. Transepithelial electrical resistance (TEER) in the EMM was $463 \pm 69 \Omega \mathrm{cm} 2$ similar to the cells without mucus ( $494 \pm 44 \Omega \mathrm{cm} 2$ ). For NMM a confluent mucus layer was only achieved after 25 days and the TEER values were barely around 300 $\Omega \mathrm{cm} 2$. Accordingly, the epithelial permeability to sodium fluorescein was slightly higher in the NMM in comparison to the EMM.

A mucus layer was successfully implemented in Calu-3 cells, yet displaying epithelial barrier properties. The EMM model will further allow the direct comparison between mucus/no mucus conditions.

\section{P-209 PREDICTED LUNG DEPOSITION OF ELECTRONIC CIGARETTE AEROSOLS}

Tomasz Sosnowski

Warsaw University of Technology, Faculty of Chemical and Process Engineering 
Background: Electronic cigarettes (ECs) are relatively novel nicotine delivery devices which are also the sources of inhaled aerosol droplets which health effects are still questionable. This work analyzes ECs in respect of their aerodynamic resistance, droplet size distribution and the predicted total lung deposition as a function of inhalation maneuver.

Methods: Two models of cartomizer-type ECs were tested. Their internal resistance was evaluated based on the pressure drop - volumetric flow curves. Size distribution of the mist released from the EC's mouthpiece was determined by laser spectrometry (Spraytec). These data were used to calculate lung deposition employing the equations proposed by Martin and Finlay (JAM, 2008).

Results: Tested ECs had a very high aerodynamic resistance $\left(1.65 \pm 0.07 \mathrm{mbar}^{0.5} \mathrm{~min} \mathrm{dm}^{-3}\right)$ as compared to a conventional to-

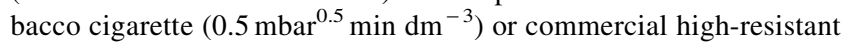
DPIs (e.g., Turbuhaler: $0.13 \mathrm{mbar}^{0.5} \mathrm{~min} \mathrm{dm}^{-3}$ ). Average size of emitted droplets is around $400 \mathrm{~nm}$ (volumetric median). The calculated lung deposition is in the range of 19 to $54 \%$ for various inhalation conditions $(\mathrm{PIF}=4.8-6 \mathrm{~L} / \mathrm{min}$ at $\mathrm{VT}=500-1500 \mathrm{ml})$.

Conclusions: Even the powerful inspiration applied when using ECs results in low flow rates of the aerosol due to the high intrinsic resistance of the device. According to the determined aerosol droplet size, the appreciable mass of the inhaled mist is breathed out.

Acknowledgment: Work supported by NCN grant 2014/13/B/ST8/ 00808 .

\section{P-214 3D CO-CULTURE OF IMMORTALIZED ALVEOLAR TYPE I CELLS AND MACROPHAGES: A NEW IN VITRO MODEL OF THE HUMAN AIR-BLOOD BARRIER FOR PULMONARY DRUG DELIVERY}

\section{Stephanie Kletting, Cristiane Carvalho-Wodarz, Anna Kühn, Nicole Schneider-Daum, Claus-Michael Lehr \\ Helmholtz-Institute for Pharmaceutical Research Saarland; Saarland University, Department of Pharmacy, Biopharmacy and Pharmaceutical Technology}

Within the past decades, pulmonary drug delivery has gained noteworthy attention by offering the possibility to administer drugs in a non-invasive way. However, despite of the large alveolar epithelial surface, it is still a challenge to assess safety and efficacy of inhaled medicines. Besides representative biological systems that are usually based on animal models, several in vitro systems are available that consist of cell lines or primary cells. Nevertheless, there is still a need for models with maintaining cell differentiation and barrier properties. Therefore, we established a 3D in vitro system of the deep lung by cocultivating immortalized alveolar type I cells, expressing functional tight junctions, and macrophage-like cells.

Primary alveolar epithelial cells (hAELVi) were immortalized by using lentiviral vectors. To set-up the co-culture, hAELVi were seeded on previous coated Transwell ${ }^{\circledR}$ membranes and prior differentiated macrophage-like cells (THP-1) were added on top. Monoand co-cultures were evaluated according to transepithelial electrical resistance (TEER) and morphology. hAELVi perform tight barriers in mono (liquid-covered; air-liquid)- and co-culture. THP-1 cells were homogeneously distributed on top of hAELVi, as observed with SEM and CLSM.

Overall, this is a promising in vitro model of the human air-blood barrier, with two important barriers: functional epithelial tight junctions and macrophages, which are essential to assess drug delivery and efficacy.

\section{P-215 TOWARDS A NEW BACTERIAL-EPITHELIAL CELL CO-CULTURE MODEL TO TEST NOVEL DRUG DELIVERY SYSTEMS AGAINST PSEUDOMONAS AERUGINOSA BIOFILMS}

\author{
Jenny Juntke ${ }^{1}$, Nazende Günday Türeli ${ }^{2}$, \\ Cristiane Carvalho-Wodarz ${ }^{1}$, Eva-Marie Prinz ${ }^{2}$, \\ Marc Schneider ${ }^{1}$, Nicole Schneider-Daum ${ }^{1}$, Claus-Michael Lehr ${ }^{1}$ \\ ${ }^{1}$ Helmholtz Institute for Pharmaceutical Research Saarland \\ ${ }^{2}$ Mjr Pharmjet GmbH
}

In the lungs of cystic fibrosis (CF) patients, the thick and sticky mucus offers good growth conditions for bacteria. Especially Pseudomonas aeruginosa, known as the major pathogen in CF, is almost impossible to eradicate once a biofilm is formed. An intriguing approach to overcome drug delivery problems, arising from the thick mucus layer and the biofilm, is the development of nano-scaled drug delivery systems (DDS). For this reason, ciprofloxacin-complex-loaded PLGA nanoparticles (NP) are prepared under controlled conditions by nanoprecipitation using the novel MicroJet Reactor technology. The NP should be able to penetrate the mucus and biofilm, thus releasing the drug in a controlled manner.

To mimic disease relevant conditions in vitro, our aim was to establish a co-culture model of human bronchial epithelial cells with $P$. aeruginosa on top, allowing the formation of a biofilm. The bronchial epithelial cell lines Calu-3 and CFBE41o- were used, representing the healthy and CF-diseased airways, respectively. Once the cells have formed an epithelial barrier they were infected with different amounts of $P$. aeruginosa to identify a critical seeding density of the bacteria which enables biofilm formation and still allows the human cells to survive. This model holds potential for evaluating novel DDS regarding their safety and their ability to disrupt the bacterial biofilm and to reach $P$. aeruginosa.

\section{P-227 BIOKINETIC ACCUMULATION OF NANOPARTICLES (NP) FROM LUNGS TO SECONDARY ORGANS AND TISSUES: CONTRIBUTION OF SYSTEMICALLY TRANSLOCATED NP ACROSS THE AIR-BLOOD BARRIER VERSUS MUCOCILIARY CLEARED, SWALLOWED AND ABSORBED NP ACROSS THE GUT WALLS}

\author{
Wolfgang Kreyling
}

Institute of Epidemiology 2, Helmholtz Center Munich

The translocation kinetics of NP across the lung air-blood barrier (ABB) depends on physicochemical NP characteristics. NP absorption across the gut walls after oral uptake is less well understood and no comparative data of either pathway exist.

Depending on NP parameters like material (gold, $\mathrm{TiO}_{2}$, carbon), size $(1.4-200 \mathrm{~nm})$, shape, protein corona, etc., translocated NP fractions across the $\mathrm{ABB}$ in rodents vary from $<0.1 \%$ to $10 \%$ of the NP deposited in the peripheral lungs with dominating fractions in soft tissue, skeleton and liver. absorption of same parameters NP across the gut walls is usually a factor 5-10 lower. Not only the high NP fraction deposited and rapidly cleared from airways but also long-term macrophage-mediated NP clearance from the alveoli towards the larynx provides a substantial NP transfer to the gut from which a non-negligible NP fraction will be absorbed and enter the circulation. This can contribute up to $10 \%$ of the NP accumulation in selected organs or tissues. Hence, after NP inhalation, accumulations in secondary organs and tissues originate from two routes: NP translocation across the $\mathrm{ABB}$ and NP absorption across the gut epithelium; both needs to be taken into account for a comprehensive risk assessment. 


\section{P-232 CHARACTERISATION OF A HIGH VOLTAGE CORONA CHARGER TO SIMULATE THE AEROSOL CHARGE STATE FOUND NEAR HV POWER LINES}

\author{
Martyn Biddiscombe ${ }^{1}$, James Matthews ${ }^{2}$, Matthew Wright ${ }^{2}$, \\ Richard Underwood ${ }^{1}$, Dudley Shallcross ${ }^{2}$, Denis Henshaw ${ }^{2}$, \\ Sally Meah ${ }^{1}$, Omar S Usmani ${ }^{1}$ \\ ${ }^{I}$ Nhli, Imperial College London and Royal Brompton Hospital \\ ${ }^{2}$ University of Bristol
}

Purpose: Electrostatic charge is an important characteristic of aerosols, which may cause increased particle deposition in the lung upon inhalation. Corona ionisation from HV power lines (HVPL) releases ions into the environment which can electrically charge pollutant aerosol already in the atmosphere, with implications for human health. We are undertaking a human volunteer study to assess whether enhanced ultrafine particle $(<100 \mathrm{~nm})$ deposition occurs at charging levels similar to those seen near HVPL.

Methods: Carbonaceous aerosol particles from a Technegas generator were artificially charged using a custom corona charger and stored in a 15 litre conducting bag for $\sim 20$ minutes to see the effect on particle size and charge. Two Scanning Mobility Particle Sizers (SMPS + C, Grimm) obtained size and mobility distributions and estimated particle charge levels.

Results: Table showing the mean number of electrical charges per particle at $100 \mathrm{~nm}(\mathrm{n})$ and geometric mean particle diameter (GMD, $\mathrm{nm}$ ) with the corona charger on (Positive) or off (Charge Neutral). Geometric standard deviations were 1.64-1.71.

Conclusion: The corona charger produces particle charge levels of the order expected near HVPL. The paper will present further characterisation of the aerosol generation, charging and delivery system for use in the human volunteer study.

\begin{tabular}{llll}
\hline Charge Neutral & & & Positive \\
$n$ & GMD & $n$ & GMD \\
& $(\mathrm{nm})$ & & $(\mathrm{nm})$ \\
\hline-0.06 & 97 & 1.32 & 110 \\
-0.01 & 103 & 1.35 & 111 \\
-0.01 & 133 & 1.44 & 109 \\
0.08 & 96 & 1.43 & 115 \\
0.01 & 112 & 1.30 & 139 \\
0.02 & 113 & 1.56 & 97 \\
-0.05 & 135 & 1.23 & 124 \\
& & 1.24 & 114 \\
& & 1.09 & 132 \\
\hline
\end{tabular}

\section{P-237 CAN A HUMAN 3D IN VITRO LUNG MODEL BE CONSIDERED AS A PREDICTIVE TOOL FOR INHALATION TOXICOLOGY?}

Carola Endes ${ }^{1}$, Craig Poland ${ }^{2}$, Rodger Duffin ${ }^{3}$, Roel Schins ${ }^{4}$, Alke Petri-Fink ${ }^{1}$, Barbara Rothen-Rutishauser ${ }^{1}$, Martin Clift ${ }^{1}$

\footnotetext{
${ }^{I}$ University of Fribourg, Adolphe Merkle Institute ${ }^{2}$ Institute of Occupational Medicine ${ }^{3}$ Uoe/Mrc Centre for Inflammation Research, The Queen's Medical Research Institute ${ }^{4}$ Iuf Düsseldorf
}

A potential alternative to replace animal experimentations in the field of inhalation particle toxicology is offered by an established and optimized 3D in vitro triple cell co-culture model of the human alveolar tissue barrier cultured at the air-liquid interface. However, due to the acute life-span of this model, it is not possible to assess long-term particulate-induced effects. Nonetheless, via gene expression profiling it is perceived that long-term hazards can be elucidated in vitro by determination of early-response genes. The objective of this study therefore, is to determine the potential of the $3 \mathrm{D}$ in vitro lung model as a predicative tool for the long-term particle-induced inhalatory effects that occur in vivo by using specific pathway analysis. To achieve this, crystalline quartz (DQ12) will be employed as a model particulate due to its known inflammogenic and fibrotic nature in vivo. Specifically, in vitro cell co-cultures will be exposed to aerosolized DQ12 at deposited doses up to $2.5 \mu \mathrm{g} / \mathrm{cm}^{2}$ and analyzed over a $72 \mathrm{~h}$ post-exposure period. Investigation of specific endpoint markers for a (pro-)inflammatory response $(I L-1 \alpha / \beta$, $I L-6, I L-8)$, apoptosis $(C A S P 8, F A S L)$ and oxidative stress $(C A T$, $P R D X)$, as well as (pro-)fibrotic events $(M M P 8, A P-1)$ will be performed via quantitative real-time polymer-chain reaction array. The findings from this study will provide essential insight towards the progression and use of alternative, in vitro models for inhalatory hazard assessment.

\section{P-240 A LAB SCALE MEASUREMENT TECHNIQUE FOR THE AIR-LIQUID INTERFACE EXPOSURE OF HUMAN LUNG CELL CULTURES TOWARDS AIRBORNE NANOPARTICLES}

\author{
Sonja Mülhopt ${ }^{1}$, Silvia Diabate ${ }^{2}$, Christoph Schlager ${ }^{1}$, \\ Marco Dilger ${ }^{2}$, Tobias Krebs ${ }^{3}$, Hanns-Rudolf Paur ${ }^{1}$, \\ Carsten Weiss $^{2}$ \\ ${ }^{1}$ Karlsruhe Institute of Technology, Institute \\ for Technical Chemistry \\ ${ }^{2}$ Karlsruhe Institute of Technology, Institute of Toxicology \\ and Genetics \\ ${ }^{3}$ Vitrocell Systems $\mathrm{GmbH}$
}

Most in vitro studies on aerosol health effects rely on submerged exposure of collected particulate matter, suspended in culture medium. However, this method does not represent the actual physiological processes in the human lung. It even may change the properties of the investigated aerosol. Research at the air liquid interface avoids these disadvantages, but requires a well-engineered system to guarantee reproducible conditions. Therefore, KIT and VITROCELL Systems developed a fully automated Exposure Station. It offers a lab scale measurement technique for parallel exposure of up to 24 human lung cell cultures towards aerosols. The exposure station provides direct aerosol sampling via a size selective inlet, a control system for flow, temperature, and humidity to simulate the conditions in the human lung and a programmable controller leading the user through standard exposure protocols while recording all data. The deposited particle dose is monitored online. An internal negative control using humidified synthetic air is implemented as well as an electrostatic particle deposition to increase the particle dose per time. Several measurement campaigns were successfully performed with these systems: Aerosols from biomass heating and aerosolised industrial nanoparticles were characterised using classical toxicological methods, e.g., cytotoxicity and metabolic activity, as well as state-of-the-art -omics methods. 


\section{P-268 INTERFACIAL EFFECTS OF SUB-MICRON PARTICLES DEPOSITED ONTO LUNG SURFACTANT FILMS}

\author{
Amir Farnoud $^{1}$, Jennifer Fiegel ${ }^{2}$ \\ ${ }^{1}$ University of Iowa, Department of Chemical and Biochemical \\ Engineering \\ ${ }^{2}$ University of Iowa, Department of Chemical and Biochemical \\ Engineering, Department of Pharmaceutical Sciences and
} Experimental Therapeutics

Pulmonary surfactant plays an important role in lung stability, thus changes to surfactant properties could lead to negative health outcomes. Loss of surfactant function has been reported upon interaction of various particle types with the lung surfactant films. However, little is known about particle-surfactant interactions when dry particles are aerosolized and deposited onto surfactant films. Thus the present study sought to examine particle-surfactant interactions after exposing lung surfactant films to aerosolized particles.

Surfactant films of dipalmitoyl phosphatidylcholine (DPPC) and Infasurf (calf lung surfactant extract) were spread in a Langmuir trough and their dynamic surface tension was probed using a Wilhelmy plate balance. A Dry Powder Insufflator ${ }^{\mathrm{TM}}$ was used to aerosolize $200 \mathrm{~nm}$ polystyrene particles, which settled and deposited onto the surfactant films. Following exposure to particles, surfactant films were subjected to two modes of surface area changes: 1. Surface compression until film collapse and 2. Compression and expansion within the range of physiologically relevant surface tension values to mimic breathing cycles.

In film collapse experiments, particle deposition led to slight changes in collapse surface pressure and surface area of both surfactants. In the lung relevant surface tension range, particles induced a significant increase $(\sim 20 \mathrm{mN} / \mathrm{m})$ in the minimum surface tension achieved with the DPPC films, which persisted throughout the compression-expansion cycles. In contrast, Infasurf films regained normal functionality within 5 cycles, suggesting that Infasurf films are more stable than DPPC in response to particle exposure.

\section{Imaging, Modelling \& Physiology of Aerosols in the Lung}

\section{P-017 AEROSOL BOLUS INHALATIONS IN HEALTHY AND COPD SUBJECTS}

Chantal Darquenne ${ }^{1}$, Wayne J. Lamm ${ }^{2}$, Janelle M. Fine ${ }^{1}$, Richard A. Corley ${ }^{3}$, Robb W. Glenny ${ }^{4}$

${ }^{I}$ Dept. Medicine, University of California, San Diego

${ }^{2}$ Dept. Medicine, University of Washington

${ }^{3}$ Pacific Northwest National Laboratory

${ }^{4}$ Dept. Medicine, University of Washington, Dept. Physiology and Biophysics, University of Washington

Despite substantial development of sophisticated subject-specific computational models of aerosol transport and deposition in human lungs, experimental validation of predictions from these new models is sparse. We performed bolus inhalations of $1 \mu \mathrm{m}$-diameter particles in 7 healthy subjects and 6 COPD subjects $\left(\mathrm{FEV}_{1}=50-80 \%\right.$ pred $)$ in the supine posture at a flow rate of $0.5 \mathrm{~L} / \mathrm{s}$ and penetration volumes $\left(\mathrm{V}_{\mathrm{p}}\right)$ ranging 200-1200 mL. Aerosol bolus dispersion (H), deposition (DE), and mode shift (MS) were calculated from these data. There was no significant difference in DE between subject groups. Yet, the rate of increase in $\mathrm{H}$ with increasing $\mathrm{V}_{\mathrm{p}}$ was higher in the COPD than in the healthy subjects $(0.798 \pm 0.205$ vs. $0.527 \pm 0.122 \mathrm{~mL} / \mathrm{mL}$, mean $\pm \mathrm{SD}$, $\mathrm{p}=0.01$ ), indicating larger ventilation inhomogeneities in the COPD than in the healthy group. The rate of decrease in MS as a function of $\mathrm{V}_{\mathrm{p}}$ was also significantly larger in the COPD subjects than in the healthy volunteers $(-0.271 \pm 0.129$ vs. $-0.145 \pm 0.076 \mathrm{~mL} / \mathrm{mL}, \mathrm{p}=0.05)$, denoting increased flow sequencing in the COPD compared to the healthy group. In conclusion, in the supine posture, deposition appears to lack sensitivity for assessing the effect of lung morphometry and/or ventilation distribution alteration induced by mild-to-moderate lung disease on the fate of inhaled aerosols. However, other parameters such as aerosol bolus dispersion and mode shift may be more sensitive parameters for evaluating lung models with moderate disease.

\section{P-031 EFFECTS OF THE INHALATIONS OF ICS, LABA AND LAMA ON DIAPHRAGM MUSCLE CONTRACTION}

\author{
Chiyohiko Shindoh ${ }^{1}$, Kazunobu Yamaguchi ${ }^{2}$, Yurina Kato ${ }^{1}$, \\ Hiroshi Takano ${ }^{3}$, Masahito Miura ${ }^{1}$ \\ ${ }^{I}$ Tohoku University Graduate School of Medicine \\ ${ }^{2}$ Tohoku University Graduate School of Medicine; Astrazeneca K.K. \\ ${ }^{3}$ Doshisha University
}

Introduction: It is still unknown whether ICS, LABA and LAMA influence diaphragm muscle contractility and whether such inhalation has a protective effect against endotoxin-induced diaphragm muscle deterioration.

Methods: We examined the effects of each inhalation with ICS, LABA, and LAMA separately, with endotoxin intra-peritoneal injection, and with inhalation plus endotoxin injection on diaphragm contractile properties and nitric oxide (NO) production during a 4-h period, using mice. The dissected diaphragm muscle of each group was mounted in an organ chamber, and force/frequency (F/f) curves were measured by electronic stimulation with a programmed computer. NADPH-diaphorase histochemistry was performed to assess NO production.

Results: The ICS did not significantly shift the F/f curves; however, the LABA significantly shifted those curves upward compared with shams at $1 \mathrm{~h}, 2 \mathrm{~h}$, and at $4 \mathrm{~h}$ after inhalation. Although the endotoxin decreased $\mathrm{F} / \mathrm{f}$ curves at $4 \mathrm{~h}$ and induced $\mathrm{NO}$, the endotoxin plus either ICS or LABA prevented downward shifts of the F/f curves and inhibited NO. With LAMA, the F/f curve shifted upward at $4 \mathrm{~h}$ rather than immediately after inhalation. The F/f curve of endotoxin plus LAMA also prevented a downward shift in endotoxin and NO.

Conclusions: These results indicate that the inhalation of LABA or LAMA potentiates diaphragm muscle contractility and that both types of inhalation inhibited NO production induced by endotoxin injection.

\section{P-065 AN IDEALIZED THROAT WITH FACE FOR FACEMASK TESTING}

\author{
Travis MacLean ${ }^{1}$, John Chen ${ }^{1}$, Andrew R. Martin ${ }^{2}$, \\ Warren H. Finlay ${ }^{1}$ \\ ${ }^{1}$ Department of Mechanical Engineering, University of Alberta \\ ${ }^{2}$ University of Alberta
}

Background: The Alberta Idealized Throat (AIT) accurately mimics average extrathoracic deposition of orally inhaled aerosols in adults. Here, we extend this model to aerosol delivery via facemask by assessing lung (filter) deposition for three jet nebulizer-facemask systems.

Methods: A face model was created from ten MRI scans and attached to two throat models: the original AIT and a modified AIT that 
smoothly transitions to the vertically oriented face. Testing was done using the PARI LC Sprint $(\mathrm{n}=5)$ with PARI Vios Compressor under humidified $(\mathrm{RH}=78 \pm 4 \%)$ and dry $(\mathrm{RH}=4 \pm 1 \%)$ conditions. The Salter 8900 Series $(n=5)$ and Westmed VixOne $(n=5)$ were also tested using 8 LPM flow rates, modified AIT and humidified conditions. All tests were done using $2.5 \mathrm{ml}$ Salbutamol $(1 \mathrm{mg} / \mathrm{ml}), 5$ minute nebulization times and breathing profile with $\mathrm{TV}=383 \mathrm{ml}, \mathrm{f}=16.6$ breaths/min and $\mathrm{I} / \mathrm{E}=0.727$ (Tobin, Chest, 1983; 84: 286-294). Deposited salbutamol was assayed and ANOVA $(\mathrm{p}=0.05)$ was used to compare results.

Results: No significant deposition difference was shown between the original and modified throat or between humidity levels. Testing of the LC Sprint, Salter 8900 and VixOne resulted in filter deposition of $281 \pm 45 \mu \mathrm{g}, 182 \pm 23 \mu \mathrm{g}$ and $258 \pm 57 \mu \mathrm{g}$ and throat deposition of $61 \pm 27 \mu \mathrm{g}, \quad 62 \pm 19 \mu \mathrm{g}$ and $35 \pm 11 \mu \mathrm{g}$ salbutamol, respectively $(\mathrm{AVG} \pm \mathrm{SD})$.

Conclusions: Similar throat model performance suggests the modified AIT can be used in place of the original for testing oral inhalation from facemask systems.

\section{P-070 REGIONAL VENTILATION AND AEROSOL DEPOSITION IN THE LUNG UNDER HELIUM-OXYGEN BREATHING}

Jose Venegas $^{1}$, Elliot Greenblatt ${ }^{2}$, Vanessa Jane Kelly ${ }^{1}$, Tilo Winkler ${ }^{1}$, Mamary Kone ${ }^{1}$, Ira Katz ${ }^{3}$, Andrew R. Martin ${ }^{4}$, Georges Caillibotte ${ }^{5}$, Dean Hess ${ }^{1}$, Robert Scott Harris ${ }^{1}$

${ }^{1}$ Massachusetts General Hospital and Harvard Medical School, Boston, MA, USA

${ }^{2}$ Massachusetts Institute of Technology, Boston, MA, Usa; Massachusetts General Hospital and Harvard Medical School, Boston, MA, USA

${ }^{3} R \& D$ Medical, Air Liquide Santé International, Les-Loges-

En-Josas, France; Department of Mechanical Engineering, Lafayette College, Easton, Pa, USA

${ }^{4}$ University of Alberta

${ }^{5} R \& D$ Medical, Air Liquide Santé International, Les-LogesEn-Josas, France

Abstract: Theoretical models suggest that replacing air with $\mathrm{He}-\mathrm{O}_{2}$ as carrier gas may lead to more homogenous ventilation and aerosol deposition. However, clinical results are inconsistent and it is unclear why subjects may or may not respond to $\mathrm{He}-\mathrm{O}_{2}$. Our aims were: 1 ) to acquire 3D-imaging data with PET-CT to provide realistic boundary conditions for future models, and 2) to compare results with $\mathrm{He}-\mathrm{O}_{2}$ against those with air (see Greenblatt Abstract).

Methods: Mean-normalized-values of lobar specific deposition $s D^{*}$ and ventilation $s V^{*}$ were measured and factors affecting $s D^{*}$ lobar-distribution estimated along with effects of breathing frequency $f_{\mathrm{N}}$ and mean lobar parenchymal-expansion $F_{V O L}$.

Results: 3D-images of $\mathrm{sD}^{*}$ and $\mathrm{sV}^{*}$ were obtained in 10 bronchoconstricted-asthmatics breathing $\mathrm{HeO}_{2}$. Lobar $s D^{*}$ and $s V^{*}$ varied greatly among lobes and subjects and their average distribution were not different with those in air. In both $\mathrm{He}-\mathrm{O}_{2}$ and air, airways leading to upper lobes showed higher aerosol escape-fractions than those to lower lobes. There were more lobes with $s V^{*}$ and $s D^{*}$ closer to unity in $\mathrm{He}-\mathrm{O}_{2}$ than air. In subjects with uneven aerosol deposition the $s V^{*}$ $s D^{*}$ correlation was higher $(\mathrm{p}<0.05)$ in $\mathrm{He}_{-} \mathrm{O}_{2}(0.84+/-0.8)$ than air $(0.55+/-0.28)$. In $\mathrm{He}-\mathrm{O}_{2} f_{\mathrm{N}}$ and $F_{V O L}$ had no effects in the $\mathrm{sD}^{*} \mathrm{sV}^{*}$ correlation or the $\mathrm{sD}^{*} / \mathrm{sV} *$ distributions.

Conclusion: Within this sample of mild-to-moderate asthmatics breathing $\mathrm{He}-\mathrm{O}_{2}$ there were subjects with the tendency for more uniform $s D^{*}$ or $s V^{*}$ distributions. Studies using these $3 \mathrm{D}$ data as input to personalized CFD models may provide a clearer understanding of when and for whom breathing $\mathrm{He}-\mathrm{O}_{2}$ during aerosol inhalation may be beneficial.

\section{P-071 PULMONARY ACINAR PARTICLE TRANSPORT: IMPLICATIONS FOR TARGETED DRUG DELIVERY}

\author{
Philipp Hofemeier, Josué Sznitman
}

Department of Biomedical Engineering, Technion - Israel Institute of Technology

The respiratory region of the lung with its large surface area and thin air-blood barrier represents an attractive and non-invasive pathway for systemic drug delivery. To date, it is widely acknowledged that inhaled particles ranging from 0.001 to $10 \mu \mathrm{m}$ are able to reach and deposit in the alveolated regions of the lungs. However, little is known about the local transport dynamics and deposition mechanisms of (ultra)fine particles affected by diffusion, convection and sedimentation. Using computational fluid dynamics (CFD) simulations, we shed some light on the local transport characteristics of inhaled aerosols in the acinar region with an outlook on implications for systemic drug delivery. We simulate particle transport and deposition in anatomically inspired networks of acinar airways under the combined affect of diffusion, convection and sedimentation. We aim to characterize the impact of a wide range of particle sizes under selective inhalation manoeuvres on various deposition metrics including deposition efficiency, particle residence time and surface dose. Our findings underline that a precise understanding of acinar aerosol transport, and ultrafine particles in particular, is paramount for estimating the deposition efficiencies and local outcomes of inhaled aerosols.

\section{P-073 TRANSPORT AND DEPOSITION OF NON- SPHERICAL AEROSOLS IN PULMONARY ACINAR FLOWS}

\author{
Lihi Shachar Berman, Yan Ostrovski, Josue Sznitman
}

\section{Technion}

Most airborne particles are intrinsically non-spherical. In particular, non-spherical particles with high aspect ratios, such as fibers, are acknowledged to be more hazardous than their spherical counterparts due to their ability to penetrate into deeper lung regions, and thus potentially causing serious pulmonary diseases such as fibrosis of the lung tissue, asbestosis and cancer. Not only do traditional particle properties such as size, shape, and density have a major impact on particle transport, for non-spherical aerosols, their orientations also greatly influence particle trajectories due to modified lift and drag characteristics. Until present, however, most of our understanding of the dynamics of inhaled particles in the deep airways of the lungs has been limited to spherical particles only. In the present work, we seek to quantify through numerical simulations the transport characteristics of non-spherical airborne particles and their deposition under respiratory oscillatory flows representative of airflows in acinar airways. Here, the Euler-Lagrangian model is used to solve the translational movement of a fiber, whereas the Eulerian rotational equations are introduced and solved to predict detailed unsteady fiber orientations. Overall, our efforts aim to shed some light on the intrinsic motion of fibers that leads to aerosol deposition patterns in the respiratory alveolated regions of the lungs and its association with the development of deep airways diseases. 


\section{P-076 ELECTROSTATIC CHARGE CHARACTERISTICS OF AEROSOLS GENERATED BY JET AND ULTRASONIC NEBULIZERS}

Adel Hashish

Dept of Physics, Faculty of Science, Uae University

When a liquid surface is disrupted by nebulization, electrical charge is separated, which may be in the form of charged droplets or free ions. Little work has been reported on the electrostatic characteristics of aerosol generated by clinical nebulizers. The electrostatic charge properties of aerosol droplets produced by Pulmasonic Ultrasonic Nebulizer (UN) and an Inspiron Jet Nebulizer (JN) were studied using a purpose-built mobility analyzer and an independent total charge monitor. The aerosols generated using both JN and UN was invariably charged. It was found that the level of electrostatic charge on droplets generated by UN was significantly less than that produced by JN. The results confirmed the presence of charge of both polarities in each case, but more negative charge was produced with Inspiron JN than the Pulmasonic UN. Solution conductivity (which increases with electrolyte concentration) may play an important part in ion production. For $\mathrm{JN}$ the charge-to-mass ratio increased with the drive-flow rate. For UN, charge-to-mass ratio varied in a random way. The JN as well as UN can be modified using an auxiliary corona electrode to manipulate the level of charge on droplets.

\section{P-084 1D SIMULATIONS OF AEROSOL DEPOSITION WITHIN HEALTHY HUMANS, USING INDIVIDUALIZED DESCRIPTION OF BOTH CONDUCTIVE AND PULMONARY REGIONS OF THE LUNGS}

\author{
Marine Pichelin ${ }^{1}$, Brun Florian ${ }^{2}$, Ira Katz ${ }^{3}$, Caroline Majoral ${ }^{1}$, \\ Spyridon Montesantos ${ }^{1}$, Cécile Dubau ${ }^{1}$, John Fleming ${ }^{4}$, \\ Conway Joy ${ }^{5}$, Georges Caillibotte ${ }^{3}$ \\ ${ }^{1}$ Air Liquide Santé International, Medical $R \& D$ \\ ${ }^{2}$ University of Bourgogne, Migs Department \\ ${ }^{3} R \& D$ Medical, Air Liquide Santé International, Les-Loges- \\ En-Josas, France; Department of Mechanical Engineering, \\ Lafayette College, Easton, PA, USA \\ ${ }^{4}$ Southampton Respiratory Nihr Biomedical Research Unit; \\ University Hospital Southampton NHS Foundation Trust \\ ${ }^{5}$ National Institute of Health Research Biomedical Research \\ Unit in Respiratory Disease, Southampton, Faculty of Health \\ Sciences, University of Southampton, Southampton
}

An analytical tool was used to mimic aerosol inhalation experiments on healthy adult male subjects, simulating particle deposition within the lungs for two aerosols (MMAD $=5.3 \mu \mathrm{m}$ and $3.1 \mu \mathrm{m}$ ). Simulations were performed using individualized asymmetric lung morphologies based on subject's morphometric data extracted from High Resolution Computed Tomography images (e.g., length and diameter of the first airway generations), completed for deeper conductive generations by asymmetric subtrees propagated within each lobar volume. Pulmonary symmetric subtrees were then generated, for each subject, based on statistical considerations from literature and specific data extracted from the medical images. Comparisons with experimental measurements have been done for tracheo-bronchial and pulmonary (PU) deposition, based on 2D gamma camera acquisitions just after inhalation and after $24 \mathrm{~h}$. The mean computed PU deposition fraction as percentage of inhaled was $15.2 \pm 2.0$ for the large aerosol $(n=7)$ and $22.5 \pm 4.8$ for the small aerosol $(n=4)$ vs. respectively $17.2 \pm 2.2$ and $28.5 \pm 4.0$ from experiments. These results are in better agreement with measured data than those obtained with symmetric conductive subtrees and pulmonary region based on Soong model, i.e. $12.5 \pm 1.9$ and $18.7 \pm 4.6$ for large and small aerosol respectively. This preliminary work highlights the need for individualized description of the respiratory tract and will serve as a basis for simulation in pathological lungs.

\section{P-096 RESPIMAT ${ }^{\circledR}$ SOFT MIST ${ }^{\mathrm{TM}}$ INHALER SHOWS HIGHER IN VITRO DEPOSITION PERFORMANCE COMPARED TO OTHER COPD INHALERS}

\author{
Anna-Maria Ciciliani ${ }^{1}$, Herbert Wachtel ${ }^{2}$, Peter Langguth ${ }^{1}$ \\ ${ }^{1}$ Johannes Gutenberg University, Institute \\ of Pharmacy and Biochemistry \\ ${ }^{2}$ Boehringer Ingelheim Pharma GmbH \& Co. \\ Kg, Analytical Development
}

The Spiriva ${ }^{\circledR}$ Respimat ${ }^{\circledR}$ Soft Mist ${ }^{\mathrm{TM}}$ inhaler has been compared to other COPD inhalers like Seebri ${ }^{\circledR}$ Breezhaler $^{\circledR}$, Eklira ${ }^{\circledR}$ Genuair $^{\circledR}$, and Relvar $^{\circledR}$ Ellipta $^{\circledR}$ in terms of their predicted lung deposition and handling properties. A combination of in-vitro throat deposition data with in-silico (via computer) lung deposition simulations were used to assess their predicted lung deposition. The particle size distributions at the exit of the throat model were determined and used for the following lung deposition simulation.

The in-vitro and in-silico results showed that Respimat ${ }^{\circledR}$ had the lowest predicted throat deposition (27-34\% nominal dose) and at the same time the highest simulated lung deposition (60-70\% nominal dose) compared to the other COPD inhalers. The in-silico lung deposition of Respimat was superior in all simulated lung regions including the periphery.

We determined the capabilities of typical patients by quantifying the handling forces and torques provided by patients at ease and with maximum power. These values are compared with the necessary forces (e.g. Respimat $^{\circledR}$ release button: $12+/-2 \mathrm{~N}, \mathrm{n}=10$ ) required for device operation.

Based on in-silico deposition simulations, Respimat ${ }^{\circledR}$ demonstrated higher lung and lower throat deposition compared to other COPD inhalers and good usability as indicated by operating forces.

Ralf Kröger (ANSYS Germany) provided help concerning CFD.

\section{P-097 FORCE ON A POINT CHARGE IN A GROUNDED CYLINDER AND ITS USE FOR DETERMINING AEROSOL DEPOSITION IN LUNG AIRWAYS}

\author{
Adel Hashish ${ }^{1}$, Trevor Williams ${ }^{2}$, Adrian Bailey ${ }^{2}$ \\ ${ }^{1}$ Dept of Physics, Faculty of Science, Uae University \\ ${ }^{2}$ Formerly of Applied Electrostatics Research Group, \\ Department of Electrical Engineering, University of Southampton
}

The aim of this work is to present a solution for the force acting on a point charge in a grounded, conducting cylinder, allowing the deposition efficiency of charged aerosol particles in lung airways to be specified for use in a computer model to calculate lung deposition. A valid force expression cannot be obtained for cylinders using the method of images though may still be referred to as an "image" force to distinguish it from space-charge effects. An expression for finite cylinders is derived from a potential function involving a double infinite summation and modified Bessel functions. To avoid the complication of 
axial dependence, a solution is developed for an infinitely long cylinder by transforming one of the summations into an integral. The solution then depends only on the radial position of the point charge and is virtually equivalent to the simple force expression for spherical geometry that can be derived by the method of images. Deposition efficiency can then be determined by simple integration whereas numerical integration would be required for the exact solution.

\section{P-100 NEW ANALYSIS TOOLS FOR 3D DEPOSITION IMAGES}

\author{
Alaeddine Chibani ${ }^{1}$, Ira Katz ${ }^{2}$, Lea Itmi ${ }^{1}$, Marine Pichelin ${ }^{1}$, \\ Cecile Dubau ${ }^{1}$, Spyridon Montesantos ${ }^{1}$, Elliot Greenblatt ${ }^{3}$, \\ Jose G. Venegas ${ }^{3}$, Georges Caillibotte ${ }^{1}$ \\ ${ }^{1} R \& D$ Medical, Air Liquide Santé International, \\ Les-Loges-En-Josas \\ ${ }^{2} R \& D$ Medical, Air Liquide Santé International, \\ Les-Loges-En-Josas, France; Department of Mechanical \\ Engineering, Lafayette \\ College, Easton, PA, USA \\ ${ }^{3}$ Department of Anesthesia (Bioengineering), Mgh/Harvard, \\ Boston, MA, USA
}

It is common in the analysis of $2 \mathrm{D}$ and $3 \mathrm{D}$ images of aerosol deposition to reduce the complex interaction of physics and lung morphology to a single scalar measure, the central-to-peripheral ratio (or the equivalents outer-to-inner ratio and penetration fraction). But clearly as the number and quality of images available has increased the heterogeneous complexity of deposition patterns has become apparent (e.g., lobar differences, hot spots); thus this single scalar measure loses much of the potential information contained in the images. Presumably this loss of information could also impact the pharmaceutical development or clinical use of this data. For this reason our team has investigated new analysis tools for 3D medical images of deposition distribution including: group analysis, coefficient of variation (COV), and skewness and kurtosis of local activity histograms. These tools are described and demonstrated on images from a positron emission tomography (PET) study of challenged asthmatics inhaling aerosol with air or helium-oxygen mixture. The COV of deposition tended to be lower, but not significantly, in helium-oxygen breathing subjects than when breathing air. The number of groups derived from the group analysis for helium-oxygen subjects was also less. These results suggest that the aerosol deposition distributions in the helium-oxygen subjects may be less patchy than for those subjects breathing air.

\section{P-107 FACTORS AFFECTING SPATIAL HETEROGENEITY IN AEROSOL DEPOSITION: A QUANTITATIVE IMAGING STUDY}

Elliot Greenblatt ${ }^{1}$, Tilo Winkler ${ }^{1}$, Robert Scott Harris ${ }^{1}$, Vanessa Jane Kelly ${ }^{1}$, Mamary Kone ${ }^{1}$, Ira Katz ${ }^{2}$, Andrew R. Martin ${ }^{3}$, Georges Caillibotte ${ }^{2}$, Jose Venegas ${ }^{1}$

\footnotetext{
${ }^{1}$ Massachusetts General Hospital and Harvard Medical School, Boston

${ }^{2} R \& D$ Medical, Air Liquide Santé International, Les-Loges-En-Josas, France; Department of Mechanical Engineering, Lafayette

College, Easton, PA, USA

${ }^{3}$ University of Alberta
}

Aerosol deposition in lung disease has been shown to be vary among lung regions and among subjects. Here we identify a set of factors contributing to that variability and quantify them using 3D images obtained with PET-CT.

Methods: After a $\mathrm{PC}_{20}$ methacholine-challenge, we measured mean-normalized peripheral lobar deposition $s D^{*}$ and ventilation $s V^{*}$ (per unit volume), mean lobar-expansion $F_{v o l}$ and breathing frequency $f_{\mathrm{N}}$ in 12 asthmatics. We formulated a theoretical framework describing 4 factors affecting lobar $s D^{*}: s V^{*}$, air-to-aerosol split at bifurcations $\Pi_{B} *$, aerosol escape from central-airways $\Pi_{E} *$, and regional fraction of exhaled aerosol. This last factor was not experimentally measured and values are reported assuming full peripheral retention of aerosol.

Results: $s D^{*}$ variability explained by $s V^{*}\left(\mathrm{R}^{2}=0.38\right), \Pi_{B} *$ $\left(\mathrm{R}^{2}=0.38\right)$ and $\Pi_{E}^{*},\left(\mathrm{R}^{2}=0.31\right) . f_{\mathrm{N}}$ and $F_{v o l}$ modulated correlations on a subject-by-subject basis: a) In low- $f_{\mathrm{N}}$-subjects, $\operatorname{corr}\left(s V^{*}, s D^{*}\right)$ was high but weakened in high- $f_{\mathrm{N}}$-subjects, b) lobar $F_{\text {vol }}$ positively affected lobar $s D^{*} / s V^{*}$ ratios in low- $f_{\mathrm{N}}$-subjects and negatively in high$f_{\mathrm{N}}$-subjects. Differences in lobar $F_{\text {vol }}$ from two static-CT-scans, a proxy for lobar ventilation, failed to explain $s D^{*}$.

Conclusions: The proposed theoretical framework allows a regional description of 3D aerosol deposition that can be compared with predictions from theoretical models. A dynamic measure of ventilation is required to simulate aerosol transport and deposition in diseased lungs. The mechanisms behind the identified effects of $f_{\mathrm{N}}$ and $F_{v o l}$ on aerosol deposition need further study as they may be related to aerosol settling and have important implications for aerosol therapy in subjects with heterogeneous ventilation.

\section{P-109 IS THE DEPOSITED DOSE IN AN AIR-LIQUID- INTERFACE EXPOSURE SYSTEM COMPARABLE TO THE HUMAN LUNGS?}

\author{
Erwin $\operatorname{Karg}^{1}$, George A. Ferron ${ }^{1}$, Sonja Mülhopt ${ }^{2}$, \\ Hanns-Rudolf Paur ${ }^{2}$, Ralf Zimmermann ${ }^{3}$ \\ ${ }^{1}$ Helmholtz, Zentrum München, Cooperation Group \\ "comprehensive Molecular Analytics" \\ ${ }^{2}$ Karlsruhe Institute of Technology \\ ${ }^{3}$ University of Rostock, Rostock
}

Cell lines are frequently used to test the toxicity of aerosol particles. Their exposure in a technical system at the air-liquid-interface (ALI) is considered as the most realistic method to mimic the situation in human lungs, i.e. in the respiratory tract including the alveoli (RT) Particle deposition, however, considerably differs between RT and ALI, mainly due to airway geometry.

To compare the deposited dose at the ALI and in the RT, the deposition probability per surface area (DPA) was calculated using computer models from literature. For the RT, a lung deposition model was employed, which gives information on both the regional deposition probability and the corresponding airway surface area.

The calculations revealed the DPA at the ALI being higher by a factor of 4-5 decades compared to the alveolar region. The reason for this is the large alveolar surface area with tens of square metres compared to several square centimetres at the ALI. In the bronchial region, however, the DPA at the ALI was found to be higher by a factor of 2-10 and therefore better comparable.

In conclusion, an ALI exposure over some minutes mimics the cumulated alveolar dose of days; therefore, the ALI exposure duration can be kept short. On the other hand, as DPA and exposure duration are similar for both ALI and bronchial airways, bronchial cell lines should be preferred in ALI exposure experiments. 


\section{P-125 SURFACE MODIFIED GOLD NANOPARTICLES TO SPECIFICALLY TARGET LUNG IMMUNE CELLS IN VITRO}

\author{
Kleanthis Fytianos ${ }^{1}$, Laura Rordriguez-Lorenzo ${ }^{1}$, Fabian Blank ${ }^{2}$, \\ Christophe von Garnier ${ }^{2}$, Alke Petri-Fink ${ }^{1}$, \\ Barbara Rothen-Rutishauser ${ }^{1}$ \\ ${ }^{1}$ Adolphe Merkle Institute University of Fribourg \\ ${ }^{2}$ Respiratory Medicine Bern University Hospital
}

In order to examine if nanoparticles with specific surface properties can target cells of the lung immune system, advanced in vitro approaches are required. A 3D model of the human epithelial airway barrier including epithelial and two immune cell types, i.e. macrophages and dendritic cells, was utilized. Suspensions of polyvinyl alcohol (PVA) coated gold nanoparticles (AuNPs), conjugated with fluorescent dye ATTO590 and functionalized either with $-\mathrm{NH}_{2}$ or - $\mathrm{COOH}$ terminal groups were aerosolized onto the lung cell surfaces using an air-liquid interface cell exposure system (ALICE). After $24 \mathrm{~h}$ of incubation, the lung cells were digested and the uptake of AuNPs into the different cell types was measured by flow cytometry. PVA$\mathrm{NH}_{2}$ AuNPs were mainly detected in the epithelial cells and in macrophages whereas their carboxyltaed $(-\mathrm{COOH})$ counterparts were hardly detected in any of the cells. No cytotoxicity or pro-inflammatory effects have been observed for all particles used, however, PVA-NH $\mathrm{N}_{2}$ AuNPs showed higher levels of late apoptosis compared to the negative controls. Currently the binding of antibodies against receptors on dendritic cells onto the surface of the various nanoparticles is ongoing in the lab in order to increase the targeting of this immune cell population.

\section{P-128 PIXEL ANALYSIS OF SCINTIGRAPHY IMAGES TO ASSESS HETEROGENEITY OF DEPOSITION AND MUCOCILIARY CLEARANCE FOLLOWING IVACAFTOR TREATMENT IN CYSTIC FIBROSIS}

Kirby Zeman, Jihong Wu, Scott Donaldson, William Bennett

University of North Carolina, Chapel Hill

The heterogeneity of particle deposition and mucociliary clearance measured by gamma scintigraphy has generally been assessed by partitioning lung images into multiple, but relatively large regions of interest (ROIs). We have developed new analytical methods for determining heterogeneity of deposition and retention on a pixel-bypixel basis, independent of ROIs. At baseline and 1 month after beginning treatment with ivacaftor, a CFTR modulator for CF patients with the G551D mutation $(n=7)$, deposition and retention images were obtained over a $60 \mathrm{~min}$ period following inhalation of radiolabeled particles (Tc99m-SC, 5um MMAD) under controlled breathing conditions. Improved homogeneity of deposition, i.e. decreased regions of hot and cold particle deposition in the lungs (JAMPDD 2014), was found following ivacaftor treatment; mean number ratio (NR) of hot spots decreased from 0.19 to 0.12 and mean NR of cold spots from 0.28 to $0.24(\mathrm{p}<0.05)$. Whole lung clearance was improved following treatment, mean clearance through $60 \mathrm{~min}=10$ vs. $25 \%(\mathrm{p}<0.05)$. Pixellevel analysis of clearance showed that the fraction of pixels clearing greater than $50 \%$ at $60 \mathrm{~min}$ was increased from 0.08 to $0.14(\mathrm{p}<0.05)$, indicating recruitment of more fast clearing regions with ivacaftor treatment. These methods may provide more sensitive measures of changes in deposition and mucociliary clearance associated with therapeutic intervention in patients with airways disease. Supported by $\mathrm{CF}$ Foundation and NIH P01 HL108808.

\section{P-133 MUCOCILIARY CLEARANCE IS SLOWED 4 HOURS POST STIMULATION WITH HYPERTONIC SALINE IN THE HEALTHY LUNG}

\author{
William Bennett ${ }^{1}$, Jihong $\mathrm{Wu}^{1}$, Fred Fuller ${ }^{2}$, Juan Balcazar ${ }^{2}$, \\ Kirby Zeman ${ }^{1}$, Heather Duckworth ${ }^{1}$, Karl Donn ${ }^{3}$, \\ Thomas O'Riordan ${ }^{4}$, Scott Donaldson ${ }^{2}$, Richard Boucher ${ }^{2}$ \\ ${ }^{1}$ Center for Environmental Medicine, Asthma, and Lung \\ Biology; University of North Carolina at Chapel Hill \\ ${ }^{2}$ Cystic Fibrosis Research and Treatment Center, University \\ of North Carolina at Chapel Hill \\ ${ }^{3}$ Parion Sciences \\ ${ }^{4}$ Gilead Sciences
}

Inhalation of hypertonic saline (HS) acutely enhances mucociliary clearance (MC) in both health and disease. Previous studies in adult $\mathrm{CF}$ subjects suggest that HS has a prolonged pharmacodynamic effect on MC. The duration of HS action on MC outside of CF is unknown and may be an important determinant of its therapeutic potential in other airways diseases. We assessed the effect of a single dose of inhaled HS ( $2.8 \%$ by Pari eFlow) by measuring MC at baseline, and again $30 \mathrm{~min}$ and $4 \mathrm{hr}$ after HS treatment. Radiotracer clearance was monitored over a 6 -hr period in 12 healthy adult subjects. The acute enhancement of MC by HS (30 min post treatment) was most pronounced during the initial $30 \mathrm{~min}$ of the $\mathrm{MC}$ assay (Ave30Clr) from the central lung region (mean Ave $30 \mathrm{Clr}=15$ vs. $9 \%$ for $30 \mathrm{~min}$ post HS treatment vs. baseline, $\mathrm{p}<0.005)$. In contrast, when assessed $4 \mathrm{hr}$ post treatment, all indices of radiotracer clearance were slower than at baseline. In the central lung region, Ave $30 \mathrm{Clr}=6 \%$ vs $9 \%(\mathrm{p}=0.10)$ and Ave $90 \mathrm{Clr}=12 \%$ vs. $17 \%(\mathrm{p}<0.05)$. Reduced $\mathrm{MC}$ at $4 \mathrm{hr}$ post treatment was also evidenced by $\mathrm{MC}$ rates measured through $3 \mathrm{hr}$ ( 29 vs. $44 \% ; \mathrm{p}<0.002)$ and $6 \mathrm{hr}(39$ vs. $50 \% ; \mathrm{p}<0.02)$ as compared to baseline. This slowing of MC $4 \mathrm{hr}$ post HS treatment in healthy subjects may reflect depletion of airway mucus resulting from the initial, acute HS enhancement of MC, a phenomenon not expected in diseases such as $\mathrm{CF}$ with copious airway secretions. Supported by Parion and Gilead Sciences.

\section{P-151 BIOLOGICAL ASSESSMENT OF SIMVASTATIN METERED DOSE INHALER FORMULATION FOR RESPIRATORY DISEASES}

\author{
Alaa Tulbah ${ }^{1}$, Paul Young ${ }^{1}$, Daniela Traini ${ }^{1}$, \\ Paolo Colombo ${ }^{2}$, Hui Xin $\mathrm{Ong}^{3}$
}
${ }^{1}$ Respiratory Technology, Woolcock Institute of Medical Research and Discipline of Pharmacology, Sydney Medical School, Sydney University
${ }^{2}$ Department of Pharmacy, University of Parma
${ }^{3}$ Faculty of Health Sciences; Level E, Centre Block, Room
Ce115 (Mp 886); Southampton General Hospital

This study focuses on the development of a Metered Dose Inhaler (MDI) solution formulation of simvastatin (SV), currently used orally as an anti-cholesterol prodrug, to be used locally to reduce inflammation and mucus overproduction in respiratory diseases. A SV MDI solution containing $6 \%(\mathrm{w} / \mathrm{w})$ ethanol, $0.25 \%(\mathrm{w} / \mathrm{w})$ SV and HFA 134a was prepared. The transport of SV across an air interface Calu-3 bronchial epithelial cell model was assessed by deposition of SV MDI formulation on the cells using a modified twin stage impinger. In addition, the ability of SV to reduce mucus secretion on Calu-3 cells was investigated and quantified based on microscopic images of the stained mucus (RedGreen-Blue (RGB) ratio) and compared to controls at day 14 of culture. Moreover, changes to the Calu-3 cell morphology after SV deposition were also studied. Results showed SV to be transported into airway epithelial cells, which was subsequently converted to its active sim- 
vastatin hydroxy acid metabolite. A significant inhibition of mucus production was observed when cells were treated with SV (RGB ratio $=0.42 \pm 0.01$ ) compared to control formulations (RGB ratio HFA only $=0.47 \pm 0.01$, RGB ratio ethanol plus $H F A=0.46 \pm 0.02)$ and untreated cells $(\mathrm{RGB}$ ratio $=0.48 \pm 0.03$ ). The epithelial cells showed no change in cell viability and morphology compared to controls. This novel formulation could potentially be used for the local treatment of respiratory diseases where hyper mucus production is present.

\section{P-155 THE AEROSOL DELIVERY TO ANATOMIC MODEL (ADAM) ADULT OROPHARYNX: VALIDATION STUDY}

\author{
Jason Suggett ${ }^{1}$, Mark Nagel ${ }^{1}$, Rubina $\mathrm{Ali}^{1}$, Jolyon Mitchell ${ }^{2}$ \\ ${ }^{I}$ Trudell Medical International \\ ${ }^{2}$ Jolyon Mitchell Inhaler Consulting Services Inc.
}

The clinically relevant ADAM model, already developed in infant and small child formats, has been extended to include an adult anatomically accurate oropharyngeal airway developed from an MRI scan. In this initial validation study of the adult model, the distal part of the airway was connected directly to the inlet of an Andersen MarkII cascade impactor (ACI) operated at $28.3 \mathrm{~L} / \mathrm{min} \pm 5 \%$. 5 replicate measurements of aerosol aerodynamic particle size distribution were made using Fostair ${ }^{\circledR}$ (Chiesi Farmaceutici, Italy; $100 \mu \mathrm{g}$ beclometasone dipropionate (BDP) $+6 \mu \mathrm{g}$ formoterol fumarate (FF)/actuation) as the test product. Assay for each recovered active ingredient was by HPLC-spectrophotometry. Impactor-delivered mass, representing the mass fraction of each component of the emitted dose potentially available for lung deposition, (mean \pm SD) was $24.0 \pm 1.8 \%$ and $26.3 \pm 2.0 \%$ of the label claim dose ex inhaler for the BDP and FF components respectively. These results are in reasonable agreement with an average lung deposition value (mean $\pm \mathrm{SD}$ ) of $34.08 \pm 9.30 \%$ relative to nominal dose for both $\mathrm{BDP}$ and $\mathrm{FF}$ components, reported by De Backer et al. (JAMPD, 2010;23:137-148) for 8 healthy adults in a gamma scintigraphic study inhaling the same pMDI-generated formulation, given the magnitude of inter-subject variability reported by them.

\section{P-158 STUDY OF AEROSOL DEPOSITION IN A REPLICA OF HUMAN LUNGS}

Frantisek Lizal, Miloslav Belka, Jan Jedelsky, Miroslav Jicha

Brno University of Technology, Faculty of Mechanical Engineering

Aerosol deposition was measured by Positron Emission Tomography on a replica of human lungs with seven generations of branching. The model consists of 32 parts. A purpose of the study was to acquire detailed data on the local deposition fraction, efficiency and density in different segments of lungs. The data had to be usable for comparison with numerical simulation of aerosol deposition.

Di-2-ethylhexyl Sebacate particles generated by condensation monodisperse aerosol generator were tagged by Fluor-18. Three different inhalatory flowrates were simulated which correspond to resting conditions, deep breath and light activity. The test rig consisted of the aerosol generator, aerosol monitor, charge equilibrator, replica of lungs with filters connected to its outlets, flow meters and a vacuum pump. The model was exposed to aerosol for 5 to 15 minutes. Afterwards the model was transported to the tomograph and scanned. Activities in individual segments were analysed using specialized software and transformed into deposition characteristics.
The study confirmed that the method yields results suitable for comparison with previous studies and numerical simulations. Our results were in agreement with studies performed on realistic replicas of human lungs.

\section{P-161 DOES OBESITY CHANGE PATTERNS OF LUNG DEPOSITION?}

Jacqueline Barcelar $^{1}$, Luciana Alcoforado ${ }^{1}$, Valdecir Galindo ${ }^{1}$, Simone Brandão ${ }^{2}$, James B. Fink ${ }^{3}$, Armele Dornelas ${ }^{1}$

${ }^{1}$ Universidade Federal de Pernambuco, Department of Physical Therapy

${ }^{2}$ Universidade Federal de Pernambuco, Department of Nuclear Medicine

${ }^{3}$ Georgia State University, Respiratory Therapy Program

Background: The impact of obesity on aerosol deposition is not well characterized. The aim of this study was to compare radioaerosol deposition in normal and obese women of normal weight, using 2-D planar scintigraphy.

Methods: 29 adult women, 14 normal (CG; $\left.\mathrm{BMI}=18.5-24.99 \mathrm{~kg} / \mathrm{m}^{2}\right)$ and 15 obese $\left(\mathrm{OG} ; \mathrm{BMI} \geq 30 \mathrm{~kg} / \mathrm{m}^{2}\right)$ inhaled $1 \mathrm{mCi}$ of $99 \mathrm{mTc}-$ DTPA with normal saline to a volume of $0.2 \mathrm{~mL}$., using a novel vibrating mesh inhaler. Scintigraphy was used to determine mass balance between compartments.

Results: The groups showed differences in $\mathrm{BMI}(\mathrm{CG}=22.06 \pm 1.97$; $\mathrm{OG}=35.66 \pm 5.13, \mathrm{p}=0.000)$, neck $(\mathrm{GC}=0.32 \pm 0.17 ; \mathrm{GO}=0.36 \pm 0.03$, $\mathrm{p}=0.005)$, waist $(\mathrm{GC}=0.75 \pm 0.08 ; \mathrm{GO}=0.99 \pm 0.12, \mathrm{p}=0.000)$ and hip circumferences $(\mathrm{CG}=1.01 \pm 0.06 ; \mathrm{OG}=1.22 \pm 0.13, \mathrm{p}=0.000)$ (Table 1).

Conclusions: The reduced pulmonary deposition with obese women was offset by greater deposition in oropharynx/stomach than found in normals.

Acknowledgment: This study was funded by a grant CNPq-PVE400801/2013-2, FACEPE APQ 0234-4.08/12.

Table 1. Distribution between compartments in normal and obese groups.

\begin{tabular}{lccc}
\hline & Normal $(\mathbf{n = 1 4 )}$ & Obese $(\mathbf{n = 1 5})$ & p-value \\
\hline Lung(\%) & $64.26 \pm 6.41$ & $55.94 \pm 8.81$ & 0.015 \\
Upper airways (\%) & $8.43 \pm 3.17$ & $18.91 \pm 6.21$ & 0.000 \\
Stomach(\%) & $4.81 \pm 2.39$ & $7.21 \pm 6.08$ & NS \\
Device(\%) & $0.36 \pm 0.51$ & $0.41 \pm 0.55$ & NS \\
MP Cartridge(\%) & $19.00 \pm 5.69$ & $14.63 \pm 4.09$ & 0.045 \\
Expiratory filter (\%) & $3.13 \pm 2.63$ & $2.89 \pm 3.90$ & NS \\
& & & \\
\hline
\end{tabular}

\section{P-162 DEPOSITION OF RADIOAEROSOL WITH JET AND MESH NEBULIZERS IN HEALTHY ADULTS}

Luciana Alcoforado ${ }^{1}$, Jacqueline Barcelar ${ }^{2}$, Valdecir Galindo ${ }^{2}$, Simone Brandão ${ }^{3}$, James B. Fink ${ }^{4}$, Armele Dornelas ${ }^{2}$

${ }^{1}$ Universidade Federal de Pernambuco, Department of Physical Therapy, Estacio College of Recife

${ }^{2}$ Universidade Federal de Pernambuco, Department of Physical Therapy

${ }^{3}$ Universidade Federal de Pernambuco, Department of Nuclear Medicine

${ }^{4}$ Georgia State University, Respiratory Therapy Program

Background: Mesh nebulizers (MN) have lower residual volume and increased inhaled dose compared to jet nebulizers (JN) per in vitro and animal models. The aim of this study was to compare radio- 


\begin{tabular}{lccc}
\hline & Jet Nebulizer & Mesh Nebulizer & p-value \\
\hline Lung & $3.4 \pm 1.2$ & $25.7 \pm 9.3$ & 0.004 \\
Upper airway & $1.3 \pm 0.3$ & $3.4 \pm 2.6$ & $\mathrm{NS}$ \\
Stomach & $0.7 \pm 0.3$ & $4.0 \pm 2.2$ & 0.010 \\
Adpater & $9.2 \pm 4.8$ & $46.8 \pm 17.9$ & 0.037 \\
Nebulizer & $53.9 \pm 3.6$ & $8.9 \pm 11.1$ & 0.004 \\
Expiratory filter & $32.5 \pm 8.6$ & $10.4 \pm 17.8$ & $\mathrm{NS}$
\end{tabular}

aerosol deposition using $\mathrm{MN}$ and $\mathrm{JN}$ in healthy subjects, using 2-D planar scintigraphy.

Methods: A randomized trial in 6 normal subjects (4 female, 2 male) inhaled 99mTc-DTPA with an activity of $1 \mathrm{mCi}$ with the normal saline to a total dose of $4 \mathrm{~mL}$ with JN (Misty Max, Air Life, Yorba Linda, USA) oxygen flow of $8 \mathrm{~L} / \mathrm{min}$ and $1.5 \mathrm{~mL}$ with MN (Aerponeb Solo with Ultra adapter; Aerogen Galway, Ireland). Scintigraphy was used to determine distribution of deposition and mass balance between compartments.

Results: Distribution between compartments with JN and MN shown in table.

Conclusions: Mesh with adapter was more efficient than jet nebulizer with higher radio-aerosol deposition in the lung and decreased residual drug in the nebulizer.

Acknowledgment: This study was funded by a grant CNPq-PVE400801/2013-2, FACEPE APQ 0234-4.08/12.

\section{P-165 APEX TO BASE DEPOSITION OF RADIOAEROSOLS IN CF LUNGS: EFFECT OF INHALATION IN SUPINE VS. SITTING POSITION}

\author{
William Bennett ${ }^{1}$, Kirby Zeman ${ }^{1}$, Jihong $\mathrm{Wu}^{1}$, \\ Heather Duckworth ${ }^{1}$, Claudia Salazar ${ }^{2}$, Scott Donaldson ${ }^{2}$ \\ ${ }^{1}$ Center for Environmental Medicine, Asthma, and Lung \\ Biology, University of North Carolina at Chapel Hill \\ ${ }^{2}$ Cystic Fibrosis Research and Treatment Center, \\ University of North Carolina at Chapel Hill
}

The lung apices in cystic fibrosis $(\mathrm{CF})$ patients are generally the first and most dramatically affected by disease. Consequently it is difficult to deliver radiolabeled aerosol to these poorly ventilated regions for in-vivo measures of mucociliary clearance (MC), a recent biomarker for new $\mathrm{CF}$ therapies. We hypothesized that having the patients inhale the radioaerosol in the supine position, to remove the gravitational dependence of ventilation to the base of the lungs, and using a slow inhalation $(80 \mathrm{ml} / \mathrm{sec})$-large particle $(9.5 \mathrm{um})$ (SILP) method, to reduce inertial impaction in the large airways, might better target these diseased lung regions. Using gamma scintigraphy and region of interest analysis we assessed the apex (top third) to base (bottom third) ratio (A/B) of deposited particles normalized to transmission images in each subject. We found that adult $\mathrm{CF}$ patients (mean FEV1\%pred=61) $(\mathrm{n}=6)$ had no change in $\mathrm{A} / \mathrm{B}$ for sitting vs. supine inhalation $(0.22+/-0.09$ vs. $0.24+/-0.13$ respectively). Furthermore, for SILP inhalation in the sitting position, CF patients $(\mathrm{n}=8)$ had lower A/B than healthy adults $(\mathrm{n}=12)(0.19+/-0.08$ vs. $0.34+/-0.19, \mathrm{p}=0.07)$. These data show that for our breathing conditions CF patients deposit less radioaerosol in their apices compared to healthy individuals, and that inhalation in the supine position is insufficient to enhance such deposition in these poorly ventilated regions for improved assessment of MC. Support by $\mathrm{CF}$ Foundation.

\section{P-170 IMMORTALIZED MURINE ALVEOLAR EPITHELIAL CELLS AS NOVEL IN VITRO MODEL OF THE AIR-BLOOD BARRIER}

Sandra Sapich ${ }^{1}$, Cristiane Carvalho ${ }^{1}$, Tobias May ${ }^{2}$, Dagmar Wirth ${ }^{1}$, Claus-Michael Lehr ${ }^{1}$, Nicole Schneider-Daum ${ }^{1}$

${ }^{1}$ Helmholtz Institute for Pharmaceutical Research Saarland (Hips), Drug Delivery, Helmholtz Centre for Infection Research (Hzi), Model Systems for Infection and Immunity

${ }^{2}$ Inscreenex $\mathrm{GmbH}$

The air-blood barrier is formed by the alveolar epithelium of the peripheral lung consisting of mainly two cell types, alveolar epithelial type I (ATI) and type II (ATII) cells. Because the mouse is still the most relevant animal model in biomedical sciences, we aimed at the immortalization of primary murine alveolar epithelial cells $(\mathrm{mAEpC})$ to provide a novel in vitro model of the murine air-blood barrier expressing functional tight junctions and thus, exhibiting transepithelial electrical resistance (TEER). Most essentially such a model accentuates the possibility to perform lung tissue regeneration experiments. On the other hand, with respect to the long-term perspective, the number of animal testing can be reduced following the $3 \mathrm{R}$ principle (refine, reduce, replace). For this purpose, we established protocols for both isolation and immortalization of $\mathrm{mAEpC}$ and lentivirally transduced bona fide immortalizing genes such as the SV40 large T antigen or a set of proliferation genes. Upon infection, several cell populations with a prolonged lifespan were expanded and characterized in comparison with $\mathrm{mAEpC}$ with special regard to barrier properties. Illustrating an ATI-like character these immortalized cells may allow standardized toxicity and transport studies for novel compounds and be helpful in elucidating infection pathways across the respiratory tract in the context of aerosol transmitted infectious diseases, such as tuberculosis or swine flu.

\section{P-174 A REALISTIC INDIVIDUALIZED 3D MODEL OF THE CONDUCTIVE AND PULMONARY REGIONS OF THE HUMAN LUNG}

Spyridon Montesantos ${ }^{1}$, Ira Katz ${ }^{2}$, Marine Pichelin ${ }^{1}$, Florian Brun ${ }^{3}$, Carolin Majoral $^{1}$, Cécile Dubau ${ }^{1}$, Georges Caillibotte ${ }^{1}$

${ }^{1}$ Air Liquide Sante International; Centre de Recherche Paris Saclay

${ }^{2} R \& D$ Medical, Air Liquide Santé International, Les-Loges-En-Josas, France; Department of Mechanical Engineering, Lafayette College, Easton, PA, USA

${ }^{3}$ Migs, University of Boulogne

Computational 3D models of the human lung are routinely being used to study lung physiology and estimate aerosol deposition and gas distribution mechanics in the human airway tree. In this study, two separate models were used to fully describe the human respiratory system. The first describes the bronchial and bronchiolar part of the respiratory system and is based on a previously published model [Tawhai et al., Annals of Biomed. Eng., 2000] which represents a systematic space-division algorithm that produces an asymmetric bifurcating system. The second model is an individualized description of the acinar region using statistical data from previous studies, the local volume and the dimensions of the last respiratory bronchiole from the previous model to produce a symmetric bifurcating system. The initial information for the development of these models is the result of segmented medical images of the first few generations of the respiratory system and the lung space. The statistics of the models are very close to the relevant literature but indicate certain issues that should be addressed for optimal results. The 
combination of the above models could be used to quantify aerosol deposition and gas flow patterns using mathematical modeling tools, or as a diagnostic tool for lung disease in conjunction with medical images.

\section{P-180 IN VIVO AND EX VIVO IMAGING OF FLUORESCENT MARKERS IN MOUSE LUNGS: ASSESSMENT OF DOSE AND 3D-DISTRIBUTION}

Winfried Möller ${ }^{1}$, Nirav Barapatre ${ }^{1}$, Jörg Hamm², Ali Önder Yildirim ${ }^{1}$, Tobias Stoeger ${ }^{1}$, Richa Srivastava ${ }^{1}$, Veronika Wörle ${ }^{1}$, Oliver Eickelberg ${ }^{1}$, Otmar Schmid ${ }^{1}$

${ }^{1}$ Helmholtz Zentrum München ${ }^{2}$ Perkinelmer $\mathrm{GmbH}$

Introduction: Fluorescent markers are available for drug monitoring in preclinical animal models. Whole lung fluorescence imaging is complicated by autofluorescence and poor light penetration. In this study in vivo and ex vivo imaging methods were developed for quantitative assessment of dose and distribution of fluorescent markers in mouse lungs.

Methods: Fluorescent beads (ex/em $=680 \mathrm{~nm} / 720 \mathrm{~nm}$ and $715 \mathrm{~nm} /$ $755 \mathrm{~nm}$ ) were applied as surrogate drug to the lungs of mice via intratracheal instillation (IT), as well as mechanically ventilated $\left(\mathrm{IH}_{\mathrm{MV}}\right)$ inhalation and nose-only $\left.\left(\mathrm{IH}_{\mathrm{NO}}\right)\right)$ inhalation. Lungs were imaged in vivo in shaved animals (IVIS Spectrum, PerkinElmer, Rodgau, Germany). Ex vivo lungs were microwave dried and cut into $1 \mathrm{~mm}$ slices. Fluorescent images were obtained from slices and associated block faces. After 3D image reconstruction central to peripheral distribution ( $\mathrm{C} / \mathrm{P}$ ratio) was analyzed.

Results and Discussion: For dried lungs the effective light attenuation coefficient was $8.8 \pm 1.9 \mathrm{~cm}^{-1}$. Both in vivo and ex vivo fluorescence imaging showed a linear intensity-dose relationship. The regional fluorophore $\mathrm{C} / \mathrm{P}$ ratio was $1.9 \pm 0.4$ (mean $\pm \mathrm{SD}$ ) for IT and $1.2 \pm 0.3$ and $1.3 \pm 0.2$ for $\mathrm{IH}_{\mathrm{MV}}$ and $\mathrm{IH}_{\mathrm{NO}}$ inhalation, respectively. IT delivers the marker preferentially into central regions, while both inhalation modes resulted in a more uniform lung distribution.

Conclusion: Despite significant light attenuation in the lung tissue quantitative fluorescence imaging in whole murine lungs is possible both ex vivo and in vivo. Inhalation leads to more uniform pulmonary drug distribution throughout the lung.

\section{P-195 SPECT IMAGING MEASUREMENTS OF AEROSOL DEPOSITION IN THE RESPIRATORY TRACT OF ASTHMATIC HUMAN SUBJECTS}

\author{
Caroline Majoral $^{1}$, John Fleming ${ }^{2}$, Joy Conway ${ }^{3}$, Ira Katz ${ }^{4}$, \\ Marine Pichelin ${ }^{5}$, Spyridon Montesantos ${ }^{5}$, Michael Bennett ${ }^{3}$, \\ Georges Caillibotte ${ }^{1}$ \\ ${ }^{1} R \& D$ Medical, Air Liquide Santé International \\ ${ }^{2}$ Southampton Respiratory Nihr Biomedical Research Unit; \\ University Hospital Southampton NHS Foundation Trust \\ ${ }^{3}$ National Institute of Health Research Biomedical Research \\ Unit in Respiratory Disease, Southampton, Faculty of Health \\ Sciences, University of Southampton \\ ${ }^{4} R \& D$ Medical, Air Liquide Santé International, Les-Loges- \\ En-Josas, France; Department of Mechanical Engineering, \\ Lafayette College, Easton, Pa, USA \\ ${ }^{5}$ Air Liquide Santé International, Medical $R \& D$
}

To provide a validation dataset for aerosol deposition modeling, a clinical study involving healthy and asthmatic subjects was designed and performed wherein as much as possible the ventilation and aerosol were controlled or characterized. This abstract focuses on asthmatic patients' data and the comparison with healthy subjects. Radioactive aerosol was administered to six male asthmatic subjects on two occasions under carefully monitored input conditions. Input parameters varied were particle size, depth of breathing, and carrier gas. The aerosol distribution was measured by combined SPECT/CT and airway anatomy by high resolution CT. The deposition distribution was described in terms of the percentage of inhaled aerosol deposited in sections of the respiratory tract and in both spatial and anatomical sub-divisions within each lung. The percentage deposition in the conducting airways was also assessed by $24 \mathrm{~h}$ clearance. The results in asthmatics were compared to previous measurements in healthy controls using an identical inhalation protocol. The percentages of deposition in extra-thoracic and thoracic compartments of the airways were not significantly affected by disease, but the regional pulmonary deposition pattern was, with asthma leading to increased deposition in the conducting airways. Indeed, the mean 3D normalized central to peripheral ratio was significantly higher $(\mathrm{p}=0.00174)$ for asthmatics $(3.72 \pm 2.2 \mathrm{SD})$ than controls $(1.82 \pm 0.57 \mathrm{SD})$.

\section{P-196 MODEL OF THE HYGROSCOPIC PARTICLE DEPOSITION IN THE MOUSE LUNGS}

\author{
George Ferron, Erwin Karg
}

Helmholtz Zentrum München, Cooperation Group

"Comprehensive Molecular Analytics"

Mice are frequently used to study the effect of aerosol particles. Most aerosol particles are hygroscopic. Their deposition probability changes when entering the airways.

The deposition of hygroscopic particles can be estimated with the hygroscopic particle lung deposition model for the human and rat lungs published previously. This model is adapted here for the mouse lungs.

The ratio of the deposition of the initial dry sodium chloride and non-hygroscopic particles is below one in the size range of $0.03-$ $0.3 \mu \mathrm{m}$ and larger than one in the size range of $0.3-3 \mu \mathrm{m}$ in the mouse, rat and human lungs, respectively. The maximal reduction is a factor of $0.5,0.5,0.7$ and the maximal increase is a factor of 1.4, 2.0 and 1.7, respectively. The influence of the profiles for temperature and relative humidity on the deposition is negligible in the mouse lungs.

In conclusion the hygroscopic properties of aerosol particle are less important in the mouse lungs compared to rat and human lungs, but should not be neglected.

\section{P-204 COMPARATIVE SIMULATION OF AIRWAY DEPOSITION OF THREE COMBINED AEROSOL DRUGS COMMONLY USED IN ASTHMA THERAPY}

\author{
Árpád Farkas, Ágnes Jókay, Péter Füri, Blanka Czitrovszky, \\ Imre Balásházy \\ Centre for Energy Research, Hungarian Academy of Sciences
}

In the last few decades the number of patients suffering from asthma has increased worldwide. The use of aerosol therapy in the treatment of asthma is widespread. The main objective of the present work was to quantify the airway deposition distribution of three selected commercially available ICS-LABA (inhalation corticosteroid and long-acting beta2-agonist) drugs and to examine the suitable directions of aerosol drug delivery optimisation. Standard spirometry measurements have been performed on seventeen volunteers, and then the same breathing parameters were measured also when they inhaled through the selected devices characterised by different flow resistances. Relationships between breathing parameter values measured during diagnostic spirometry 
and those characterising breathing during drug administration through inhalers have been established. Spirometry test values served also as input data for the modelling of regional deposition distributions of the selected aerosol drugs. The Stochastic Lung Model has been applied to quantify the amount of medication deposited in the airways both in the targeted region (receptors) and outside of it. Based on our computational results, the appropriateness of the different drugs and breathing modes proved to be quite sensitive to the selection of the target area. The efficiency of the deposition of each selected aerosol drug was patientspecific highlighting the need for and possibility of simulation assisted personalised drug selection and delivery in the future.

\section{P-205 COMPARATIVE PERFORMANCE OF HEPARIN DRY POWDER INHALATION FORMULATIONS}

\author{
Nick Childerhouse, Iain Davidson, Andrew Wahl
}

\section{Vectura Ltd}

The development of a heparin inhalation powder clinical investigation presented a number of challenges that were addressed through the combined use of novel excipients and a spray dried particle engineering approach.

Heparin is a naturally occurring sulphated glycosaminoglycan (GAG) produced by mast cells found predominantly in the lungs and gut; it is a heterogeneous polymer with molecular weight of $3-30 \mathrm{kDa}$ (average typically $12-15 \mathrm{kDa}$ ). As such it is an interesting material that is analogous to many biologic materials that could be considered for particle engineering techniques such as spray drying.

Heparin is reported to possess multiple and complementary pharmacological activities relevant to the treatment of various respiratory disorders including CF. A target dose of between $10 \mathrm{mg}$ and $20 \mathrm{mg}$ was established based on the literature of successful clinical use.

Several particle engineering approaches were investigated in order to develop particle for use in a dry powder inhaler, namely; jet milling, spray drying without excipients and spray drying with a variety of process enhancers.

Challenges addressed were the need to include little or no carrier material due to the high target dose, to ensure good fine particle mass (FPM) and to obtain consistent delivered mass through high dose clearance from the inhaler dosage form. An idealised formulation was developed from the spray drying process and the product was progressed to successful phase I/II clinical studies.

\section{P-206 ACOUSTIC MIXING-HIGHLY EFFICIENT NEW TECHNOLOGY FOR DRY POWDER INHALERS}

Nick Childerhouse, Matthew Green

Vectura Ltd

A novel laboratory scale mixer (LabRAM) was evaluated as a potential mixing technology for dry powder inhalation formulations. The LabRAM is an impeller free system which uses low frequency, high intensity acoustic energy to rapidly fluidise and disperse material in a vessel. The energy is applied at the resonant frequency of the media, causing the natural harmonics of the system to enable pressure wave propagation. This causes microscopic and macroscopic cycling of the material, resulting in a fast and efficient process that can mix a variety of materials, from highly viscous fluids to cohesive powders.

The mixer was investigated in to determine the capability of producing uniform blends from highly cohesive powders typical in inhaled formulations, its ability to blend without giving rise to temperature gains (a common feature of impellor driven blenders) and its ability to mix particles that have a tendency to shatter in impellor mixers.

Once the blend efficiency capability was demonstrated the aerodynamic particle size distribution of the resulting blends was determined and found able to match specific deposition profiles of existing products, as well as exceed the FPM produced by traditional impeller blending. Overall it was demonstrated that acoustic mixing can enhance a pharmaceutical companies processing capability and can be employed as one of many techniques available to achieve successful product manufacture for inhalation powders.

\section{P-218 DYNAMICS OF THE GLOTTIS DURING BREATHING}

Olivier Boiron ${ }^{1}$, Adam Scheinherr ${ }^{1}$, Ann R. Elliott ${ }^{2}$, Lucie Bailly ${ }^{3}$, Rebecca J. Theilmann ${ }^{2}$, Chantal Darquenne ${ }^{2}$

${ }^{1}$ Centrale Marseille, Cnrs Irphe Umr 7342, Aix Marseille Université ${ }^{2}$ Dept. Medicine, University of California, San Diego

${ }^{3}$ Univ. Grenoble Alpes, Cnrs 3sr Umr5521

Upper airways (UA) present a complex 3D geometry including sudden narrowing, expanding and bending. Although most of the UA can be considered as static this is not the case of the laryngeal region, where movements of the epiglottis and the glottis can be observed with ENT techniques during breathing. Many studies have recognized the filtering role of the glottal region (GR) for the delivery of inhaled therapies into the lungs. For instance, in vitro work of Conway et al. (2012) showed that aerosol deposition in the UA can reach up to $40 \%$ of inhaled aerosol mass. Furthermore, most in silico and in vitro studies neglected the larynx specificities in terms of realistic shape, area and dynamic of the GR. We imaged the glottal dynamics during breathing on 26 volunteers with a laryngo-fiberscope and on 5 healthy subjects using MRI. Both imaging techniques were performed with simultaneous flow measurements. While glottal areas measured with the laryngo-fiberscope were larger than those measured by MRI, both techniques showed two types of glottal timevariations: a "static" behavior with almost constant glottal area during breathing and a "dynamic" behavior where the glottal area during inspiration could be up to $50 \%$ higher than during expiration. The variability observed in both behavior and size of the glottal area strongly advocates for the use of realistic UA geometries both in terms of shape and temporal behavior in in silico and in vitro studies of aerosol delivery to the lung.

\section{P-235 REGIONAL VENTILATION IS THE MAIN DETERMINANT OF ALVEOLAR DEPOSITION OF COARSE PARTICLES IN THE HEALTHY HUMAN LUNG DURING TIDAL BREATHING IN THE SUPINE POSTURE}

\author{
Rui C. Sa ${ }^{1}$, Kirby Zeman ${ }^{2}$, William Bennett ${ }^{3}$, G. Kim Prisk ${ }^{1}$, \\ Chantal Darquenne ${ }^{1}$ \\ ${ }^{1}$ Dept. Medicine, University of California, San Diego \\ ${ }^{2}$ University of North Carolina, Chapel Hill \\ ${ }^{3}$ Center for Environmental Medicine, Asthma, and Lung Biology, \\ University of North Carolina at Chapel Hill
}

We aimed at quantifying the relation between lung ventilation and aerosol deposition in the healthy lung, an important but poorly characterized determinant of inhalation therapy. We measured regional ventilation in a $15 \mathrm{~mm}$ sagittal lateral slice of the right lung (MRI, in-plane $\sim 6 \times 6 \mathrm{~mm}$ ), in 8 supine subjects (free tidal volume, 12 breaths $/ \mathrm{min}$ ). Alveolar deposition $\left(\mathrm{R}_{22 \mathrm{~h}}\right)$ was measured by planar gamma scintigraphy from coronal scans $22 \mathrm{~h}$ post inhalation of $5.1 \mu \mathrm{m}$ MMAD ${ }^{99 \mathrm{~m}} \mathrm{Tc}$ labelled particles in the supine posture (flow $0.5 \mathrm{~L} / \mathrm{s}, 15$ breaths $/ \mathrm{min}$ ). Ventilation 
maps were used to define 4 equal height regions of interest (ROI) from the apex of the lung to the dome of diaphragm. These ROIs were projected on the $R_{22 h}$ scan, at the same slice location, with apices aligned. The ratio of fractional alveolar deposition to ventilation (r) to each region was computed $(r=1$, regional alveolar deposition proportional to ventilation; $r>1$, aerosol deposition relatively larger than ventilation).

The ratio was close to 1 in all but the apical region where $r$ was significantly greater $(\mathrm{p}<0.05): 1.62 \pm 0.36$ vs. $0.99 \pm 0.12,0.90 \pm 0.05$ and $0.90 \pm 0.12$. These data indicate alveolar deposition is directly proportional to ventilation in most of the lung as apical region accounts for only $13 \%$ of the total ROI volume. This suggests that, in the supine posture, convective flow is the main determinant of aerosol transport to the lung periphery, agreeing with previous simulation studies.

\section{P-247 DEVELOPMENT OF A DRY POWDER INHALER FORMULATION OF CURCUMIN FOR LUNG CANCER TREATMENT}

\author{
Yuosef AL Ayoub, Khaled Assi, Anant Paradkar, \\ Mohammad Amin \\ University of Bradford
}

Purpose: to develop and evaluate a dry powder inhaler of curcumin for lung cancer treatment. As curcumin has a potential effect against cancers.

Experimental Design: An aerosol of curcumin particles ranging from $1-5 \mu \mathrm{m}$ in diameter was prepared by a Jet milling. The solid state characteristics of the respirable curcumin particles were determined by differential scanning calorimetry (DSC), x-ray powder diffraction (XRPD), laser diffraction and SEM. The formulation of dry powder inhaler was prepared by blending the micronized particles $(3.5 \mu \mathrm{m})$ of curcumin with $\alpha$-lactose monohydrate (particles size $50-100 \mu \mathrm{m}$ ) in three ratios. These ratios were 1:5 (F1), 1:9 (F2) and 1:20 (F3) (curcumin: lactose w/w). The in-vitro deposition profile of curcumin delivered from easyhaler was assisted using Next Generation Impactor at flow rate $43 \mathrm{~L} / \mathrm{min}$.

Results: The D50 of the micronized curcumin particle was $3.5 \mu \mathrm{m}$. The polymorphic structures of the micronized curcumin powder remained stable. The means of the fine particle fraction were 28.8, 30.6, and $29.6 \%$ for F1, F2 and F3 respectively. The mean of the MMAD was 4.3 and GSD was 1.7 .

Conclusions: This study demonstrated the development of dry powder formulation of curcumin using jet-milling. The in-vitro characterisation showed the potential of using easyhaler for the delivery of curcumin to the lung.

\section{P-250 USE OF REGIONAL PARTICLE DEPOSITION PREDICTIONS TO TEST A MODEL OF VIRTUAL NASAL SURGERY AND POST-OPERATIVE HEALING}

\author{
Zainab Farzal, Gitanjali Fleischman, Charles Ebert, Jr., \\ Brent Senior, Adam Zanation, Julia Kimbell
}

University of North Carolina at Chapel Hill

Prediction of post-operative drug delivery using computational fluid dynamics (CFD) in patients with chronic rhinosinusitis (CRS) may improve surgical outcomes. A method was developed to mimic functional endoscopic sinus surgery (FESS) and post-FESS healing virtually in a pre-operative CFD model based on one CRS patient. The objective of this study was to test the method in a second individual using regional particle deposition (PD) prediction. Three-dimensional sinonasal reconstructions from pre- and post-FESS CT scans of two adult CRS patients were created. To develop the method, a virtual model was created by altering the pre-surgery reconstruction (PSR) of one subject to mimic FESS and healing by direct post-FESS comparison. To test the method, the other subject's PSR was altered to mimic FESS by direct post-FESS comparison, but healing alterations were extrapolated from a protocol based on the extent of healing in the first subject. Steady-state, inspiratory airflow and nebulized PD in vestibular, middle, and nasopharyngeal regions were simulated in all models. Regional PD in virtual and postFESS models agreed in the first subject but not in the second subject, suggesting that inter-individual differences in healing effects need to be taken into account. PD is an effective tool for virtual nasal model development. This research was funded in part by NIH NRSA Institutional Training Grant T32DC005360. The content is solely the authors' responsibility and does not represent the official views of the NIH.

\section{P-255 A GAS DEPENDANT MODEL FOR TRACHEO- BRONCHIAL VENTILATION IN HEALTHY AND PATHOLOGICAL SITUATIONS}

\author{
Nicolas Pozin ${ }^{1}$, Cécile Dubau², Ira Katz², Marine Pichelin², \\ Spyridon Montesantos ${ }^{2}$, Georges Caillibotte ${ }^{2}$, Céline Grandmont ${ }^{3}$, \\ Irène Vignon-Clementel ${ }^{3}$ \\ ${ }^{1}$ Inria Paris-Rocquencourt, Medical $R \& D$, Air Liquide Santé \\ International; Sorbonne Universités Upmo \\ ${ }^{2}$ Medical R\&D, Air Liquide Santé International \\ ${ }^{3}$ Inria Paris-Rocquencourt, Sorbonne Universités Upmc
}

A ventilation model of the tracheo-bronchial tree is presented. This model is used to assess ventilation heterogeneities in pathological situations such as asthma and emphysema. The upper generations are segmented from a patient-specific image. Together with the imaged lung envelope, they provide inputs to compute a realistic distal airway tree geometry by a space-filling algorithm. Three resistance models accounting for pressure drops in the tree are compared: a Poiseuille linear model accounting for viscous pressure drops only, and two non-linear ones which also account for inertial effects. The air storage and mechanical dynamics of the parenchyma are modeled by local compliances obtained through an extensive distribution of global static lung compliance. Both tidal and forced breathing are simulated, the system is driven by an heterogeneous pressure field boundary condition. Asthma is modeled by local branches diameter reduction, emphysema is taken into account through local compliance increase. Results obtained include typical flow patterns in healthy and pathological situations. The tree resistance plays a negligible role in the tidal breathing dynamics. Inertial effects must be taken into account in pathological situations as in some cases gas mixtures with different physical properties than air can provide improved ventilation of injured areas compared to air, hence increasing aerosolized drug deposition -and efficiency- in such areas.

\section{P-256 HIGH RESOLUTION PHASE CONTRAST IMAGING OF SUB-MICRON PARTICLES IN UNSTAINED LUNG PARENCHYMA}

\author{
Johannes C. Schittny ${ }^{1}$, Barré Sébastien F. ${ }^{1}$, Haberthür David ${ }^{2}$, \\ Semmler-Behnke Manuela ${ }^{3}$, Takenaka Shinji ${ }^{3}$, \\ Kreyling Wolfgang G. ${ }^{3}$, Stampanoni Marco ${ }^{4}$ \\ ${ }^{1}$ University of Bern, Institute of Anatomy \\ ${ }^{2}$ Paul Scherrer Institut, Swiss Light Source \\ ${ }^{3}$ Helmholtz Center Munich, Institute of Lung Biology \\ ${ }^{4}$ University and Eth Zürich, Institute for Biomedical Engineering
}

To judge the risks and chances of deposited ultrafine particles in the lung a precise three-dimensional (3D) localization inside the acini is 
very important, because local hot spots are expected. After intratracheal instillation of $200 \mathrm{~nm}$ gold particles, rat lungs were fixed by vascular perfusion and embedded in paraffin. Gold particles were 3D-visualized in unstained lung tissue by synchrotron radiation X-ray tomographic microscopy (SRXTM) combining absorption contrast (gold particles) and phase contrast (unstained tissue). We achieved a very good contrast for the gold particles and the tissue which enabled us to perform an automatic segmentation of both structures. The smallest particles detected possessed a volume of 1-2 voxels of $370 \mathrm{~nm}$ side length. Using our protocol for multimodal imaging combining SRXTM and electron microscopy we verified that these voxels contained 1-3 gold particles. After detection of the particles the site of deposition was localized inside the acinus. We would like to apply this new method to study the distribution of ultrafine particles in the lung parenchyma.

\section{P-261 SUBMERSION AND TRANSPORT BEHAVIOR OF MICROPARTICLES AT A LUNG SURFACTANT INTERFACE ON MODEL MUCUS HYDROGELS}

Daniel Schenck, Jennifer Fiegel

University of Iowa, Department of Pharmaceutical Sciences and Experimental Therapeutics

The goal of this study was to investigate the submersion and transport behavior of deposited microparticles at the surface of a fluid that mimics both the bulk viscoelastic and surface tension properties of non-diseased tracheobronchial mucus. Mucus mimetics were formulated using Carbopol at varying polymer concentrations. Infasurf, a calf lung surfactant extract, was spread onto the surface of the polymer hydrogels and was compressed to lower the surface tension. Surfactant phase domains were identified by fluorescence microscopy. Microparticles were aerosolized by insufflation and deposited onto the model mucus surface. The particles were imaged by brightfield microscopy at varying surface tensions and the extent of particle submersion into the subphase determined using ImageJ. Lateral transport across the surfactant interface was quantified using particle tracking techniques.

Gel viscoelasticity was observed to inhibit surfactant spreading and, as a result, the Infasurf phase domain structure demonstrated increasing inhomogeneity. Key particle properties (size and surface hydrophilicity) influenced particle submersion and mobility on the hydrogel surface. Generally, submersion and transport were inhibited by increasing gel viscoelasticity and transport was additionally hindered by decreasing the surface tension. Overall, these studies are expected to aid our understanding of particle behavior on mucus surfaces and help guide the development of drug delivery systems for pulmonary applications.

\section{P-263 SIMULATING NASAL SPRAY DEPOSITION: EFFECTS OF SPRAY NOZZLE PRESENCE IN THE NASAL VESTIBULE}

\author{
Julia Kimbell ${ }^{1}$, Daniela Stricklin ${ }^{2}$, Jeffry Schroeter ${ }^{2}$ \\ ${ }^{1}$ University of North Carolina School of Medicine, \\ Department of Otolaryngology/Head \& Neck Surgery \\ ${ }^{2}$ Applied Research Associates
}

Intranasal corticosteroids are often used to treat nasal symptoms. Regional nasal deposition estimates of sprayed corticosteroid droplets are needed to quantify drug delivery. Many computational fluid dynamics (CFD) studies have shown that inspiratory airflow affects spray deposition, but most have not included effects from the presence of a spray nozzle in the nasal vestibule. Inspiratory airflow and sprayed particle transport using a realistic particle size distribution (PSD) were simulated with and without a nozzle in the nasal vestibule in one side of a nasal CFD model based on CT scans of a healthy individual. Deposition fractions (DFs) in anterior, nasal valve, main cavity, and nasopharyngeal regions were estimated. Nozzle presence did not substantially affect regional particle distribution. A small decrease in anterior DF with accompanying slight increases in posterior DFs were predicted with a nozzle present over predictions with no nozzle present. Preliminary results indicate that inclusion of a spray nozzle may not be necessary to simulate particle size distributions accurately from common nasal spray pumps. Funding was provided by Grant U01FD005201, from the Department of Health and Human Services (DHHS), Food and Drug Administration. Views expressed in this presentation do not necessarily reflect the official policies of the DHHS; nor does any mention of trade names, commercial practices or organizations imply endorsement by the United States government.

\section{P-264 ANALYSIS OF RADIOAEROSOL SCINTIGRAPHY DELIVERED AND MESH NEBULIZERS COUPLED TO NONINVASIVE VENTILATION IN STABLE COPD}

\author{
Armele Dornelas ${ }^{1}$, Valdecir Galindo ${ }^{1}$, James B. Fink ${ }^{2}$, \\ Luciana Alcoforado ${ }^{1}$, Catarina Rattes ${ }^{3}$, Simone Brandão ${ }^{4}$ \\ ${ }^{1}$ Universidade Federal de Pernambuco; Department of Physical \\ Therapy; Department of Physical Therapy \\ ${ }^{2}$ Georgia State University; Respiratory Therapy Program \\ ${ }^{3}$ Universidade Federal de Pernambuco \\ ${ }^{4}$ Universidade Federal de Peranmbuco - Nuclear Medicine \\ Department
}

Background: Jet nebulizer (JN) and Vibrating Mesh nebulizer (VMN) have been used to delivery aerosol in COPD patients coupled to noninvasive ventilation (NIV). In vitro studies have shown that VMN deposited more radio-aerosol from the nominal dose in association to NIV.

Objectives: To compare aerosol distribution using JN and VMN coupled to NIV in stable COPD.

Material and methods: A crossover of 9 moderate to severe stable COPD randomly allocated to aerosol from JN (MistyNeb) and VMN (NIVO)during NIV (BiPAP Synchrony, Respironics ${ }^{\circledR}$ )) of 12/ $5 \mathrm{~cm} \mathrm{H}_{2} \mathrm{O}$. 2-D gamma camera (STARCAM $3200 \mathrm{GE}$ )) measured radiation counts in areas of interest. For statistical analysis we used Kolmogorov-Smirnov and Wilcoxon Tests through SPSS 20.0, considering $\mathrm{p}<0.05$

Results: VMN higher counts in lung than JN $(1867044 \pm 456120$ versus $579729 \pm 312261, \mathrm{p}=0.008$ ). Table shows distribution between compartments.

Conclusion: VMN deposited $>3$ fold radio-aerosol into the lungs than $\mathrm{JN}$ in subjects with stable to severe COPD.

\begin{tabular}{lccc}
\hline COMPARTMENTS & \multicolumn{1}{c}{ MN } & JN & p value \\
\hline Inhaled dose (\%) & $19.90 \pm 3.18$ & $7.03 \pm 2.97$ & $0.008^{*}$ \\
Lungs (\%) & $8.75 \pm 2.23$ & $2.82 \pm 1.21$ & $0.008^{*}$ \\
Upper airways (\%) & $10.46 \pm 3.57$ & $4.45 \pm 3.29$ & $0.008^{*}$ \\
Stomach (\%) & $0.67 \pm 0.26$ & $0.77 \pm 058$ & $0.008^{*}$ \\
Nebulizer (\%) & $3.20 \pm 1.33$ & $49.53 \pm 6.40$ & $0.008^{*}$ \\
Circuit (\%) & $14.06 \pm 4.82$ & $14.60 \pm 5.13$ & 0.575 \\
Facemask (\%) & $19.38 \pm 3.55$ & $5.37 \pm 1.62$ & $0.008^{*}$ \\
Inspiratory filter (\%) & $0.34 \pm 0.28$ & $0.50 \pm 0.93$ & 0.400 \\
Expiratory filter (\%) & $43.25 \pm 5.33$ & $23.05 \pm 5.63$ & $0.008^{*}$ \\
\hline Values are mean SD. Wilcoxon test * * $<0.05$ & &
\end{tabular}




\section{P-266 EFFECTS OF NASAL VESTIBULE MORPHOLOGY ON INTRANASAL PARTICLE TRANSPORT}

\author{
Dennis Frank-Ito \\ Division of Otolaryngology - Head and Neck Surgery, \\ Duke University Medical Center
}

The effects of inter-individual or within-individual morphologic variability around the nasal vestibule (NV) on intranasal particle distribution pattern in the nasal and sinus cavities are poorly understood. Very little has been done to investigate the association between the anatomic shape (and architecture) of the human NV and transportation of aerosolized particles in the nose. This study uses computational fluid dynamics (CFD) modelling to assess the role of anterior nasal morphology on regional particle deposition in the human nasal and sinus airspace. Three-dimensional models of 32 unilateral nasal passages were created from computed tomography scans. The NV of these models was classified into three groups based on their shape: No-notched, Notched, Elongated. CFD simulations were carried out in ANSYS Fluent in two phases: The airflow phase was done by numerically solving the Navier-Stokes equations for steady state laminar inhalation; and the particle dispersed phase was solved by tracking particulate matter mimicking nasal sprays $(5 \mu \mathrm{m}-50 \mu \mathrm{m}$, $5 \mu \mathrm{m}$ size increment) and nebulizers $(1 \mu \mathrm{m}-15 \mu \mathrm{m}, 1 \mu \mathrm{m}$ size increment), through the calculated airflow field. Preliminary results showed that "Elongated" NV had the least anterior particle deposition for smaller particles, while "No-notched" NV had the least anterior deposition for larger particles. These results suggest that variability in human nasal vestibule morphology may impact overall regional particle deposition in the nose.

\section{P-267 SIMULATION OF INHALED PERFLUOROCARBON DROPLETS IN THE UPPER RESPIRATORY TRACT AND UPPER LUNG AIRWAYS}

Jeffry Schroeter, Owen Price, Bahman Asgharian

\section{Applied Research Associates}

The assessment of particle deposition in the upper respiratory tract and upper lung airways is important for drug delivery applications to estimate localized dose in these regions and the amount entering distal lung airways. Perfluorocarbons (PFCs) are inert, semi-volatile compounds that have been proposed for use as aerosolized drug delivery carriers. A computational fluid dynamics (CFD) model of the complete upper respiratory tract (nasal and oral passages) and upper lung airways (to generations 4-6) was used to simulate inhaled airflow and the transport, phase change, and deposition of inhaled liquid PFC droplets and PFC/drug particles. Outlet boundary conditions consisted of either equal pressure conditions at all outlets or mass-flow conditions weighted according to distal lung volume. Droplet transport was modeled according to the Lagrangian equations of motion, with liquid droplet size change occurring by molecular diffusion from the droplet surface to the vapor phase. The selection of outlet boundary condition significantly affected the airflow distribution through the lung airways. PFC droplet deposition efficiency was primarily dependent on initial droplet size and saturation vapor pressure. With no vapor present, pure PFC droplets were predicted to either deposit or completely evaporate; however, high airway vapor concentrations limited evaporation allowing further penetration into the lung. This work was funded by the Office of Naval Research.

\section{P-273 PHYSICAL AND CHEMICAL CHARACTERIZATION OF ELECTRONIC CIGARETTE EMISSIONS}

\author{
Philip Kuehl, Tom Holmes, \\ Hammad Irshad, Dean Kracko, \\ Benjamin Moeller, Jacob McDonald \\ Lovelace Respiratory Research Institute
}

Despite the explosion in electronic cigarettes (e.cigs), the peer reviewed literature surrounding their emission profiles is lacking. While the FDA has the authority to regulate these products, the dearth of literature in this area has contributed to the fact that e.cigs are not currently regulated. To this end, a series of studies have been conducted to explore/refine testing methods to characterize mainstream and side stream emissions from Blu e.cigs. The mainstream emissions were analyzed for total material (mass and particle count), nicotine (gas and particulate phase), formaldehyde by DNPH, and for particle size distribution. The side stream emissions were evaluated from a preclinical smoke generation system physically (particle size, number, surface area and mass) and chemically (nicotine, cotinine, CO, aldehydes and TSNA's). The mainstream emissions were found to have dose (labeled nicotine strength) proportional amounts of nicotine and formaldehyde. The nicotine was determined to be $\sim 3 \%$ gaseous nicotine, similar to a conventional cigarette. The particle size distribution was found to have a mass median diameter of $\sim 0.8 \mu \mathrm{m}$ and a number median distribution of $\sim 110 \mathrm{~nm}$. Chemical analysis of impactor substrates indicated that the particles are a homogeneous mixture of nicotine, propylene glycol and glycerin. Analysis of the side stream emissions from the preclinical exposure system indicated that all components measured were not elevated above background levels.

\section{P-277 CALCULATION METHOD FOR DETERMINING HOMOGENEITY OF LUNG DEPOSITION BY 2D GAMMA SCINTIGRAPHY}

\author{
Claudius Kietzig, Knut Sommerer
}

Inamed GmbH

2D gamma scintigraphy is an excellent method to determine the dose of deposited aerosol in the lungs. In addition the regional distribution of the deposited aerosol can be estimated by calculating the normalized central to peripheral deposition ratio $(\mathrm{C} / \mathrm{P})$ or central to peripheral shells. However 2D gamma scintigraphy can also provide parameters that describe the homogeneity of lung deposition, which can be used as an indicator of physiological changes in the lungs and help in the interpretation of deposition results.

As a measure of homogeneity of lung deposition the variance of pixel counts (VAR) was calculated in a 2D lung deposition study with 6 healthy subjects and 15 patients with cystic fibrosis (mean FEV1 $(\%$ pred $)=103.2 \pm 12.9 / 61.3 \pm 19.4)$. The inhalation was performed using the breath triggered I-neb nebulizer $(\mathrm{MMAD}=4.2 \mu \mathrm{m}$, $\mathrm{FPF}=57 \%$ ). The VAR parameter is defined as variance of the pixel count histogram distribution relative to the count rate. This means the VAR parameter increases with the amount of pixels with differing count rates and decreases to zero if the total count rate is homogenous distributed (identical count rate for all pixels).

The mean VAR of the lung deposition was $2.44 \pm 2.43$ at the $\mathrm{CF}$ and $1.6 \pm 0.96$ at the healthy group. This significant difference confirms that the VAR parameter is suitable to describe homogeneity directly in 2D lung deposition images and has therefore the potential for an indicator of physiological changes in the lungs. 


\section{P-279 AEROSOL DEPOSITION IN THE WHOLE LUNG: COUPLING 3D AND 1D IN SILICO PARTICLE TRANSPORT MODELS}

\author{
Jessica Oakes ${ }^{1}$, Celine Grandmont ${ }^{2}$, Shawn Shadden ${ }^{3}$, \\ Irene Vignon-Clementel ${ }^{2}$ \\ ${ }^{1}$ University of California, Berkeley, Department \\ of Mechanical Engineering; Inria Paris-Roquencourt, \\ Reo, France; Upmc Universite Paris 6, Laboratoire \\ Jacques-Louis Lions, France \\ ${ }^{2}$ Inria Paris-Rocquencourt, Reo, France; Upmc Universite \\ Paris 6, Laboratoire Jacques-Louis Lions, France \\ ${ }^{3}$ University of California, Berkeley, Department \\ of Mechanical Engineering, USA
}

Recent advances in computational resources have enabled sophisticated airflow and particle transport simulations, however it is currently infeasible to solve for airflow and transport for all scales of the lung. Instead, multi-dimensional methods must be employed. In this current work, we developed a new framework that couples the 3D time-dependent Lagrangian description of particles in the conducting airways (Oakes et al. (2014), Annals of Biomedical Engineering, 42: 899-914) to a 1D single path convection-diffusion model (Taulbee and Yu (1975), Journal of Applied Physiology, 38: 77-85). The 1D model was parameterized for the rat airways and included a deposition loss term. During respiration, the time dependent flow rate and particle concentration are passed between the domains (inspiration: 3D to 1D, expiration: 1D to 3D). Simulations predicted that $16 \%$ and $17 \%$ and $23 \%$ of 1 -micron diameter particles deposit in the lung in the first, second and tenth breath, respectfully. This coupled 3D-1D model enables prediction of whole-lung particle transport throughout respiration.

\section{P-287 MODELING PARTICLE DEPOSITION IN THE MOUSE LUNG AND EXTRAPOLATION TO THE HUMAN LUNG}

\author{
Werner Hofmann ${ }^{1}$, R. Winkler-Heil ${ }^{1}$, W. Möller ${ }^{2}$, \\ P. Madl ${ }^{1}$, O. Schmidt ${ }^{2}$ \\ ${ }^{1}$ University of Salzburg \\ ${ }^{2}$ Helmholtz Center Munich
}

The mouse lung has become increasingly important as a surrogate for the human lung to investigate pharmaceutical effects of inhaled particles. We have recently developed a computational model of particle deposition in the murine lung. The objective of the present study was to validate this model with experimental data from noseonly and intubated-ventilated inhalation systems.

The main structural difference between the human and the mouse lung is that the airway branching of the human lung is rather symmetric, while that of the mouse lungs is distinctly asymmetric or monopodial, which affects related particle deposition patterns. While the asymmetric tracheobronchial airway geometry of the Balb/c mouse is based on a rigorous statistical analysis of several lung casts, the acinar airway geometry is, in the absence of pertinent data, represented by an allometrically scaled-down version of the asymmetric acinar model of the rat lung, assuming structural, though not dimensional, similarity between the two species.

In the present study (i) total, regional and generational deposition patterns for nanometer and micrometer particles were calculated, (ii) theoretical predictions were compared with available nose-only and endotracheal experimental data, and (iii) predicted deposition patterns were extrapolated to the human lung. For the comparison with corresponding human deposition data, airway diameter seems to be a more appropriate morphometric parameter than the commonly used airway generation. 